\title{
Copyright
}

By

\section{Yang Joel Wong}

2007 
The Dissertation Committee for Yang Joel Wong certifies that this is the approved version of the following dissertation:

The Potential Benefits of Expressive Writing for Male College Students with Varying Degrees of Restrictive Emotionality

Committee:

$\overline{\text { Aaron Rochlen, Supervisor }}$

James Pennebaker

Keenan Pituch

Stephanie Rude

Alissa Sherry 
The Potential Benefits of Expressive Writing

for Male College Students with Varying Degrees of Restrictive Emotionality

by

Yang Joel Wong, L.L.B.; M.A.

\author{
Dissertation \\ Presented to the Faculty of the Graduate School of \\ The University of Texas at Austin \\ in Partial Fulfillment \\ of the Requirements \\ for the Degree of
}

Doctor of Philosophy

The University of Texas at Austin

August 2007 
I dedicate this dissertation to my wife

Wan-Teng Angelyn Seow 


\section{Acknowledgements}

I am grateful to:

Dr. Aaron Rochlen, my advisor and dissertation supervisor. Thank you so much for your generous support. I will always be grateful for your mentoring and the opportunity to work with you.

Dr. James Pennebaker for introducing me to the wonders of expressive writing and the psychosocial dimensions of language.

My other committee members Drs. Keenan Pituch, Stephanie Rude, and Alissa Sherry for their kind support and advice.

Chris Leeth for his assistance with administering the experiment and for data collection.

Andre Lai and Johnny Lin for their help with data cleaning.

Kway Gordon for his help with administering the experiment.

My professors and classmates in the counseling psychology program at the University of Texas at Austin for their support. I am proud to be a graduate of our program.

Dr. Lynn Rew - I will always remember your kindness, warmth, boundless energy, and passion for research.

Scott Hosford - thank you for your friendship and companionship.

JK Lam - friend, kayaking partner, and confidant. The genesis of this dissertation occurred during a conversation on one of our hiking trips.

My mother-in-law Wendy Tong for the practical help she provided my family.

My parents Chiang Siang and Lily Wong and my sister Constance Wong for their immense support, encouragement, and prayers. Thank you for believing in me.

My children Kaitlyn and Shawn Wong for reminding me daily of what's truly important and beautiful in life.

My wife and soul mate, Wan-Teng Angelyn Seow, without whom I could not have embarked on this journey. Words alone cannot express my appreciation for you. This Ph.D. belongs to you as much as it does to me.

God, Giver of every good and perfect gift. 


\title{
The Potential Benefits of Expressive Writing for Male College Students with Varying Degrees of Restrictive Emotionality
}

\author{
Publication No.
}

Yang Joel Wong, Ph.D.

The University of Texas at Austin, 2007

\author{
Supervisor: Aaron Rochlen
}

This study examined the potential psychosocial benefits of writing about one's best possible emotional connectedness with a romantic partner for male college students with varying levels of restrictive emotionality. One hundred and fifty-eight male college students were randomly assigned to either an experimental or a control writing condition. Experimental participants wrote for 20 minutes each day for three days about how their lives would be different if they had the best possible emotional connectedness with a real or imaginary romantic partner while control participants wrote about impersonal topics.

Before and after the writing intervention (on the last day of writing and four weeks after the writing), participants completed self-report measures of their restrictive emotionality, psychological distress, positive relations with others, and personal growth. Participants also completed a questionnaire on their expression of emotional intimacy to their romantic partners/significant others four weeks after the writing intervention. It was 
hypothesized that experimental participants would report better psychosocial health than control participants. Further, among high restrictive emotionality participants, the experimental group was expected to benefit more from the writing intervention than the control group, although among low restrictive emotionality participants, both conditions were expected to produce equivalent results.

The results indicated that the only significant difference between the experimental and control groups on the main outcome variables was change in psychological distress. Experimental participants reported a significantly greater decrease in psychological distress than did control participants four weeks after the writing intervention. None of the hypothesized condition by restrictive emotionality interactions were confirmed. In addition, the expressive writing intervention produced approximately equal results for men who were in romantic relationships and men who were not. Further, a multiple regression analysis of the main pretest outcome variables indicated that participants' restrictive emotionality was positively associated with not being in a romantic relationship and negatively related to their positive relations with others. 


\section{Table of Contents}

Chapter I: Introduction $\quad 1$

Chapter II: Review of Literature $\quad 5$

Theoretical Foundations of Men's Restrictive Emotionality 5

Gender Role Strain Paradigm 5

Gender Role Conflict Paradigm 5

Overview of Research Men's Restrictive Emotionality 8

Problems Associated with Restrictive Emotionality 9

Reasons Why Restrictive Emotionality is Problematic for Men $\quad 10$

Addressing the Psychosocial Needs of Emotionally Restricted Men 11

$\begin{array}{ll}\text { Review of Previous Research } & 11\end{array}$

$\begin{array}{ll}\text { Limitations in Previous Research } & 14\end{array}$

$\begin{array}{ll}\text { Developmental Perspectives on Masculinity } & 15\end{array}$

The Expressive Writing Paradigm 16

Potential Benefits of Expressive Writing for Emotionally Restricted Men $\quad 17$

$\begin{array}{ll}\text { Reasons Why Expressive Writing is Beneficial } & 21\end{array}$

$\begin{array}{ll}\text { Inhibitory Processes Model } & 21\end{array}$

Cognitive Processes Model 22

Emotional Processing/Exposure Model 23

$\begin{array}{ll}\text { Self-Regulation Model } & 24\end{array}$

Writing Topics in Previous Expressive Writing Studies 26 
Research Applications of the Possible Selves Perspective 28

Counseling Applications of the Possible Selves Perspective 29

Application of the Possible Selves Perspective to Expressive Writing 30

Benefits of Writing About One's Best Possible Emotional Connectedness 32

With Significant Others for Emotionally Restricted Men

Specific Benefits of Writing about One's Best Possible Emotional 36

Connectedness with a Romantic Partner

Lower Levels of Restrictive Emotionality 36

$\begin{array}{ll}\text { Reduced Psychological Distress } & 37\end{array}$

$\begin{array}{ll}\text { Increased Psychological Well-Being } & 37\end{array}$

Increased Personal Growth $\quad 38$

Increased Positive Relations With Others 40

Increased Expression of Emotional Intimacy 41

Overview of the Present Study 42

$1^{\text {st }}$ Set of Hypotheses: Relations Between Restrictive Emotionality and 45 Other Variables

$2^{\text {nd }}$ Set of Hypotheses: Decrease in Restrictive Emotionality 45

$3^{\text {rd }}$ Set of Hypotheses: Decrease in Psychological Distress 46

$4^{\text {th }}$ Set of Hypotheses: Increase in Personal Growth 47

$5^{\text {th }}$ Set of Hypotheses: Increase in Positive Relations With Others 47

$6^{\text {th }}$ Set of Hypotheses: Greater Expression of Emotional Intimacy 48

Chapter III: Methodology $\quad 50$

$\begin{array}{ll}\text { Participants } & 50\end{array}$ 
$\begin{array}{lr}\text { Restrictive Emotionality Scale } & 50\end{array}$

Brief Symptom Inventory-18 51

Positive Relations With Others Scale 52

Personal Growth Scale $\quad 53$

Questionnaire on the Expression of Emotional Intimacy 53

Questionnaires on Self-Regulation $\quad 55$

Linguistic Inquiry and Word Count 55

Questionnaire on Participants' Subjective Experience 56

$\begin{array}{ll}\text { Procedures } & 56\end{array}$

$\begin{array}{ll}\text { Time } 1 \text { Procedures } & 57\end{array}$

$\begin{array}{ll}\text { Instructions for Experimental participants } & 57\end{array}$

Instructions for Control Participants $\quad 58$

Time 2 Procedures $\quad 59$

Time 3 Procedures $\quad 59$

Chapter IV: Results 61

$\begin{array}{ll}\text { Missing Data } & 61\end{array}$

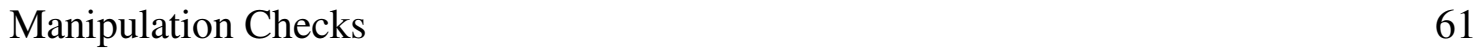

LIWC Analyses

$\begin{array}{ll}\text { Participants' Subjective Experience } & 63\end{array}$

$\begin{array}{ll}\text { Self-Regulation } & 64\end{array}$

Potential Racial Differences on Time 1 Measures $\quad 65$

$1^{\text {st }}$ Set of Hypotheses: Relations Between Restrictive Emotionality and Other 65 Variables 
$2^{\text {nd }}$ Set of Hypotheses: Restrictive Emotionality 67

$3^{\text {rd }}$ Set of Hypotheses: Psychological Distress 68

$4^{\text {th }}$ Set of Hypotheses: Personal Growth 71

$5^{\text {th }}$ Set of Hypotheses: Positive Relations With Others 73

$6^{\text {th }}$ Set of Hypotheses: Expression of Emotional Intimacy 76

$\begin{array}{ll}\text { Preliminary Analyses } & 76\end{array}$

Profiles of participants whose romantic partners/ significant $\quad 76$ others responded to the QEEICR

$\begin{array}{ll}\text { Factor Analyses } & 76\end{array}$

$\begin{array}{ll}\text { Construct Validity of the QEEICR } & 77\end{array}$

Demographic Profile of Relationships $\quad 80$

Expression of Emotional Intimacy (Participants' Perspective) 81

Expression of Emotional Intimacy (Others' Perspective) 83

$\begin{array}{lr}\text { Self-Regulation as a Potential Mediator } & 83\end{array}$

$\begin{array}{ll}\text { Chapter V: Discussion } & 86\end{array}$

Review of Findings $\quad 86$

Relationship Between Men's Restrictive Emotionality and Other 86 Variables

Differences Between Experimental and Control Groups $\quad 87$

Interaction Effects Relating to Restrictive Emotionality and Romantic $\quad 91$ Relationship Status

$\begin{array}{ll}\text { Additional Analyses } & 93\end{array}$

$\begin{array}{ll}\text { Participants' Subjective Experience } & 93\end{array}$

$\begin{array}{lr}\text { Self-Regulation as a Potential Mediator } & 94\end{array}$ 
$\begin{array}{ll}\text { Strengths of the Study } & 94\end{array}$

$\begin{array}{ll}\text { Limitations of the Study } & 97\end{array}$

Recommendations for Future Research $\quad 99$

Clinical Implications and Concluding Comments 103

$\begin{array}{ll}\text { Appendices } & 106\end{array}$

$\begin{array}{ll}\text { References } & 127\end{array}$

$\begin{array}{ll}\text { Vita } & 147\end{array}$ 


\section{Chapter I: Introduction}

The subject of men's psychosocial health has gained increasing attention in recent years. Studies indicate that, in general, men tend to utilize the mental health system less often than women but suffer significant problems (for summaries, see Addis \& Cohane, 2005; Addis \& Mahalik, 2003). For example, research suggests that men are up to six times more likely than women to commit suicide, especially through violent means (U. S. Department of Health and Human Services, 1992). Men also constitute two-thirds and four-fifths of the population of those who abuse alcohol or illicit substances (Brooks \& Good, 2001).

The above troubling statistics have led scholars and researchers to explore the reasons underlying men's psychosocial problems. In this regard, a growing topic of interest has been how men's rigid adherence to traditional European American masculine norms contributes to negative psychosocial outcomes (e.g., Addis \& Cohane, 2005; Balswick, 1988; Brooks, 1998; Brooks \& Good, 2001; Pollack \& Levant, 1998). In particular, one dimension of masculinity that has attracted considerable scholarly attention has been the construct of men's restrictive emotionality. Rooted in the gender role conflict paradigm, restrictive emotionality refers to men's difficulty and fears about expressing emotions (O’Neil, Good, \& Holmes, 1995). Significantly, men’s restrictive

emotionality has been found to be related to numerous intrapersonal and interpersonal problems , such as depression and relationship dissatisfaction (see O'Neil et al., 1995; Wong \& Rochlen, 2005, for reviews).

In view of the negative outcomes associated with men's restrictive emotionality, an important research agenda is to identify appropriate interventions that address the 
psychosocial needs of emotionally restricted men. Several studies have examined men's preferences for specific counseling approaches (e.g., Rochlen, Land, \& Wong, 2004; Rochlen \& O'Brien, 2002) as well as psychoeducational interventions aimed at reducing men's gender role conflict, including men's restrictive emotionality (e.g., Gertner, 1994). Nevertheless, no known empirical study has directly examined a clinical intervention that improves the psychosocial health of emotionally restricted men.

Consequently, the proposed study aimed to fill this gap in the extant literature by examining the benefits of expressive writing for male college students with varying degrees of restrictive emotionality. Participants in expressive writing studies typically write about their thoughts and feelings concerning stressful experiences for about 15-25 minutes over three or four consecutive days. Expressive writing was of interest in this study because of a large body of research demonstrating its psychological and physiological benefits (for summaries, see Pennebaker, 1997; Pennebaker \& Chung, 2007). Expressive writing might be an especially suitable clinical intervention for emotionally restricted men in light of previous studies indicating that it yielded greater benefits for individuals with impoverished emotional resources (e.g., Paez, Velasco, \& Gonzalez, 1999).

The vast majority of previous expressive writing studies appear to have been premised on the assumption that individuals need to confront their negative or stressful experiences to benefit from expressive writing (King, 2002). In recent years, this presupposition has been challenged by Laura King (2002) who proposed instead that individuals need only to write about personally significant events to benefit from expressive writing. King (2002) theorized that the advantages of expressive writing lie in 
increased self-regulation because it enables individuals to articulate their significant experiences and to integrate these experiences into their selves. In so doing, individuals gain greater awareness of their needs and priorities, thus leading to greater clarity of and more effective pursuit of their goals.

Without the necessity of focusing on negative experiences, the self-regulation model has expanded the range of possible writing topics used in expressive writing research. Within the self-regulation model, a promising theoretical basis for generating writing topics is the possible selves paradigm. Markus and Nurius (1986) introduced the concept of possible selves to distinguish how individuals perceive themselves in the present and the future. From this framework, possible selves are viewed as personalized representations of goals and reflect how individuals think about their potential and future. Markus and Nurius (1986) proposed that possible selves furnish the psychological ingredients for motivation and also influences one's interpretation of his or her current self-concept.

The concept of possible selves has been applied in diverse fields of research (e.g., King \& Smith, 2004; Ruvolo \& Markus, 1992; Whitty, 2002) as well as in the practice of psychotherapy (e.g., Buirs \& Martin, 1997). However, a relatively unexplored facet of the possible selves perspective is its applicability to expressive writing. The present study is intended as a modest step toward exploring the interface of the possible selves and expressive writing paradigms. Writing and thinking about one's ideal possible self can be interpreted as a form of creative mental visualization that transforms one's vague and generic hopes to concrete, personalized visions of the future (cf. Ruvolo \& Markus, 1992). Arguably, such a process engenders greater self-regulation: through a positive 
reappraisal of one's self concept and the fostering of motivational resources (Markus \& Nurius, 1986), individuals become more aware of and are better able to pursue their goals.

The construct of possible selves offers expressive writing researchers a new paradigm of writing topics to explore. In a study that examined ideal possible selves in expressive writing (King, 2001), participants who wrote about their best possible future selves demonstrated equivalent health improvements compared to participants who wrote about traumatic experiences. To date, no known study has assessed the benefits of writing about one's best possible emotional connectedness with a romantic partner. Such a topic might be particularly suitable for emotionally restricted male college students in light of their tendency to experience difficulties with romantic relationships (e.g., Rochlen \& Mahalik, 2004) and also because romantic relationships appear to be a defining feature of many male emerging adults' lives (Korobov \& Thorne, 2006). In addition, the emphasis on men's ideal relational life instead of their current life difficulties is consistent with a developmental perspective on masculinity that emphasizes men's latent assets (Heesacker \& Pritchard, 1992; Kelly \& Hall, 1992).

In the following chapter, the theoretical and empirical foundations of men's restrictive emotionality are discussed, followed by overviews of the expressive writing paradigm and the concept of possible selves. Next, the specific benefits of writing about one's best possible emotional connectedness with a romantic partner for male college students are outlined. Finally, the chapter concludes with an introduction of the goals and hypotheses for the present study. 


\section{Chapter II: Review of Literature}

\section{Theoretical Foundations of Men's Restrictive Emotionality}

Considered the most pervasive and problematic aspect of White, North American masculinity (Balswick, 1988), men's difficulty expressing emotions has been a subject of growing interest in the popular (e.g., Pease \& Pease, 2004) and scholarly literature (e.g., Levant, 2001; Wester, Vogel, Pressly, \& Heesacker, 2002; Wong \& Rochlen, 2005). Although a range of theoretical approaches have been applied to the empirical study of men's difficulty with emotionality, the majority of such research has relied on the restrictive emotionality construct, a dimension of the gender role conflict paradigm (O’Neil, 1981a; 1981b). Restrictive emotionality has been defined as "having difficulty and fears about expressing one's feelings and difficulty finding words to express basic emotions" (O'Neil et al., 1995, p. 176). In the following sections, the theoretical foundations of restrictive emotionality are reviewed through the lenses of the gender role strain and gender role conflict paradigms.

\section{Gender Role Strain Paradigm}

The theoretical underpinnings of men's restrictive emotionality are found in the gender role strain paradigm (Pleck, 1981; 1995). To best understand the gender role strain paradigm, a distinction is made between sex roles and gender roles. Sex roles are specific behaviors related to one's biology (e.g., reproductive functions). In contrast, gender roles are behaviors men and women enact based on socially constructed notions of femininity and masculinity. Hence, men's gender roles are not biologically-based, but are constructions created by social forces such as the media, parents, peers, and teachers concerning what constitutes masculinity (Pleck, 1981; 1995). Through the process of 
gender role socialization, boys and men are influenced by societal expectations of what is acceptable and unacceptable masculine behavior and attitudes. Learning of one's gender roles is suggested to occur through reinforcement; for instance, fathers might make their sons feel ashamed for expressing feelings of vulnerability, such as sadness and fear (Levant, 2001).

Importantly, the gender role strain paradigm suggests that gender roles are not only socially constructed, but also are frequently problematic for men. Brooks and Good (2001) summarized several key assumptions of this perspective:

1. Gender role norms are often inconsistent and contradictory.

2. A large proportion of gender role norms are frequently violated.

3. Social condemnation and stressful psychological consequences commonly follow role violations.

4. Many characteristics and behaviors prescribed by gender role norms are psychologically dysfunctional.

The underlying result of gender role socialization is that men develop a fear of appearing feminine (O’Neil, 1981b). As a result of this fear, men are believed to over-conform to traditional masculine roles as a coping strategy (Pleck, 1981; 1995).

\section{Gender Role Conflict Paradigm}

Although Pleck's $(1981,1995)$ gender role strain paradigm is a useful contribution to the study of masculinity, it does not specify the precise patterns of negative consequences that follow for men adhering to masculine role norms. (O'Neil et al., 1995). O’Neil (1981a; 1981b) addressed this important topic by developing the gender role conflict paradigm. Defined as a "psychological state in which gender roles 
have negative consequences or impact on the person or others" (O'Neil, 1981b, p. 203), gender role conflict is posited to reflect less mature masculine identity in that men adhere to inflexible gender role norms that do not allow them to express themselves freely and reach their fullest human potential (O’Neil et al., 1995).

According to O'Neil and his colleagues (1995), gender role conflict is experienced at four interactive levels. In light of the present study's focus on the restrictive emotionality dimension of gender role conflict, examples of men's difficulties with emotionality will be provided to support the following description of these four levels. First, at the cognitive level, conflict arises from the restrictive, stereotypical ways men think about masculine gender roles. For example, some men might believe that crying is associated with feminine behavior and should be avoided at all cost. Second, gender role conflict experienced at an affective level involves deep emotional conflict about the meanings of gender roles. For example, a man might be distressed about his experience of vulnerable feelings such as sadness and loneliness because such feelings are incompatible with his notions of masculinity. Third, at the behavioral level, gender role conflict is experienced as men interact with themselves and others. Taking the earlier example of crying, to avoid being perceived as "feminine," men might try hard to appear tough and hold back their tears even when experiencing intense sadness. Finally, at the unconscious level, gender role conflict takes the form of intrapsychic conflicts that are beyond conscious awareness. For instance, a man might have an unconscious desire for emotional intimacy with his partner but represses these desires because of a perception that such behavior violates masculine role norms. 
In addition to the four levels at which gender role conflict operates, O'Neil et al. (1995) proposed that men typically experience gender role conflict in six separate contexts; when they (1) deviate from or defy masculine gender role norms; (2) fail to meet masculine gender role norms; (3) experience discrepancies between their real and ideal self-concepts based on masculine gender role stereotypes; (4) personally devalue, restrict or violate themselves; (5) encounter personal devaluations, restrictions, or violations from others; and (6) personally devalue, restrict, or violate others because of masculine gender role stereotypes. In short, O'Neil and his colleagues theorized that traditional gender role socialization provides contradictory and unrealistic messages resulting in considerable intrapersonal and interpersonal conflict (O’Neil, et al., 1995).

O'Neil and his colleagues have operationalized gender role conflict theory by developing the Gender Role Conflict Scale (GRCS; O’Neil, et al., 1986). The GRCS comprises four subscales: (1) Success, Power, and Competition (persistent worries about personal achievement, success and winning); (2) Restrictive Emotionality (difficulty and fears about expressing one's feelings); (3) Restrictive Affective Behavior Between Men (difficulty sharing feelings and thoughts with other men as well as fear of physical contact with other men); (4) Conflict Between Work and Family (difficulty balancing the demands of work with the responsibilities of family). Numerous studies have provided support for the reliability as well as construct and factorial validity of the GRCS (for reviews, see Moradi, Tokar, Schaub, Jome, \& Serna, 2000, and O’Neil et al., 1995).

\section{Overview of Men's Restrictive Emotionality}

Among the four dimensions of gender role conflict, restrictive emotionality appears to have attracted the most attention among scholars. In particular, several studies 
have focused specifically on the correlates of restrictive emotionality (e.g., Bruch, 2002; Fischer \& Good, 1997; Rochlen et al., 2004; Wester, Vogel, \& Archer, 2004). There are two possible reasons why restrictive emotionality has generated considerable interest. First, as intimated earlier, men's emotional inexpressiveness has been a popular topic in the masculinity literature (see e.g., Balswick, 1988). Second, among the four factors of gender role conflict, research suggests that men's restrictive emotionality is the most robust predictor of psychological problems (see O'Neil et al., 1995; Shepard, 2002, for reviews). Consistent with the gender role strain and gender role conflict paradigms (Pleck, 1995; O'Neil, 1981b), there is growing empirical evidence that men's restrictive emotionality is linked to several intrapersonal and interpersonal difficulties.

\section{Problems Associated with Men's Restrictive Emotionality}

With regard to intrapersonal problems, men's restrictive emotionality has been found to be related to psychological distress (Liu, Rochlen, \& Mohr, 2005), anxiety, (Cournoyer, 1994; Sharpe \& Heppner, 1991; Wong, Pituch, \& Rochlen, 2006), depression (Good \& Mintz, 1990; Mahalik \& Cournoyer, 2000; Sharpe \& Heppner, 1991; Shepard, 2002; Zamarripa, Wampold, \& Gregory, 2003), a negative view of help-seeking (Robertson \& Fitzgerald, 1992), immature psychological defenses (Mahalik, Cournoyer, Defranc, Cherry, \& Napolitano, 1998), an increased similarity in personality style to chemical abusers (Blazina \& Watkins, Jr., 1996), paranoia and psychoticism (Good, Robertson, Fitzgerald, Stevens, \& Bartels, 1996), and negative attitudes toward emotional expression (Wong et al., 2006).

In addition, given that emotional self-disclosure is considered by some scholars to be a vital component of intimate relationships (e.g., Hook, Gerstein, Detterich, \& 
Gridley, 2003), men's restrictive emotionality might suggest a lack of emotional exchange with others (Shepard, 2002). The interpersonal nature of men's restrictive emotionality was underscored in a recent analysis of restrictive emotionality and other emotion-related variables (Wong et al., 2006). A factor analysis of various emotionrelated constructs revealed that restrictive emotionality formed part of a higher-order factor that tapped into men's difficulty with emotional communication in interpersonal contexts (Wong et al., 2006). Congruent with these notions, there is a widening body of studies showing that emotionally restricted men suffer a range of interpersonal problems such as difficulties with relationship intimacy (Sharpe \& Heppner, 1991), fear of intimacy (Fischer \& Good, 1997; Thomas, 2005), marital and relationship dissatisfaction (Campbell \& Snow, 1992; Sharpe, 1994), decreased closeness in male friendships (Sileo, 1996), and hostile and rigid interpersonal behavior (Mahalik, 2000).

In a recent study that is of relevance to the current study, 175 women reported perceptions of their most recent or current male romantic partners' gender role conflict and rated their own levels of psychological distress and romantic relationship satisfaction (Rochlen \& Mahalik, 2004). Women who perceived their partners as having lower levels of restrictive emotionality also reported greater relationship satisfaction. A unique strength of this study is that unlike previous studies that relied on men's self-reports (e.g., Campbell \& Snow, 1992; Sharpe \& Heppner, 1991), the researchers examined women's perceptions of their male partners.

Reasons Why Restrictive Emotionality is Problematic for Men

In contrast to the accumulating evidence on the correlates of men's restrictive emotionality, research exploring the mechanisms through which men's restrictive 
emotionality is related to psychosocial outcomes is surprisingly sparse. To date, only two studies have found variables explaining the variance between restrictive emotionality and psychological outcomes. Tokar, Fischer, Schaub, and Moradi (2000) found that Big-Five personality variables (e.g., neuroticism and agreeableness) partially or fully accounted for the association between restrictive emotionality and eight out of nine counseling-related variables (e.g., depression). In another study (Wong et al., 2006), the difficulty identifying feelings dimension of the Toronto Alexithymia Scale (Bagby, Parker, \& Taylor, 1994) fully explained the shared variance between restrictive emotionality and trait anxiety. More studies investigating variables that link restrictive emotionality to psychosocial outcomes are needed. The above review of problems associated with restrictive emotionality points to the importance of identifying appropriate interventions that address the psychosocial needs of emotionally restricted men (Good, Thomson, \& Brathwaite, 2005).

\section{Addressing the Psychosocial Needs of Emotionally Restricted Men}

The discussion in this section begins with a review of previous research addressing gender role conflicted and emotionally restricted men's psychosocial needs, a discussion of limitations in such research, followed by an examination of developmental perspectives on masculinity. Because the number of experimental studies that specifically examined restrictive emotionality is limited, the review below includes studies that utilized GRCS overall scores as well as the Restrictive Emotionality Scale.

Review of Previous Research

Research addressing gender role conflicted men's psychosocial needs generally has followed two trajectories (Betz \& Fitzgerald, 1993). One perspective focuses on 
changing or "liberating" men (Scher, 1981). Research adapting this perspective has largely utilized psychoeducational interventions targeted at reducing men's gender role conflict (including men's restrictive emotionality).

Four experimental studies have examined the impact of structured psychoeducational interventions on gender role conflict. Brooks-Harris, Heesacker, and Mejia-Millan (1996) assessed the effectiveness of two video interventions focused on masculine role attitudes (e.g., expression of emotions and acceptance of vulnerability) and the positive results of help-seeking. Gertner (1994) tested the effects of a semesterlong men's studies course that covered topics such as power and patriarchy, masculine violence, men's health, and intimacy. Moore (1993) developed a psychoeducational intervention comparing alcoholics, nonalcoholics, and a control group over a four-week period. Finally, Nahon (1992) designed a program for recently separated men designed to reduce their gender role conflict and help with marital transitions. Among the above four studies, three of them found no significant differences in GRCS overall scores or scores on any of its four subscales between treatment and control groups. Only Gertner's study (1994) found that treatment group participants had significantly reduced levels on one of the four dimensions of gender role conflict (restrictive emotionality) compared to control participants.

A second perspective on addressing gender role conflicted men's psychological needs subscribes to the philosophy that it is the type of clinical interventions, not men, that must change (Wilcox \& Forrest, 1992). Studies in this field have focused on examining the types of counseling approaches that are more attractive to gender role conflicted men. Five such studies are reviewed below. 
Robertson and Fitzgerald (1992) found that gender role conflicted men had more interest in seeking professional psychological help after viewing brochures about nontraditional counseling services (e.g., classes, videotapes, and workshops), rather than brochures describing traditional counseling services (individual and group counseling).

In another study examining different types of counseling approaches, men with higher levels of gender role conflict reported more positive help-seeking attitudes after viewing a video demonstrating a cognition-centered counseling approach compared to a video illustrating an emotion-focused counseling approach (Wisch, Mahalik, Hayes, \& Nutt, 1995).

In the third study, Hurst (1997) analyzed men's reactions to video vignettes demonstrating four different counseling theoretical orientations. He found that men who preferred solution-focused brief therapy and cognitive-behavioral therapy had significantly higher levels of gender role conflict than men who preferred psychodynamic and person-centered therapies.

In the fourth study, Rochlen and O'Brien (2002) analyzed men's perceptions of different theoretical approaches to career counseling. They found that, overall, men preferred a more directive approach to career counseling compared to an emotionoriented career counseling approach. Preference for counseling style was not modified by gender role conflict.

Finally, Rochlen et al. (2004) found that after reviewing face-to-face and online counseling vignettes, more emotionally restricted men reported less favorable evaluations of face-to-face counseling, but roughly equal evaluations of online counseling, compared to men with lower levels of restrictive emotionality. 
In general, the above studies demonstrate that men who adhere strongly to traditional masculine role norms might prefer cognitive-oriented, problem-solving, structured, as well as more private and anonymous counseling approaches (e.g., online counseling).

\section{Limitations in Previous Research}

There are several limitations in the above research addressing gender role conflicted and emotionally restricted men's psychosocial needs. First, the studies that focused on reducing gender role conflict and restrictive emotionality were not particularly successful. Only one out of four studies (Gertner, 1994) found reduced levels of posttest restrictive emotionality. In reviewing the literature on this topic, BrooksHarris et al. (1996) concluded that it is difficult to change men's attitudes and behaviors as measured by the GRCS. Nevertheless, it is argued that this conclusion might be premature. All the above studies that sought to reduce gender role conflict and/or restrictive emotionality utilized psychoeducational interventions. As will be discussed in subsequent sections of this literature review, other interventions that might reduce men's restrictive emotionality have yet to be empirically examined.

Second, many of the above studies utilized the composite measure of gender role conflict (GRCS overall scores) and did not examine specific gender role conflict factors (e.g., restrictive emotionality). Hence, it is unclear if their results generalize to emotionally restricted men.

Third, and most importantly, the studies examining clinical interventions focused on men's attitudes toward different counseling approaches or help-seeking; none of them actually utilized a clinical intervention to improve the mental health or interpersonal 
functioning of men with varying degrees of gender role conflict and/or restrictive emotionality. Clearly, a critical next step in the research agenda is to empirically investigate such interventions (Good et al., 2005).

\section{Developmental Perspectives on Masculinity}

Before discussing a potentially useful clinical intervention for emotionally restricted men, a general comment about the theoretical underpinnings of masculinity research is warranted. Several scholars have observed that a pathological approach to understanding masculinity informs much of research and theorizing on men's emotional behavior in the last two decades (Heesacker \& Pritchard, 1992; Kelly \& Hall, 1992; Wester et al., 2002; Wong \& Rochlen, 2005). As shown in the above literature review, both the gender role strain and the gender role conflict paradigms emphasize the negative aspects of masculinity. Anchored in these paradigms, masculinity research has leaned heavily toward elucidating the problems associated with masculinity rather than on harnessing men's strengths to improve their lives (Mahalik, Good, \& Englar-Carlson, 2003.)

The emphasis on the pathological nature of masculinity is to be welcomed as a counterbalance to earlier conceptualizations of masculine traits as the hallmark of men's psychological health prior to the 1970s (cf. Smiler, 2004). Nevertheless, several dissenting voices have raised concerns that the scholarly pendulum has swung toward an overemphasis on men's pathology (e.g., Heesacker \& Pritchard, 1992; Kelly \& Hall, 1992; cf. Mahalik et al., 2003). Writing in the context of counseling men, Kelly and Hall (1992) observed that the literature on men's mental health tended to view masculinity as a sickness to be cured. In contrast to the pathology model, they proposed a positive, 
developmental model for understanding masculinity and counseling men. First, the developmental model assumes that men's behavior is not a consequence of pathology. So-called behavioral, cognitive, or affective deficits merely suggest that men have not had adequate opportunities for learning the skills necessary for adaptive functioning. Second, men are viewed as possessing skills and assets. Mental health counselors acknowledge these strengths and apply them toward the resolution of men's presenting issues. Third, preventive interventions that promote healthier environments for men are preferred to remediation. Fourth, men's lack of participation in counseling should not be viewed as an inherent problem with men, but as indicative that the counseling profession has failed to understand their counseling needs.

Arguably, Kelly and Hall's positive, developmental model need not be viewed as the polar opposite of the gender role strain and gender role conflict paradigms. Indeed, several scholars have called for theoretical and clinical approaches that acknowledge both the strengths and problems associated with masculine behavior (e.g., Mahalik et al., 2003) and men's emotional behavior (Wong \& Rochlen, 2005). The following section describes expressive writing, a clinical intervention that potentially incorporates such a balanced approach in addressing the psychosocial needs of emotionally restricted men.

\section{The Expressive Writing Paradigm}

Over the past 15 years, expressive writing has been an increasingly popular topic of research. The procedure in expressive writing studies typically unfolds in the following manner: participants in the experimental group write about their thoughts and feelings concerning significant (usually traumatic or stressful) experiences for about 15- 
30 minutes each day over a few consecutive days, while control participants write about trivial topics (Pennebaker, 1997).

There is a widening body of research demonstrating the benefits of expressive writing (see Pennebaker \& Chung, 2007; Sloan \& Marx, 2004; Smyth, 1998, for reviews); these include fewer visits to the doctor for illnesses (e.g., Pennebaker \& Beall, 1986), improved immune and hormonal functioning ( Booth, Petrie, \& Pennebaker, 1997; Pennebaker, Kiecolt-Glaser, \& Glaser, 1988), shorter stays in the hospital after surgical operations (Solano, Donati, Pecci, Persichetti, \& Colaci, 2003), increase in job offers after being laid off (Spera, Buhrfeind, \& Pennebaker, 1994), improved grades for college students (Pennebaker, Mayne, \& Francis, 1997), a decline in depressive symptoms (Lepore, 1997), and improved psychological well-being (King, 2001). Significantly, the therapeutic effects of expressive writing have been found to bring about benefits comparable to short-term therapy (Esterling, L'Abate, Murray, \& Pennebaker, 1999). Further, the benefits of expressive writing have been demonstrated across diverse samples including most social classes and major racial and ethnic groups in the United States (Smyth, 1998).

Potential Benefits of Expressive Writing for Emotionally Restricted Men

Pennebaker (2004) has proposed that an important research agenda for the expressive writing paradigm is to understand when writing does or does not work and with whom. In this regard, no known study has examined its potential benefits for men with varying degrees of restrictive emotionality. There are several theoretical and empirical reasons why expressive writing might be a suitable intervention for emotionally restricted men. 
First, expressive writing might have benefits that are consistent with the values of emotionally restricted men. Wong and Rochlen (2005) posited that men, especially emotionally inexpressive men, might be more comfortable expressing their feelings through nonverbal means compared to verbal forms of communications. Men who adhere to traditional masculine gender role norms (e.g., emotionally restricted men) tend to appreciate clinical approaches that emphasizes structure and control (Robertson, 2001). Writing, in contrast to talking, provides more structure to communication and may help men develop coherent explanations of their problems, leading to an increased sense of control (cf. Clark, 1993).

Second, a key differences between expressive writing and psychotherapy lies in the interpersonal element inherent in psychotherapy (Esterling et al., 1999). Research evidence has consistently linked men's restrictive emotionality to interpersonal difficulties such as shyness (Bruch, 2002) and interpersonal sensitivity (Good et al., 1996). Expressive writing might provide emotionally restricted men with the freedom to explore their feelings without fears about their interpersonal functioning. In other words, men who are uncomfortable disclosing their feelings verbally in a face-to-face environment might reap the psychological benefits of exploring their emotions through writing, a nonverbal and private medium of communication. Some indirect empirical support for these notions was demonstrated in a study that compared the effects of expressive writing to traditional face-to-face psychotherapy (Donnelly \& Murray, 1991). Participants were randomly assigned to either an expressive writing or a short-term psychotherapy condition. Women expressed more negative emotions in the psychotherapy condition than in the expressive writing condition. In contrast, men who 
engaged in expressive writing disclosed more negative feelings compared to men in the psychotherapy condition. In commenting on this sex difference, the authors speculated that, in general, men had more difficulty communicating emotions in interpersonal contexts, and therefore found it easier to confront their feelings through writing.

Third, the empirical evidence is consistent with the proposition that expressive writing is likely to benefit emotionally restricted men more than those who have less difficulty expressing emotions. Smyth's (1998) meta-analysis of 13 studies indicated that men were more likely to benefit from expressive writing than women. Smyth (1998) attributed this result to the possibility that men tend to be less emotionally expressive than women and may experience greater benefits from writing due to lower prewriting levels of emotional expression.

In a study of patients who had undergone a minor surgical operation (Solano et al., 2003), participants in the expressive writing condition spent significantly less time in the hospital after the operation and reported less psychological distress than control participants. An examination of interaction effects revealed that the above beneficial effects of writing were significant only among participants with higher levels of alexithymia (difficulty identifying one's feelings). In contrast, there were no significant differences between the expressive writing and control groups among participants with lower levels of alexithymia. In discussing the interaction effects, the authors argued that highly alexithymic patients derived greater benefits because expressive writing might have activated previously unavailable emotional resources in them. In another study (Paez et al., 1999), participants with higher scores on the Difficulty Describing Feelings subscale of the Toronto Alexithymia Scale (Bagby et al., 1994) and who wrote about 
traumatic experiences reported significantly less negative affect two months after the writing intervention compared to the control group, whereas this pattern was not repeated for those with less self-reported difficulty describing feelings. The Paez et al. (1999) study is particularly relevant to the present study because in a recent analysis of men's emotional inexpressiveness, men's difficulty describing feelings was found to be strongly related to men's restrictive emotionality (Wong et al., 2006). In addition, a factor analysis of several emotion-related variables revealed that difficulty describing feelings and restrictive emotionality formed part of a higher-order construct that tapped into men's difficulty communicating emotions in interpersonal contexts (Wong et al., 2006).

Finally, in a recent expressive writing study (Langens \& Schuler, 2005), participants high in the fear of social rejection who wrote about upsetting experiences reported lower levels of negative mood than control participants. However, the expressive writing intervention did not have a significant influence on negative mood for participants low in the fear of rejection. This result was replicated in a second study with similar procedures and measures. In explaining the difference between participants high and low in the fear of rejection, the authors speculated that the capacity to cope with stressful events may be impaired in individuals high in the fear of rejection. Written emotional expression was a useful coping strategy for these individuals. In contrast, individuals who had less fear of rejection may have had the natural capacity to cope with stressful events and did not require expressive writing to regulate their mood.

To summarize, the above studies suggests that expressive writing is particularly beneficial for men, alexithymic individuals, participants with greater difficulty describing feelings, and individuals high in the fear of rejection. The common thread in these studies 
seems to be that individuals who are not emotionally open or who have lower levels of perceived social support may be the very people who benefit most from expressive writing. Such people tend to have lower prewriting levels of emotional expressiveness, and as such, expressive writing might activate psychosocial resources previously untapped within them (Niederhoffer \& Pennebaker, 2002; Smyth, 1998; Solano et al., 2003). Based on the above findings, one could speculate that expressive writing would be especially helpful to emotionally restricted men, given their tendency to be less emotionally open and have impoverished interpersonal relationships (e.g., Sharpe \& Heppner, 1991).

\section{Reasons Why Expressive Writing is Beneficial}

Despite the above evidence for the salutary effects of expressive writing, an important question remains: why is expressive writing beneficial? Several theoretical models have been proposed to explain the benefits of expressive writing. Sloan and Marx (2004) recently reviewed three such models: the inhibitory processes model, the cognitive processes model, and the emotional processing/exposure model. In addition, King (2002) has proposed the self-regulation model as another explanation for the benefits of expressive writing. These four models are briefly reviewed below.

Inhibitory Processes Model. Initially, Pennebaker (1989) proposed a theory of disinhibition to explain the benefits of expressive writing. According to this theory, people cope with life's negative experiences by actively refraining from disclosing their feelings associated with these experiences. This process of inhibition acts as a cumulative stressor on people's minds and bodies such that they are prevented from effectively assimilating their negative experiences. Expressive writing is viewed as beneficial 
because it helps people confront their negative experiences and thus reduces the work of inhibition. Consequently, the disclosure of formerly inhibited thoughts and feelings is believed to lead to less stress as well as better immune functioning and health. Support for this theoretical model comes from research demonstrating that after expressive writing, participants showed reductions in physiological markers of inhibition such as skin conductance, blood pressure, and muscle tension (Pennebaker, 1989).

Despite the above supporting evidence for the inhibitory processes model, no empirical study has demonstrated that a decrease in inhibition mediates the relations between writing about stressful events and health improvements (Sloan \& Marx, 2004). Further, some studies have shown that writing about stressful events that had been previously disclosed to others produced comparable health benefits to writing about previously undisclosed stressful experiences (e.g., Greenberg \& Stone, 1992). These results raise questions regarding the necessity of writing about previously inhibited thoughts and feelings. Sloan and Marx (2004) concluded that, overall, the disinhibiton theory has not received substantial support as an underlying mechanism of the writing paradigm.

Cognitive Processes Model. According to the cognitive processes model (Pennebaker, 1997), the act of converting emotions into language helps people organize and think about their painful experiences in a more meaningful way. Drawing from research in narrative psychology, Pennebaker and colleagues proposed that the mere expression of negative emotions is not enough to bring about the positive effects of writing, and that what is needed is the construction of a cohesive narrative through language (Pennebaker $\&$ Seagal, 1999). Such a process allows individuals to gain a sense of resolution and 
control over their lives, and hence move beyond their emotional upheaval. Consistent with this emphasis on cognitive processes, Pennebaker's research has found that participants whose health improved the most used an increasing amount of causal and insight words (e.g., reason, realize, and understand) over the course of the writing experiments (Pennebaker, 1997).

Despite these encouraging findings, there has not been unequivocal support for the cognitive model processes model. Subsequent writing studies have not consistently replicated the above results regarding the linguistic markers of cognitive processes (e.g., Burton \& King, 2004; Lepore \& Greenberg, 2002). Moreover, Sloan and Marx (2004) argued that since the evidence on language use is correlational in nature, it is possible that it reflects some other process of change other than the restructuring of cognitive processes.

Emotional Processing/Exposure Model. The emotional processing/exposure model proposes that the benefits of expressive writing lies in individuals' exposure to aversive stimuli that had been previously avoided (Sloan \& Marx, 2004). Drawing from learning and cognitive theories of responses to stressful experiences, Foa and Kozak (1986) posited that pathological fear is viewed as a cognitive structure that contains erroneous information about stimuli and their meanings. Repeated exposure to the feared stimuli is viewed as activating the cognitive fear structure and producing corrective information about the feared stimuli (Foa \& Kozak, 1986). Several researchers have applied this exposure model to the writing paradigm by conceptualizing expressive writing as an opportunity for repeated exposure to previously avoided stressful experiences and the correction of stress-inducing cognitive structures (Sloan \& Marx, 2004). Hence, writing 
is viewed as a means of facilitating the extinction of negative associations with previously avoided stressful experiences.

Studies congruent with these notions have examined changes in intrusive thoughts and avoidance as a result of expressive writing. The findings from these studies have been mixed with some studies showing reductions in intrusive thoughts and avoidancerelated symptoms (e.g., Klein \& Boals, 2001; Schoutrop, Lange, Davidovich, \& Salomon, 2002) while others reporting no beneficial outcomes (Lepore, 1997; Stroebe, Stroebe, Schut, Zech, \& van den Bout, 2002). A possible explanation for the mixed results is that the writing instructions in most studies typically give participants the choice of writing about the same or a different traumatic experience across sessions, whereas exposure to the same traumatic experience may be critical for habituation to occur (Sloan \& Marx, 2004). In sum, empirical support for the emotional processing/exposure model has not been consistent.

Thus far, the abovementioned theoretical models are predicated on the assumption that the expression of negative thoughts and feelings are an essential mechanism underlying the benefits of writing. This assumption has been directly challenged by the self-regulation model proposed by King (2002).

Self-Regulation Model. Self-regulation refers to "the capacity of a person to effectively pursue goals, to register feedback in that pursuit, and to adjust his or her behavior accordingly" (King, 2002, p. 120). Self-regulation is enhanced through activities that enable a person to more accurately identify goals, receive feedback about one's behavior, and generate strategies for achieving goals (King, 2002). Laura King and her colleagues proposed that the positive outcomes of expressive writing lie in increased self-regulation 
because it enables individuals to articulate their significant experiences and to integrate these experiences into their selves (King \& Burton, 2004). In so doing, individuals gain greater awareness of their needs, values and or priorities, thus leading them to greater clarity of and more effective pursuit of their goals. King (2002) suggested that expressive writing need not be about negative or highly emotional experiences, as long as they relate to personally significant events. Consistent with this premise, King and her colleagues have found that writing about best possible future selves (King, 2001), the perceived benefits of traumatic events (King \& Miner, 2000), and intensely positive experiences (Burton \& King, 2004) resulted in psychological and/or physiological benefits. Importantly, the health benefits of writing about the perceived benefits of traumatic events (King \& Miner, 2000) and about one's best possible future self (King, 2001) were found to be similar or even better than that of writing about traumatic experiences. Nevertheless, writing about traumatic experiences presented the added disadvantage of inducing more negative moods in the immediate aftermath of the writing sessions compared to writing about positive topics (King, 2001; King \& Miner, 2000). Consequently, King and Miner (2000) proposed that writing about positive topics might be a less upsetting but equally effective way to benefit from expressive writing.

Burton and King (2004) argued that a key advantage of the self-regulation model is that it provides a more parsimonious explanation for the salutary effects of expressive writing because it liberates the writing paradigm from a potentially artificial dichotomy of positive and negative life experiences. Nevertheless, research on the self-regulation model is still in its infancy. If greater clarity and the effective pursuit of one's goals lie at the heart of the expressive writing paradigm, one would expect that these self-regulating 
strategies would mediate the relations between writing condition and health improvements. However, this hypothesis has yet to be empirically tested.

In short, there is insufficient evidence to conclusively favor one model over the rest. The possibility exists that a combination of theorized mechanisms, instead of a single theory, underlies the beneficial effects observed in expressive writing (Sloan \& Marx, 2004). Another possibility is that the applicability of the above theoretical models varies depending on the writing topic. Different writing topics might elicit different psychological and physiological mechanisms of change (King, 2002). What follows is a brief review of writing topics in previous writing experiments.

Writing Topics in Previous Expressive Writing Studies

Studies utilizing the expressive writing paradigm have investigated a wide range of writing topics. The most commonly used topic involves writing about one's deepest thoughts and feelings about stressful or traumatic experiences (e.g., Pennebaker \& Beall, 1986). Other writing topics include relationship breakups (Lepore \& Greenberg, 2002), experiences related to a surgical operation (Solano et al., 2003), emotional and existential issues arising from terminal illnesses (Schwartz \& David, 2002), and the emotional effects of job losses (Spera, Buhrfeind, \& Pennebaker, 1994).

More recently, some researchers have utilized the self-regulation model as the basis for writing topics, e.g., writing about intensely positive experiences (Burton \& King, 2004). Free from the necessity of focusing on negative experiences, the selfregulation model has expanded the range of possible writing topics used in expressive writing research. Within this model, a promising theoretical basis for generating writing topics is the concept of possible selves. The following section discusses the theoretical 
underpinnings of the possible selves perspective, its compatibility with the self-regulation model, and its suitability as a writing topic for emotionally restricted men.

\section{Possible Selves}

Markus and Nurius (1986) introduced the concept of possible selves to distinguish how individuals perceive themselves in the present and the future. Possible selves are viewed as personalized representations of goals and reflect how individuals think about their potential and their future. The concept of possible selves encompasses all of one's imaginable futures, such as expected selves, best possible selves, and feared selves. According to Markus and Nurius (1986), possible selves are not just any set of imagined roles or state of being, but are specific, individualized hopes and fears. For instance, a graduate student who hopes to complete a Ph.D. program tends not to harbor this hope in vague abstraction, but might hold a vivid possible self as a Ph.D. holder, an applicant to an academic position, or as a scholar conducting cutting-edge research.

Importantly, possible selves are conceptualized as psychological resources that motivate future behavior (e.g., one's vision of a thinner self might motivate a person to eat less food) as well as an interpretive context for one's current self-concept (Markus \& Nurius, 1986). Hence, one's attributes and abilities are not evaluated in isolation; possible selves furnish the criteria for assessing outcomes. An undergraduate student with a psychology doctoral student possible self will attach a different interpretation of an A grade in statistics compared to one without such a possible self.

The concept of possible selves offers several advantages to the theoretical conceptualization of self-concept. It provides a future orientation that is useful for explaining one's motivation and goal-oriented action (Nurius, 1989). It also contributes 
to a more multifaceted view of self-concept that encompasses one's future possibilities and potential (Hoskins \& Leseho, 1996). Consequently, one's self-concept is depicted as inherently malleable, as opposed to an authentic self that is the essence of a person (Markus \& Nurius, 1986).

Research Applications of the Possible Selves Perspective

The construct of possible selves has attracted considerable interest among researchers. In particular, scholars have examined the relationship between specific aspects of possible selves and a variety of outcomes such as parenting (Strauss \& Goldberg, 1999), health behaviors (Hooker \& Kaus, 1994), memory (Kato \& Markus, 1993), academic performance among low-income adolescents (Oyserman, Bybee, Terry, \& Hart-Johnson, 2005), and juvenile delinquency (Oyserman \& Markus, 1990).

The potential use of the possible selves perspective as an intervention to foster positive outcomes was explored in a series of three experimental studies examining the effects of representations of various possible selves on performance. Across the three studies, those who imagined successful possible selves outperformed those who imagined unsuccessful possible selves on a series of tasks involving effort and persistence (Ruvolo \& Markus, 1992). Ruvolo and Markus (1992) speculated that participants' motivation to succeed was sustained by the individualized translation of generic desires to do well to specific successful possible selves.

Recently, researchers have explored narrative approaches to examining possible selves. Narrated possible selves have been shown to be a successful method of elucidating individuals' hoped-for future selves when compared to the use of questionnaires (Whitty, 2002). For example, in a recent study that applied a narrative 
approach to the possible selves perspective (King \& Smith, 2004), gay participants wrote narrative descriptions of their straight and gay best possible selves. The salience of participants' gay possible selves (i.e., participants' rating of how easy it was to imagine their possible selves) was positively related to subjective well-being and outness of their sexual identity, while the salience of their straight possible selves was negatively related to subjective well-being and being out.

\section{Counseling Applications of the Possible Selves Perspective}

In addition to research applications, some therapists and counselors have applied the concept of possible selves to the practice of psychotherapy and counseling. Hoskins and Lesho (1996) proposed that counselors can use the possible selves perspective to engage clients in activities that promote creative visualizations such as writing letters indicating what their lives would be like five years from now. Meara (1995) applied the possible selves perspective to career counseling by suggesting that thinking about one's possible occupational self in the future yields benefits such as the personalization of career-related choices and an explicit focus on the future. Finally, Buirs and Martin (1997) observed that the possible selves perspective is especially useful in psychotherapy because the uniquely human ability to imagine future possibilities is an important vehicle for therapeutic change. Drawing from constructivist and social constructionist perspectives on psychotherapy, the authors theorized that when clients discuss their ideal possible selves, they create and revise their personal theories of themselves based on past experiences. Hence, an important goal in psychotherapy is to devise interventions that respect the influences of past and current life experiences on the client's experiences, and yet provide opportunities for constructing and internalizing more positive personal 
theories of the self. In sum, these scholars emphasize that the possible selves perspective, especially the exploration of ideal possible selves, is a potentially valuable clinical intervention that fosters better psychological outcomes.

Application of the Possible Selves Perspective to Expressive Writing

Narrative investigations of possible selves and the application of the possible selves perspective to counseling raise an intriguing question: would the exploration of ideal possible selves through expressive writing improve one's health? Surprisingly, few researchers have investigated this issue, possibly because prior to the introduction of the self-regulation model to expressive writing, it had been uncritically assumed that one had to focus on stressful or traumatic experiences to benefit from writing (King, 2002). Only a few studies have applied the possible selves perspective to expressive writing.

The genesis of the possible selves perspective in expressive writing can be traced to a novel study by Greenberg, Wortman, and Stone (1996). College women were randomly assigned to write about their feelings concerning real or imaginary traumas, or about trivial events. Participants in the imaginary trauma group were asked to mentally experience an imaginary traumatic event as vividly as they can, and then to write about their feelings associated with the event. Imaginary trauma writers were significantly less depressed than real-trauma participants at immediate posttest. Compared to control participants, both trauma groups also made significantly fewer illness visits at 1-month posttest. Interestingly, one of the explanations offered by the authors for the health benefits in the imaginary-trauma group was that participants were constructing more resilient possible selves. The authors posited that the hypothetical nature of the trauma meant that imagined coping decisions were potentially controllable, thus providing 
opportunities for mastery and control. Although the Greenberg et al. (1996) study did not directly examine participants' ideal possible selves, it demonstrates the potential benefits of writing about imaginary selves that are different from one's current experiences.

In the first known study to explicitly examine ideal possible selves in expressive writing (King, 2001), participants were randomly assigned to write about a traumatic event, their best possible future selves, both of these topics, or a trivial topic. Participants in the best possible future selves condition wrote about their lives in the future based on the assumption that everything had gone as well as it possibly could. Controlling for prewriting mood, participants who wrote about their best possible selves reported significantly more positive moods immediately after the writing sessions than those who wrote about trauma. Three weeks after the writing experiment, the best possible selves group reported significantly better subjective well-being than participants in all other groups. Participants in the best possible selves and trauma conditions also had fewer illness visits than control participants and those in the combination group five months posttest. The best possible selves and trauma groups did not differ significantly in their number of illness visits.

Theorizing from the standpoint of the self-regulation model, King $(2001 ; 2002)$ suggested that by writing about their best possible selves, participants were encouraged to consider their priorities and values and about what they needed to make a good life. By having greater clarity of their goals, individuals were better able to pursue their goals, hence increasing their self-regulation. King (2002) also speculated that increased selfregulation could be explained by participants engaging in a process of self-construction. That is, through writing, participants transformed their life goals from something they 
hoped for to something that was being incorporated into their present life experiences. Although not explicitly discussed by King, the notion of writing about possible selves as a means of self-construction seems to converge with Markus and Nurius' (1986) conceptualization of possible selves as providing an interpretive context for one's current self-concept. It may be that when individuals write about their ideal possible selves, they construct a more nuanced perspective of themselves concerning what is possible and hoped for, a process that precipitates the reinterpretation of their current self-concept.

Hence, it appears that the integration of the self-regulation model with the possible selves perspective might offer a theoretical sound explanation for the benefits of writing about one's ideal possible self. Cast against the earlier discussion on the possible selves perspective, writing and thinking about one's ideal possible self can be interpreted as a form of creative mental visualization that transforms one's vague and generic hopes to concrete, personalized visions of the future. Such a process engenders greater selfregulation: through a positive reappraisal of one's self concept and the fostering of motivation for future behavior (Markus \& Nurius, 1986), individuals become more aware of and are better able to pursue their goals.

Benefits of Writing About One's Best Possible Emotional Connectedness With A

\section{Romantic Partner for Emotionally Restricted Men}

The construct of possible selves offers expressive writing researchers a new paradigm of writing topics to explore. In addition to the generic best possible future selves in King's (2001) study, future research could address possible selves in specific roles or life domains (e.g., best possible partner or best possible career) as well as specific populations for which such writing topics would be helpful. In this regard, 
no known controlled study has assessed the benefits of writing about one's ideal emotional connectedness with a romantic partner. There are several reasons why such a topic would be particularly suitable for men, especially those with difficulty expressing emotions.

First, an advantage of writing about one's best possible emotional connectedness with a romantic partner is that emotionally restricted men might be able to enjoy the benefits of expressive writing without the emotional cost typically associated with writing instructions that focus on one's deepest feelings about negative experiences (cf. King, 2002). Such a benefit is pertinent to emotionally restricted men because they tend to be uncomfortable with the experience and expression of negative emotions (cf. O'Neil, 1981b; Shepard, 2002).

A second advantage is that writing about one's best possible emotional connectedness with a romantic partner could be relevant to men, especially during emerging adulthood (the age group to which most participants in the present study belong). Several scholars have observed that the need for relatedness with other human beings is a fundamental human need (e.g., Berscheid, 2003; Deci \& Ryan, 1991). Good et al. (2005) commented that the importance of men's need for relatedness is underscored by increasing expectations on men to "assume greater interpersonal involvement as fathers, partners, and coworkers in ways requiring greater emotional awareness and relational skills than men typically acquire through traditional [European American] masculine socialization experiences.” Moreover, romantic relationships appear to be a defining feature of many male emerging adults' lives (for a review, see Korobov \& Thorne, 2006). Romantic relationships during emerging adulthood, the developmental 
period roughly from ages 18 to 25 , tends to be more serious, intimate, and identity focused compared to those in adolescence (Arnett, 2000; Arnett, 2004; Montgomery, 2005). Arnett (2000) has proposed that among emerging adults, explorations of romantic relationships are characterized by identity-related questions such as the kind of person one is and the kind of person one hopes to have as a romantic partner through life. Given the centrality of romantic relationships in emerging adulthood, it is likely that writing about the ideal emotional connectedness with a romantic partner would speak to a personal need that many male emerging adults can identify with. Such a topic might be particularly appropriate for emotionally restricted men, given their tendency to experience difficulties in romantic relationships (Campbell \& Snow, 1992; Rochlen \& Mahalik, 2004; Sharpe \& Heppner, 1991).

From the perspective of self-regulation theory (King, 2002), writing about having the best possible emotional connectedness with a romantic partner might help men to better understand their emotional life and relationship priorities, and thus enable them to re-orientate their goals to lead more effective lives. The nature of this self-regulatory process can be further explained using the possible selves perspective. By writing about how their lives would be different if they had the best possible emotional connectedness with a romantic partner, men could be creating a vivid mental picture of what is attainable in their emotional and relational lives (cf. Ruvolo \& Markus, 1992), which might inspire them to achieve the outcomes they write about. In addition, such a writing exercise might positively restructure their self-concepts (cf. Markus \& Nurius, 1986). For instance, the writing intervention might heighten individuals' awareness of instances in their lives where they have demonstrated emotional expressiveness or relational intimacy. 
Hence, individuals' self-concepts might change from viewing themselves as being uncomfortable with emotions and intimacy to having the potential for emotionallysatisfying relationships.

Third, writing about one's ideal emotional connectedness with a romantic partner dovetails with a developmental perspective on masculinity that emphasizes men's strengths and resources and not just the pathological aspects of masculinity (Heesacker \& Pritchard, 1992; Kelly \& Hall, 1992). From a developmental perspective, men's restrictive emotionality is viewed as a lack of opportunity for learning the emotional skills for adaptive functioning (cf. Kelly \& Hall, 1992). Expressive writing provides the opportunity for practicing these skills in an anonymous, non-threatening environment. Further, the writing topic of emotional connectedness with a romantic partner potentially empowers men to focus on how their lives can be better, rather than merely on what is wrong with their lives.

In addition, writing about one's ideal emotional connectedness with a romantic partner might tap into emotionally restricted men's latent strengths. In particular, emotionally restricted men's desire for greater comfort with emotional expression can be conceptualized as a strength to be utilized in expressive writing. Some empirical support for this view can be found in a recent study of men's current and ideal level of gender role conflict (Liu et al., 2005). Male participants were asked to imagine their ideal version of themselves in the perfect world and then rate themselves accordingly on the Gender Role Conflict Scale. With regard to restrictive emotionality, more than $90 \%$ of participants desired lower levels of restrictive emotionality in the ideal world compared to their current experience of restrictive emotionality. The authors inferred that these men 
may be aware of their problems of living up to traditional masculine norms and could potentially envision a world in which they had less discomfort with emotional expression (Liu et al., 2005). Writing about one's ideal emotional connectedness with a romantic partner might tap into men's preexisting desire for greater emotional expressiveness and help translate this desire into more personal and concrete details (cf. Ruvolo \& Markus, 1992).

\section{Specific Benefits of Writing About One's}

\section{Best Possible Emotional Connectedness With a Romantic Partner}

Having elucidated the reasons why writing about one's best possible emotional connectedness with a romantic partner is a suitable topic for emotionally restricted men, what follows is a discussion of specific benefits that might accrue from such a writing intervention. It was theorized that such a writing intervention would lead to (1) lower levels of restrictive emotionality, (2) reduced psychological distress, (3) increased positive relations with others, (4) increased personal growth; and (5) a greater expression of emotional intimacy. These proposed benefits formed the basis of the main hypotheses in the present study.

\section{Lower Levels of Restrictive Emotionality}

Although no previous study has examined whether expressive writing can facilitate less restrictive emotionality for men, it was reasonable to expect that writing about being emotionally connected to a romantic partner would lead to a greater comfort with emotional expression. From the viewpoint of the self-regulation and possible selves paradigms, men might gain greater awareness of their present emotional life by writing about being emotionally connectedness to another person. This might, in turn, harness 
their motivation to be more emotionally expressive in interpersonal contexts.

Alternatively, writing about emotional connectedness in interpersonal contexts might highlight instances of emotional expressiveness in individuals' current life experiences, and thus alter their perception of their capacity for disclosing feelings.

\section{Reduced Psychological Distress}

It was further theorized that writing about one's best possible emotional connectedness with others would lead to better mental health outcomes in terms of reduced psychological distress, more positive relations with others, and increased personal growth. Previous studies have shown that men's restrictive emotionality is associated with heightened levels of psychological distress (e.g., Liu et al., 2005). Congruent with the results of previous expressive writing studies (for summaries, see Sloan \& Marx, 2004; Smyth, 1998), writing about one's best possible emotional connectedness with a romantic partner was expected to reduce psychological distress. Using the possible selves perspective, it was theorized that the opportunity to construct a potentially inspiring story of one's experience of an emotionally connected romantic relationship would positively alter one's self-concept via increased self-efficacy, a process that could enhance self-regulation and undo one's experience of psychological distress.

Increased Psychological Well-Being

In recent years, a growing number of scholars have called for a more holistic study of mental health that includes the examination of optimal functioning in additional to mental illness (e.g., Keyes, 2003; Maddux, Snyder, \& Lopez, 2004; Seligman, 2002). One attempt at articulating dimensions of optimal functioning is the concept of 
psychological well-being, which focuses on perceived thriving vis-à-vis life's existential challenges (Keyes, Shmotkin, \& Ryff, 2002; Ryff, 1989). Ryff posited that the construct of psychological well-being comprises at least six dimensions: self-acceptance, positive relations with others, autonomy, environmental mastery, purpose in life, and personal growth. Among the above, two dimensions of psychological well-being: positive relations with others and personal growth might be especially relevant to a writing intervention on one's best possible emotional connectedness with a romantic partner.

Increased Personal Growth. Rooted in humanistic and existential theories of psychological growth, personal growth refers to one's view of the self as growing, improving, and being open to new experiences (Ryff, 1989). Although no study has examined the link between restrictive emotionality and personal growth, there is some indirect evidence that emotionally restricted men might have lower levels of personal growth. Tokar et al. (2000) found that men's restrictive emotionality was negatively related to the Big-Five openness to experience dimension of personality, a result that might hint at emotionally restricted men's lack of personal growth.

It was thus reasonable to speculate that expressive writing can enhance personal growth, especially for emotionally restricted men. Writing about one's experiences can be understood as a form of self-construction that opens the writer to a broader perspective of the self (King, 2002; Pennebaker \& Seagal, 1999), thus fostering a sense of personal growth. Nevertheless, few studies have specifically examined the hypothesis that expressive writing facilitates personal growth.

Previous expressive writing studies that examined personal growth tended to utilize trauma-related growth measures. For example, the Posttraumatic Growth 
Inventory (Tedeschi \& Calhoun, 1996), a measure of perceived beneficial change in the wake of traumatic experiences, was used as an outcome measure in two expressive writing dissertation studies. In the first study (Kirk, 1998), female participants who wrote essays focusing on the cognitive processing of stressful interpersonal experiences reported increased posttraumatic growth three months posttest, although male participants in a similar experimental group did not demonstrate similar gains. In the second study (Weis, 2004), experimental participants who wrote about their feelings concerning the 9/11 terrorist attacks did not report growth that differed significantly from that of control participants. The author speculated that participants might not have experienced a direct sense of connection to the $9 / 11$ terrorist attacks, thus, constraining the effects of expressive writing.

Although the results of the above two studies did not provide consistent support for the notion that expressive writing facilitates posttraumatic growth, it should be noted that the outcomes might be a function of the writing topics and the specific type of measure used. To date, no expressive writing study has examined personal growth within the context of non-stressful events. Writing topics that examine possible selves might be particularly useful for developing personal growth since such topics invite participants to focus on new experiences and possibilities. From the possible selves perspective, it might be theorized that writing about the best possible emotional connectedness with a romantic partner would stimulate a re-evaluation of self-concept toward viewing the self as being more open to new experiences in emotionality and intimacy. This process might engender enhanced self-regulation by providing greater clarity and more effective pursuit of one's 
personal growth-related goals, e.g., being open to new experiences in interpersonal intimacy.

Increased Positive Relations With Others. The ability to love and be loved has been viewed by some scholars as an important component of mental heath (Keyes, 2003; Ryff \& Singer, 1998). Nevertheless, the emphasis of past expressive writing research has been on intrapersonal outcomes at the expense of relational processes (Snyder, Gordon, Baucom, 2004). The few studies that have examined social processes provide preliminary evidence that expressive writing might lead to better social relationships.

In a study on broken romantic relationships, participants who wrote about their feelings concerning relationship breakups were more likely to reunite with their expartners than control participants (Lepore \& Greenberg, 2002). In another study by Mehl and Pennebaker (discussed in Niederhoffer \& Pennebaker, 2002), an electronically activated recorder (EAR) was used to record participants' naturalistic conversations two weeks after an expressive writing intervention. Preliminary results indicated that participants who wrote about traumatic topics talked to their friends more and laughed more compared to control participants. Significantly, these effects were far stronger for men than for women, suggesting that expressive writing might be more beneficial for individuals who are less socially integrated (Niederhoffer \& Pennebaker, 2002). In another study that utilized the EAR (Kim, 2004), participants who engaged in expressive writing about distressing experiences showed stable social patterns at one month posttest while control participants spent more time alone and less time with others. Finally, in a recent study on expressive writing and dating couples (Slatcher \& Pennebaker, 2006), participants who wrote about their deepest thoughts and feelings about their romantic 
relationships were more likely than control participants to still be dating their partners three months later. Taken together, these studies indicate that expressive writing can potentially have positive effects on people's interpersonal relationships.

Although no study has examined the effects of writing about possible selves on one's interpersonal relationships, it seems reasonable to expect that writing about one's best possible emotional connectedness with a romantic partner would also lead to improved relations with others. Applying the possible selves perspective, it was surmised that such a writing intervention would transform one's vague wishes for interpersonal intimacy into more personalized accounts of desired intimacy. This process, in turn, enhances self-regulation by drawing attention to one's present relationship priorities and increasing one's motivation and ability to connect with others in more fulfilling ways. Such an intervention might be especially beneficial to emotionally restricted men given the accumulating evidence for the association between men's restrictive emotionality and difficulties with interpersonal relationships (e.g., Sharpe \& Heppner, 1991).

Increased Expression of Emotional Intimacy. Defined as the closeness and emotional tone of a relationship, emotional intimacy is a central tenet in many contemporary theories of close relationships (e.g., Knobloch \& Solomon, 2004; Monsour, 1992; Park \& Floyd, 1996). A study on college students' definitions and expression of intimacy (Monsour, 1992) revealed that the most frequently endorsed definitions of intimacy included self-disclosures, emotional expressiveness, unconditional support, physical contact and trust. Similar to the theoretical foundations underlying the predictions about one's positive relations with others, it was expected that writing about one's ideal emotional connectedness would also improve men's comfort with and desire for 
emotional intimacy, thus leading to greater expression of emotional intimacy in their close relationships. Such an intervention might be particularly helpful for emotionally restricted men given their difficulty with close interpersonal relationships (Sileo, 1996; Campbell \& Snow, 1992).

\section{Overview of the Present Study}

The above literature review reveals evidence of numerous psychosocial problems associated with men's restrictive emotionality. What is critically needed is an empirical evaluation of a clinical intervention that improves emotionally restricted men's psychosocial functioning (Good et al., 2005). Hence, the main purpose of the present study was to examine the potential salutary effects of writing about one's best possible emotional connectedness with a romantic partner for male college students with varying degrees of restrictive emotionality. A secondary objective of this study was to explore the relationship between male college students' restrictive emotionality and several other psychosocial variables.

This study was unique in several ways. First, it aimed to extend the research on men's restrictive emotionality by exploring its relationship with several other psychosocial variables. This study may be the first to elucidate the relations between men's restrictive emotionality and the construct of personal growth. Based on previous evidence of the inverse association between restrictive emotionality and the Big-Five openness to experience personality dimension (Tokar et al., 2000), men's restrictive emotionality was hypothesized to be negatively related to personal growth. In addition, this study was expected to replicate previous studies that have shown that more emotionally restricted men tend to report elevated levels of psychological distress (e.g., 
Liu et al., 2005) and less positive relations with others (e.g., Sharpe \& Heppner, 1991). In view of past research on the association between restrictive emotionality and problems in romantic relationships (e.g., Rochlen \& Mahalik, 2004), it was also anticipated that emotionally restricted men were less likely to be in romantic relationships.

Further, advances in the use of computer programs to examine individuals' psychosocial functioning through their written language (Pennebaker, Mehl, \& Neiderhoffer, 2003) have presented new opportunities for research on men's restrictive emotionality. A recent but growing body of research indicate that people's cognitive, emotional, and social processes can be empirically analyzed by counting and categorizing the written words they use (for reviews, see Pennebaker \& King, 1999; Pennebaker et al., 2003). Research in this emerging field has been conducted largely through a computerized text analysis program called the Linguistic Inquiry and Word Count (LIWC; Pennebaker, Francis, \& Booth, 2001). By analyzing text samples according to 72 linguistic dimensions, LIWC produces an output comprising of the proportion of words in each linguistic dimension. Given that no published study has utilized LIWC in the study of masculinity-related variables, this study may be one of the first to examine the relationship between men's restrictive emotionality and their language usage. Because restrictive emotionality has been defined as men's difficulty expression emotions (O'Neil et al., 1995), it was predicted that men's restrictive emotionality would be negatively related to their use of affect words in their written essays.

Second, this study aimed to break new ground by empirically examining a clinical intervention that potentially improves emotionally restricted men's psychosocial functioning. Specifically, this study sought to apply the self-regulation model and the 
possible selves perspective to expressive writing. Consistent with the results of King's (2001) expressive writing study on best possible selves, it was anticipated that writing about one's best possible emotional connectedness with a romantic partner would lead to less restrictive emotionality, less psychological distress, more positive relations with others, greater personal growth, and greater expression of emotional intimacy in close relationships.

Finally, this study might be the first expressive writing study to examine a masculinity-related variable, i.e., men's restrictive emotionality, as a potential moderator between the writing condition and the outcome variables. Based on the previous review of studies indicating that expressive writing tends to yield greater benefits for individuals with impoverished emotional resources (e.g., Paez et al., 1999), it was predicted that emotionally restricted men would benefit more from expressive writing than less emotionally restricted men.

Romantic relationship status was also examined as a potential moderator because it was possible that men who were in romantic relationships would react differently to the expressive writing intervention than men who were not. Since this was the first known expressive writing study to focus on the topic of one's ideal emotional connectedness with a romantic partner, it was unclear how men's relationship status would moderate the effects of the writing intervention. On the one hand, it could be argued that the expressive writing topic would be more beneficial to men with romantic partners because it was more applicable to their current relationship experiences. On the other hand, it could be surmised that men who were not in romantic relationships would benefited more from the expressive writing intervention because it presented greater opportunities for growth and 
identity exploration in an area of life they lacked. In the current study, both sets of alternative hypotheses were explored with regard to how men's romantic relationship status would modify the effects of the writing intervention on the outcome variables.

To summarize, this study had six main sets of hypotheses:

$I^{\text {st }}$ Set of Hypotheses: Relations Between Restrictive Emotionality and Other Variables

1. Participants' restrictive emotionality would be:

a. positively related to their psychological distress.

b. negatively related to their personal growth.

c. negatively related to their positive relations with others.

d. positively related to not being in a romantic relationship.

e. negatively related to the use of affect words in their essays.

$2^{\text {nd }}$ Set of Hypotheses: Decrease in Restrictive Emotionality

2a. Experimental participants would report greater reductions in restrictive emotionality after the writing intervention compared to control participants.

2b. There would be a condition by romantic relationship status by time interaction. Two alternative hypotheses were proposed:

i. Among participants in romantic relationships, the experimental group would report greater reductions in restrictive emotionality than the control group. In contrast, among participants not in romantic relationships, there would be no significant difference in the change in restrictive emotionality between the control group and the experimental group; or

ii. Among participants not in romantic relationships, the experimental group would report greater reductions in restrictive emotionality than the control 
group. In contrast, among participants in romantic relationships, there would be no significant difference in the change in restrictive emotionality between the control group and the experimental group.

$3^{\text {rd }}$ Set of Hypotheses: Decrease in Psychological Distress

3a. Experimental participants would report greater reductions in psychological distress after the writing intervention compared to control participants.

3b. There would be a condition by restrictive emotionality by time interaction: With regard to less emotionally restricted participants, there would be no significant difference in the change in psychological distress between the two conditions. In contrast, among more emotionally restricted participants, the experimental group would report greater reductions in psychological distress than the control group.

3c. There would be a condition by romantic relationship status by time interaction. Two alternative hypotheses were proposed:

i. Among participants in romantic relationships, the experimental group would report greater reductions in psychological distress than the control group. In contrast, among participants not in romantic relationships, there would be no significant difference in the change in psychological distress between the control group and the experimental group; or

ii. Among participants not in romantic relationships, the experimental group would report greater reductions in psychological distress than the control group. In contrast, among participants in romantic relationships, there would be no significant difference in the change in psychological distress between the control group and the experimental group. 


\section{$4^{\text {th }}$ Set of Hypotheses: Increase in Personal Growth}

4a. Experimental participants would report a greater increase in personal growth after the writing intervention compared to control participants.

4b. There would be a condition by restrictive emotionality by time interaction: With regard to less emotionally restricted participants, there would be no significant difference in the change in personal growth between the two conditions. In contrast, among more emotionally restricted participants, the experimental group would report a greater increase in personal growth than the control group.

4c. There would be a condition by romantic relationship status by time interaction. Two alternative hypotheses were proposed:

i. Among participants in romantic relationships, the experimental group would report a greater increase in personal growth than the control group. In contrast, among participants not in romantic relationships, there would be no significant difference in the change in personal growth between the control group and the experimental group; or

ii. Among participants not in romantic relationships, the experimental group would report a greater increase in personal growth than the control group. In contrast, among participants in romantic relationships, there would be no significant difference in the change in personal growth between the control group and the experimental group.

$5^{\text {th }}$ Set of Hypotheses: Increase in Positive Relations With Others 
5a. Experimental participants would report a greater increase in positive relations with others after the writing intervention compared to control participants.

5b. There would be a condition by restrictive emotionality by time interaction: With regard to less emotionally restricted participants, there would be no significant difference in the change in positive relations with others between the two conditions. In contrast, among more emotionally restricted participants, the experimental group would report a greater increase in positive relations with others than the control group.

5c. There would be a condition by romantic relationship status by time interaction. Two alternative hypotheses were proposed:

i. Among participants in romantic relationships, the experimental group would report a greater increase in positive relations with others than the control group. In contrast, among participants not in romantic relationships, there would be no significant difference in the change in positive relations with others between the control group and the experimental group; or

ii. Among participants not in romantic relationships, the experimental group would report a greater increase in positive relations with others than the control group. In contrast, among participants in romantic relationships, there would be no significant difference in the change in positive relations with others between the control group and the experimental group.

$6^{\text {th }}$ Set of Hypotheses: Greater Expression of Emotional Intimacy 
6a. Experimental participants would express more emotional intimacy to their romantic partners/significant others after the writing intervention compared to control participants.

6b. There would be a condition by restrictive emotionality interaction: With regard to less emotionally restricted participants, there would be no significant difference in the expression of emotional intimacy between the two conditions. In contrast, among more emotionally restricted participants, the experimental group would express more emotional intimacy to their romantic partners/significant others than the control group.

6c. There would be a condition by romantic relationship status interaction. Two alternative hypotheses were proposed:

i. Among participants in romantic relationships, the experimental group would express more emotional intimacy to their romantic partners/significant others than the control group. In contrast, among participants not in romantic relationships, the control and experimental groups would not differ significantly in the expression of emotional intimacy to their romantic partners/significant others; or

ii. Among participants not in romantic relationships, the experimental group would express more emotional intimacy to their romantic partners/significant others than the control group. In contrast, among participants in romantic relationships, the control and experimental groups would not differ significantly in the expression of emotional intimacy to their romantic partners/significant others. 


\section{Chapter III: Methodology \\ Participants}

One hundred and sixty-three male students taking undergraduate educational psychology classes at the University of Texas at Austin participated in the study. Participants were given course credit in exchange for participation in the study. Data from five participants were excluded because they either did not attend all three days of the writing intervention or did not comply with the writing intervention, resulting in a final sample of 158 participants (mean age $=21.64, \mathrm{SD}=3.96) .54 .5 \%$ of the participants were White, $35.3 \%$ were Asian, $1.9 \%$ were African American/Black, 1.3\% were Latino, $5.8 \%$ were biracial/multiracial, and $1.3 \%$ reported other racial backgrounds. $96.1 \%$ of participants identified as heterosexual, 2.6\% identified as gay, and 1.3\% identified as bisexual. On the first day of the writing intervention, $38.1 \%$ of participants reported that they were in romantic relationships while $60.9 \%$ reported that they were not.

\section{Measures}

\section{Restrictive Emotionality Scale}

The 10-item RES (O'Neil et al, 1986; Appendix C) is one of four subscales of the Gender Role Conflict Scale (GRCS; O’Neil et al., 1986). The RES is used to assess men's difficulties and fears about expressing feelings and difficulty finding words to express basic emotions (O’Neil et al., 1995). A sample item is, "I have difficulty expressing my tender feelings." Respondents are asked to report the extent to which they agree or disagree with statements using a 6-point Likert-type scale ranging from 1 (strongly disagree) to 6 (strong agree) with higher scores reflecting higher levels of restrictive emotionality. Previous samples have yielded an average coefficient alpha of 
.84 across 11 studies (O'Neil et al., 1995) and a 4-week test-retest reliability of .76

(O'Neil et al., 1986). In the present study, the coefficient alphas were $.87, .92$, and .91 for

Time 1, Time 2, and Time 3 respectively. Many researchers who studied the factor structure of the GRCS (e.g., Good, Robertson, O'Neil, Fitzgerald, Stevens, \& DeBord, 1995; Moradi et al., 2000) have found a similar factor structure to that found in O’Neil and his colleagues' original study (O'Neil et al., 1986). O'Neil et al. (1995) reviewed 35 studies that provided abundant evidence for the construct validity of the RES: restrictive emotionality was found to be associated with psychological and interpersonal problems, e.g., low self-esteem, difficulties with relationship intimacy, marital dissatisfaction, anxiety, depression, and a negative view of help-seeking.

\section{Brief Symptom Inventory-18}

The BSI-18 (Derogatis, 2000; Appendix D) is an 18-item questionnaire used to assess respondents' distress on three psychological dimensions: Somatization, Depression, and Anxiety. Participants rate the extent to which they have been distressed or bothered by various problems over the past seven days on a 5-point Likert scale ranging from 0 (no distress) to 4 (extreme distress). In the original norming of over 1100 community participants, the subscales of the BSI-18 were found to be highly correlated (>.90) with the original 53-item Brief Symptom Inventory (Derogatis, 2000). In the present study, the Global Severity Index (GSI) of the BSI-18, the sum of scores on all items was used to provide overall symptom scores. The GSI is regarded as the single best indicator of current distress levels and is typically used in instances where a single summary measure is required (Derogatis \& Melisaratos, 1983). With respect to the GSI of the original BSI, Derogatis and Melisaratos (1983) found 2-week, test-retest reliability 
of .90, while Sher, Wood, and Gotham (1996) found that the coefficient alpha ranged from .94 to .95 . In the present study, the coefficient alphas were $.91, .92$, and .94 for Time 1, Time 2, and Time 3 respectively. Validity of the BSI was demonstrated through association of the subscales of the original BSI with like dimensions of the Minnesota Multiphasic Personality Inventory (Derogatis \& Melisaratos, 1983).

\section{Positive Relations With Others Scale}

Together with the Personal Growth Scale, the PRWOS (Ryff, 1989; Appendix E). is one of six scales designed by Ryff (1989) to measure dimensions of psychological well-being. Psychological well-being has often been contrasted with subjective wellbeing. Keyes et al. (2002) posited that psychological well-being is concerned with perceived thriving vis-à-vis the existential challenges of life whereas subjective wellbeing involves more global evaluations of affect and life quality. The PRWOS is a 14item, 7-point Likert scale with responses ranging from 1 (strongly disagree) to 6 (strongly agree). An example of an item is, "Most people see me as loving and affectionate.” After negatively scored items are reversed, high scores represent perceiving oneself as having warm, satisfying, trusting, and intimate relationships with others. Ryff (1989) reported a coefficient alpha of .91 and a test-retest reliability of .83 for this scale. In the present study, the coefficient alphas were $.85, .86$, and .88 for Time 1 , Time 2 , and Time 3 respectively. Construct validity of the PRWOS has been shown through correlations with other measures of well-being such as self-esteem and negative associations with measures of negative functioning such as depression (Ryff, 1989). Using 3-item versions of the six scales of psychological well-being, Keyes et al. (2002) found evidence of discriminant validity through a series of factor analyses of the six 
scales and measures of subjective well-being, e.g., life satisfaction. The authors reported that psychological well-being (which includes positive relations with others) and subjective well-being represented distinct but related conceptions of well-being.

\section{Personal Growth Scale}

The PGS (Ryff, 1989; Appendix F) is a 14-item, 7-point Likert scale with responses ranging from 1 (strongly disagree) to 6 (strongly agree). An example of an item is, "I think it is important to have new experiences that challenge how you think about yourself and the world." After negatively scored items are reversed, high scores represent having a feeling of continued development and seeing oneself as growing and being open to new experiences. Ryff (1989) reported a coefficient alpha of .87 and a testretest reliability of .81 for the scale. In the present study, the coefficient alphas were .85 , .90 , and .92 for Time 1, Time 2, and Time 3 respectively. Construct validity of the PGS has been shown through correlations with other measures of well-being such as selfesteem and negative associations with measures of negative functioning such as depression (Ryff, 1989). Keyes et al.'s (2002) factor analyses indicated that personal growth was one of two dimensions of psychological well-being that was most cleanly distinguishable from the affective and life quality assessments of subjective well-being, thus, attesting to the discriminant validity of the PGS.

Questionnaire on the Expression of Emotional Intimacy

Although several measures of emotional intimacy exist (for a review, see Stein, 2001), many of these measures focus on the affective aspects of emotional intimacy (e.g., how an individual feels toward another person) rather than on behavioral expressions of emotional intimacy. The 18-item QEEICR (Appendix J) was created for the purposes of 
this study to measure concrete, behavioral indicators of participants' non-sexual expression of emotional intimacy in close relationships.

In this study, two versions of the QEEICR were used. In the QEEICR (participants' version), each participant was asked how many days within the past seven days he had demonstrated acts of emotional intimacy to a specific individual (either his romantic partner if his was in a romantic relationship or a significant other, e.g., a close friend). Examples of items reflecting acts of emotional intimacy to each participant's romantic partner/significant other include doing something to encourage him/her and expressing concern for him/her. Overall scores are computed by the sum of scores from all items divided by the total number of items. High scores represent more frequent expressions of emotional intimacy to specific individuals in close relationships (participants' romantic partners or significant others). In the QEEICR (others'version), participants' romantic partners/significant others responded to the same 18 items on the QEEICR with regard to participants' behavior over the past seven days, e.g., "Over the past seven days, how many days did he do something to encourage you?"

As will be explained in the results section, the QEEICR was reduced to 14 items pursuant to an exploratory factor analysis. The coefficient alphas of the revised QEEICR were .96 for the participants' version and .95 for the others' version. Because participants responded to the QEEICR by describing their expression of emotional intimacy to either their romantic partners (if they were in romantic relationships) or other significant others (if they were not in romantic relationships), it was important to examine whether the internal stability of the QEEICR varied depending on the type of person described in participants' responses. The coefficient alphas for the QEEICR (participants'version) 
was .94 based on a sub-sample of participants who described their romantic partners and .95 based on a sub-sample of participants who described their significant others. Hence, the internal consistency of the QEEICR remained high across the two sub-samples.

\section{Questionnaire on Self-Regulation}

To provide validation of the writing procedures, a manipulation check was conducted via a questionnaire on self-regulation and the Linguistic Inquiry and Word Count. Because the self-regulation model is the theorized basis for improvements in psychological functioning in this study, an 8-item Questionnaire on Self-Regulation (QSR; Appendix H) was created to assess the extent to which participants developed enhanced self-regulation as a result of the writing intervention. In concert with selfregulation theory, the items in the questionnaire focus on whether participants were more aware of their goals in life and better able to pursue those goals as a result of the writing intervention, e.g., "As a result of the writing experiment, I have a better idea of how to achieve my goals.” Participants respond on a 6-point Likert scale ranging from 1 (strongly disagree) to 6 (strongly agree), with higher scores representing greater levels of self-regulation resulting from the writing intervention. The coefficient alpha for this questionnaire in the present study was .97 .

\section{Linguistic Inquiry and Word Count}

All participants' essays were analyzed by a computerized text analysis program called LIWC (Pennebaker et al., 2001). LIWC analyzes written or spoken text samples by comparing each word against a dictionary of more than 2000 words categorized into 72 linguistic dimensions. LIWC counts the number of words that matches its dictionary and produces an output consisting of the percentage of words in each linguistic dimension. 
Inter-rater reliability for agreement on the list of words in each category ranged from 93 to $100 \%$ (Pennebaker et al., 1997). Pennebaker and King (1999) provided evidence for the reliability and factor structure of written language analyzed by LIWC. Further, LIWC was found to detect language use as a reliable individual difference and had good divergent and convergent validity with measures of motivation, behavior, and the fivefactor personality dimensions (Pennebaker \& King, 1999). For the purposes of the manipulation check, this study focused only on a few LIWC dimensions: (1) the affect words category as well as two subcategories: positive feeling words and negative emotion words; (2) causal words (e.g., because, effect); (3) insight words (e.g., understand, know); and (3) social words, i.e., words that indicate references to other people and interpersonal communication (e.g., we, friend, share); (4) first personal singular pronouns (e.g., I, me, myself); and (5) the number of words in participants' essays. Note that participants' essays were subject to a computerized spell check before they were analyzed by LIWC. Questionnaire on Participants' Subjective Experiences

As is commonly done at the conclusion of expressive writing studies (e.g., Pennebaker et al., 1990), participants responded to the Questionnaire on Participants' Subjective Experiences (QPSE; Pennebaker, Colder, \& Sharp, 1990; Appendix L), a questionnaire with 7-point Likert-scale items and open-ended questions about their subjective experiences in the study, e.g., "Since your participating in the writing experiment, how much have you thought about what you wrote?"

\section{Procedures}

Prior to the onset of the study, approval from the Institutional Review Board at the University of Texas at Austin was obtained. All questionnaires as well as the writing 
intervention were administered via computers using an internet-based program. One benefit of collecting data via the internet is that it obviates data entry error (Gosling, Vazire, Srivastava, \& John, 2004). Gosling et al. (2004) compared survey data collected via the internet with data collected through traditional methods and concluded that participants in internet studies were just as likely to take the study seriously and provide accurate information compared to traditional samples. With the exception of data collected at Time 3 (four weeks after the writing intervention), participants were required to complete all questionnaires and the writing experiment in computer labs.

\section{Time 1 Procedures}

Participants were randomly assigned to either an experimental or a control group on the first day of the study. All participants were invited to a computer lab where they logged on to a website with the study questionnaires. First, they provided consent (Appendix A) to participate in the experiment. Next, all participants filled out a demographic questionnaire (Appendix B), the RES, BSI-18, PRWOS, and the PGS.

Finally, researchers blind to the participant's writing condition provided all participants with several generic verbal instructions about the writing procedure, e.g., participants should write continuously for 20 minutes and not worry about grammar and spelling. (See Appendix $\mathrm{G}$ for verbal and written instructions on all three days of the writing intervention for experimental and control participants.) On all three days of the writing intervention, a researcher told participants to stop writing after 20 minutes. It should be noted that although the three writing sessions of writing did not occur on consecutive days, all participants completed the three sessions within a week.

\section{Instructions for Experimental Participants}


Participants in the experimental condition were told on Day 1 to imagine that they had the best possible emotional connectedness with either an actual or imaginary/future romantic partner. They were told to write about how their lives would be different and about how they would communicate with their romantic partners. On Day 2, experimental participants were given similar instructions as on Day 1. On Day 3, experimental participants were asked to write about what they had learned concerning their relationships, goals, values, and priorities from their previous writing sessions, as well as whether they wanted to change any aspects of their lives as a result of their writing.

\section{Instructions for Control Participants}

Participants in the control group were told on Day 1 that over the next 3 sessions, they would be writing about important topics related to human connections. Previous expressive writing studies have tended to utilize trivial writing control topics (e.g., a description of participants' surroundings in Greenberg et al., 1996). However, the control group writing topics chosen for this study were intended to be non-trivial and intellectually demanding, but impersonal and non-emotional. On Day 1, they were instructed to write about how technology has influenced the way humans relate to one another. On Day 2, they were told to write about the changes in the way humans relate to one another over the past 100 years. On Day 3, experimental participants were asked to write about why a country might have a close relationship with one country but an unfriendly relationship with another country. On all three days, they were instructed to be as objective as possible and that they should not discus their personal feelings in their writing. 


\section{Time 2 Procedures}

Immediately after completing their essays on Day 3 (Time 2), participants filled out the RES, BSI-18, PRWOS, PGS, and the QSR.

\section{Time 3 Procedures}

Approximately four weeks after the writing phase of the study, participants were sent an email instructing them to log on to a website containing Time 3 measures. A fourweek time lag was chosen in view of past research demonstrating that the benefits of expressive writing typically emerge only after a few weeks, rather than immediately after the experiment (Pennebaker, 1997).

Participants were allowed to complete the measures from any computer of their choice. Participants completed the RES, BSI-18, PRWOS, and the PGS. Each participant also completed a demographic questionnaire about his romantic partner (if he was in a romantic relationship) or about a person he was close to (e.g., a close friend or family member) if he was not in a romantic relationship (see Appendix I). Next, all participants completed the QEEICR (participants'version). Participants who were in romantic relationships responded to the QEEICR with regard to their romantic partners while those who were not in romantic relationships responded to the QEEICR with respect to the significant others they had described in the above demographic questionnaire. The participants were then asked to provide their romantic partners or significant others' email addresses with the understanding that researchers would request their romantic partners/significant others to complete a brief online questionnaire about their relationships with participants (see Appendix K). Finally, participants completed the QPSE. After these measures were completed, participants were informed of the purposes 
of the study and about services available at the university counseling center (Appendix M).

Seventy-nine participants provided email addresses of their romantic partners/significant others. These romantic partners/significant others were invited by email to participate in the study (see Appendix N). As an incentive to participate in the study, these romantic partners/significant others were informed that by completing an online questionnaire, they could participate in a draw for a gift of fifty dollars. 35 individuals (14 romantic partners and 21 significant others) responded to the QEEICR (others' version) by rating participants' expression of emotional intimacy to them. The vast majority (85.7\%) of respondents to the QEEICR (others' version) completed the questionnaire within 5 weeks after the writing intervention. 


\section{Chapter IV: Results}

\section{Missing Data}

A few minor computer glitches during the administration of the study (e.g., participants' computers freezing) resulted in missing data for some measures as well as some participants' essays. An examination of frequencies on all measures revealed that the number of missing responses on the overall score of each measure did not exceed six. Because there was no evidence that the computer glitches were non-random, missing data was handled using pairwise deletion during subsequent analyses.

\section{Manipulation Checks}

\section{LIWC Analyses}

In the present study, experimental participants wrote about how their lives would be different if they had the best possible emotional connectedness with a romantic partner while control participants wrote about impersonal topics related to human relationships. As part of a manipulation check to assess whether participants complied with the writing instructions, the content of participants' essays on all three days were analyzed by LIWC. The experimental participants' essays were expected to be more personal, emotionally laden, and insightful than control participants' essays. Hence, it was anticipated that experimental participants' essays would be longer, and they would use a significantly greater proportion of affect words and first person singular pronouns (e.g., I, me, myself) than control participants. Because both writing conditions involved topics related to human relationships, participants were not expected to differ in their use of social words. Further, the control group's writing topics were expected to be cognitively engaging, but less insightful than the expressive writing topics. Hence, it was predicted that both groups 
would not differ in their use of causal words (e.g., therefore, because), a linguistic indicator of cognitive engagement, but that experimental participants would use a significantly greater proportion of insight words (e.g., understand, know) than control participants.

Independent samples t-tests were conducted to evaluate differences between the expressive and control writing groups. As shown in Table 1, the above predictions were mostly confirmed. Overall, experimental participants' essays were significantly longer, and they used a significantly greater proportion of affect words (including a greater percentage of negative and positive emotion words) and first person singular pronouns. Control and experimental participants did not differ significantly in their use of social words. Experimental participants used a significantly greater percentage of insight words than did control participants, but unexpectedly, control participants used a significantly greater proportion of causal words than did experimental participants.

Table 1 Means and Standard Deviations for Linguistic Categories in Participants' Essays

\begin{tabular}{lrrrrrrr}
\hline Linguistic Category & \multicolumn{2}{c}{$\begin{array}{c}\text { Experimental } \\
(\mathrm{N}=79)\end{array}$} & \multicolumn{2}{c}{ Control } & t-value & df & p-value \\
& $\mathrm{M}$ & $\mathrm{SD}$ & $\mathrm{M}$ & $\mathrm{SD}$ & & & \\
\hline Word Count & 1428.85 & 485.07 & 1217.24 & 542.73 & 2.55 & 151 & .012 \\
Total Affect & 6.04 & 1.18 & 3.10 & .92 & 17.12 & 151 & $<.001$ \\
$\quad$ Negative emotions & 1.88 & .70 & 1.08 & .46 & 8.43 & $136.75^{*}$ & $<.001$ \\
$\quad$ Positive emotions & 4.00 & 1.06 & 1.95 & .68 & 14.30 & $134.39 *$ & $<.001$ \\
Causal & 1.30 & .45 & 1.57 & .67 & -2.85 & $127.31 *$ & .005 \\
Insight & 3.94 & 1.14 & 2.92 & 1.11 & 5.58 & 151 & $<.001$ \\
First person singular & 8.47 & 2.07 & .65 & 1.14 & 29.14 & $123.24 *$ & $<.001$ \\
Social & 9.56 & 2.30 & 9.87 & 2.33 & -.83 & 151 & .410 \\
\hline
\end{tabular}

Note: $\mathrm{df}=$ degrees of freedom.

* Levene's test for equality of variances was statistically significant; equal variances not assumed. 
The findings from the LIWC analyses are consistent with the predictions that both types of essays had roughly equal levels of focus on human relationship, but that the experimental participants' essays were more personal, emotionally laden, and insightful than control participants' essays. The higher usage of causal words by control participants might suggest that in some ways, control participants' essays were more intellectually demanding than experimental participants' essays. This might not be altogether surprising, given the intellectual nature of the control writing topics, e.g., how technology has influenced the way humans relate to one another.

\section{Participants' Subjective Experience}

At Time 3 (about 4 weeks after the writing), participants responded to the QPSE. Included in this questionnaire were eight Likert-scale questions about their subjective experience in the study. A MANOVA was conducted to assess whether participants differed in their responses based on their writing condition. The independent variables were condition (experimental group versus control group) and the dependent variables were (1) how much participants had thought about their writing experience, (2) how much participants had talked about their writing experience, (3) the extent to which participants experienced positive long-lasting effects of writing, (4) the extent to which participants experienced negative long-lasting effects of writing, (5) how happy participants had felt since the writing exercise, (6) how sad or depressed participants had felt since the writing experiment, (7) how valuable or meaningful participants perceived the experiment to be, and (8) how likely they were to participate in the study again.

Means and standard deviations for all eight Likert-scale items in the QPSE are reported in Table 2. The results indicated a non-significant main effect for condition, 
Hotelling's Trace $=.10, F(8,144)=1.71, p=.102$. However, univariate analyses revealed significant main effects for thinking about the writing experience, $F(1,151)=$ $4.18, p=.043$, and positive long-lasting effects, $F(1,151)=8.83, p=.003$. Overall, experimental participants reported that they thought more about what they wrote and that the experiment had more positive long-lasting effects than did control participants. There were no significant main effects for the other six items on participants' subjective experiences (all $p s \geq .2$ ).

Table 2.

Means and Standard Deviations for Items in the QPSE by Condition.

\begin{tabular}{lllllll}
\hline \multirow{2}{*}{ Items } & \multicolumn{2}{c}{$\begin{array}{c}\text { Control } \\
(\mathrm{N}=71)\end{array}$} & \multicolumn{2}{c}{$\begin{array}{c}\text { Experimental } \\
(\mathrm{N}=76)\end{array}$} & \multicolumn{2}{c}{ Total } \\
& $\mathrm{M}$ & $\mathrm{SD}$ & $\mathrm{M}$ & $\mathrm{SD}$ & $\mathrm{M}$ & $\mathrm{SD}$ \\
\hline Thought about writing & 2.27 & 1.45 & 2.76 & 1.50 & 2.53 & 1.49 \\
Talked about writing & 1.73 & 0.99 & 1.93 & 1.39 & 1.83 & 1.22 \\
Positive long-lasting effect & 2.08 & 1.22 & 2.79 & 1.66 & 2.45 & 1.50 \\
Negative long-lasting effect & 1.45 & 1.05 & 1.70 & 1.12 & 1.58 & 1.09 \\
Happy & 4.22 & 1.69 & 4.43 & 1.42 & 4.33 & 1.56 \\
Sad or depressed & 2.47 & 1.41 & 2.34 & 1.19 & 2.40 & 1.29 \\
Valuable/meaningful & 2.27 & 1.42 & 2.61 & 1.55 & 2.45 & 1.50 \\
Participate again? & 3.33 & 1.21 & 3.28 & 1.28 & 3.30 & 1.25 \\
\hline
\end{tabular}

\section{Self-Regulation}

An additional manipulation check was conducted using the QSR. An independent samples t-test was conducted to evaluate differences between the two writing conditions on QSR scores. As predicted, expressive writing participants reported greater levels of self-regulation resulting from the writing intervention compared to control writing participants, $t(155)=3.57, p<.001$. 
Potential Racial Differences on Time 1 Measures

In view of the relatively diverse racial composition of the sample (almost half the participants were non-Whites), a MANOVA was conducted to assess potential racial differences on the main Time 1 measures. The independent variable was participants' race while the dependent variables were Time 1 BSI-18, RES, PRWOS, and PGS. The analysis yielded a non-significant result for race, Wilks' lambda $=.90, F(20,471.91)=$ $.79, p=.73$. At the univariate level, no significant results emerged, $p>$.4. Hence, there was no evidence that participants of different races differed systematically on the Time 1 variables.

\section{$1^{\text {st }}$ Set of Hypotheses: \\ Relationships Between Restrictive Emotionality and Other Variables}

It was predicted that restrictive emotionality would be positively related to greater psychological distress and not being in a romantic relationship, as well as negatively associated with positive relations with others, personal growth, and usage of affect words in their written essays.

Intercorrelations for the main Time 1 measures as well as participants' romantic relationship statuses and use of affect words are shown in Table 3. As hypothesized, RES was positively related to BSI-18 and not being in a romantic relationship as well as negatively related to PRWOS and PGS.

RES was not associated with participants' usage of affect words in their essays ( $p$ $=.8$ ). Because there are several LIWC linguistic sub-categories within the affect words linguistic category, a posthoc correlation analysis was conducted to assess whether RES 
would be related to any of the following linguistic subcategories: positive emotion words, negative emotion words, anxiety words, anger words, and sadness words. None of the correlations were significant, $p \geq .5$.

To summarize, men with higher levels of restrictive emotionality reported greater psychological distress, less positive relations with others, and less personal growth; they also were less likely to be in romantic relationships compared to less emotionally restricted men. Restrictive emotionality was not related to participants' use of affect words in their essays.

Table 3

Intercorrelations among Time 1 Measures and Use of Affect Words

\begin{tabular}{|c|c|c|c|c|c|c|}
\hline & \multicolumn{3}{|c|}{ Affect } & \multirow[b]{2}{*}{ BSI-18 } & \multirow[b]{2}{*}{ PRWOS } & \multirow[b]{2}{*}{ PGS } \\
\hline & RES & words & RR & & & \\
\hline RES & - & -.024 & $.22 * *$ & $.21 * *$ & $-.50 * *$ & $-.16^{*}$ \\
\hline Affect words & & - & -.02 & .07 & .08 & .12 \\
\hline $\mathrm{RR}$ & & & - & .10 & -.11 & .08 \\
\hline BSI-18 & & & & - & $-.38 * *$ & $-.25 * *$ \\
\hline PRWOS & & & & & - & $.50 * *$ \\
\hline PGS & & & & & & - \\
\hline
\end{tabular}

Note. RES = Restrictive Emotionality Scale; RR = romantic relationship status (not being in a romantic relationship); BSI-18 = Brief-Symptoms Inventory-18; PRWOS = Positive Relations With Others Scale; PGS = Personal Growth Scale. $p<.05 . * * p<.01$

To assess the relative associations between restrictive emotionality and each of the other Time 1 variables that were statistically correlated with restrictive emotionality, a multiple regression analysis was conducted with restrictive emotionality as the criterion variable and the other four variables as the explanatory variables. Standardized regression coefficients $(\beta)$ and the variation in restrictive emotionality that was uniquely due to each explanatory variable (i.e., $\Delta \mathrm{R}^{2}$ ) were computed. Controlling for the other explanatory 
variables, PRWOS was negatively related to RES; $\beta=-.51, \Delta \mathrm{R}^{2}=.18, t=-6.02, p<.001$. A significantly positive but much weaker relationship was found between RES and romantic relationship status; $\beta=.15, \Delta \mathrm{R}^{2}=.02, t=2.05, p=.042$. The results indicated that participants who were not in romantic relationships tended to have higher levels of restrictive emotionality. After controlling for the other explanatory variables, BSI-18 was not related to RES; $\beta=.03, \Delta \mathrm{R}^{2}<.01, t=.38, p=.703$. Similarly PGS was not related to RES after controlling for the other explanatory variables, $\beta=.08, \Delta \mathrm{R}^{2}<.01, t=.99, p=$ .322. Hence, after controlling for the other explanatory variables, positive relations with others and participants' romantic relationship status were the only variables that were significantly associated with restrictive emotionality.

\section{$2^{\text {nd }}$ Set of Hypotheses: Restrictive Emotionality}

It was hypothesized that participants in the experimental group would report a greater decrease in restrictive emotionality compared to control participants. Further, it was predicted that there would be a condition $\mathrm{x}$ relationship status $\mathrm{x}$ time interaction.

A repeated measures ANOVA was used to examine changes in restrictive emotionality across time and interaction effects. Means and standard deviations of RES scores by time, condition, and relationship status are reported in Table 4 . The betweensubject factors were condition and romantic relationship status, and the within-subject factor was time (Times 1, 2, and 3). There were no main effects and interaction effects (all $p s>.2$ ). Hence, the prediction that experimental participants would report a greater decrease in restrictive emotionality than control participants was not confirmed. In addition, there was insufficient evidence to support the hypothesized condition $\mathrm{x}$ relationship status $\mathrm{x}$ time interaction. 
Table 4

Means and Standard Deviations for RES scores (Restrictive Emotionality) by Time, Condition, and Romantic Relationship Status

\begin{tabular}{lllllrrr}
\hline & \multicolumn{2}{c}{ Time 1 RES } & \multicolumn{2}{c}{ Time 2 RES } & \multicolumn{2}{c}{ Time 3 RES } \\
Condition & RR & M & SD & M & SD & M & SD \\
\hline Control & yes & & & & & & \\
$(\mathrm{N}=70)$ & & 27.94 & 9.29 & 28.23 & 9.24 & 27.71 & 9.36 \\
& no & 33.41 & 8.04 & 34.49 & 10.03 & 33.51 & 10.63 \\
& total & 30.99 & 8.98 & 31.71 & 10.12 & 30.94 & 10.43 \\
Experimental & yes & & & & & & \\
$(\mathrm{E}=76)$ & & 29.04 & 7.76 & 28.41 & 8.11 & 29.67 & 8.26 \\
& no & 30.98 & 7.91 & 32.96 & 9.45 & 32.43 & 9.36 \\
& total & 30.29 & 7.86 & 31.34 & 9.21 & 31.45 & 9.03 \\
Total & yes & & & & & & \\
$(\mathrm{N}=146)$ & & 28.45 & 8.56 & 28.31 & 8.66 & 28.62 & 8.85 \\
& no & 32.06 & 8.01 & 33.64 & 9.68 & 32.91 & 9.90 \\
& total & 30.62 & 8.39 & 31.52 & 9.62 & 31.21 & 9.70 \\
\hline
\end{tabular}

Note: $R R=$ romantic relationship.

\section{$3^{\text {rd }}$ Set of Hypotheses: Psychological Distress}

It was hypothesized that experimental participants would report a greater decrease in psychological distress than control participants after the writing intervention. In addition, it was predicted that there would be a restrictive emotionality $\mathrm{x}$ condition $\mathrm{x}$ time interaction as well as a relationship status $\mathrm{x}$ condition $\mathrm{x}$ time interaction.

Participants were classified as having high versus low restrictive emotionality based on a median split in their Time 1 RES scores (median $=31$ ). An independent samples t-test was conducted to examine differences in Time 1 RES scores between the high and low restrictive emotionality groups. As expected, the high restrictive emotionality group $(M=37.40)$ reported significantly higher Time 1 RES scores than the low restrictive emotionality group $(\mathrm{M}=23.73), t(151)=-17.43, p<.000$.

A repeated measures ANOVA was used to examine changes in BSI-18 scores over time as well as interaction effects. The between-subject factors were condition, relationship status, and Time 1 restrictive emotionality (high versus low). The within- 
subject factor was time (Times 1, 2, and 3). Means and standard deviations for BSI-18 scores by time, condition, romantic relationship status, and restrictive emotionality are reported in Table 5.

Table 5

Means and Standard Deviations for BSI-18 Scores (Psychological Distress) by Time, Condition, Romantic Relationship Status, and Restrictive Emotionality.

\begin{tabular}{|c|c|c|c|c|c|c|c|c|}
\hline \multirow[b]{2}{*}{ Condition } & \multirow[b]{2}{*}{ RR } & \multirow[b]{2}{*}{ RE } & \multicolumn{2}{|c|}{ Time 1} & \multicolumn{2}{|c|}{ Time 2} & \multicolumn{2}{|c|}{ Time 3} \\
\hline & & & M & SD & M & SD & M & SD \\
\hline \multirow{9}{*}{$\begin{array}{l}\text { Control } \\
(\mathrm{N}=70)\end{array}$} & \multirow[t]{3}{*}{ yes } & low & 12.44 & 13.94 & 10.19 & 13.61 & 15.44 & 19.81 \\
\hline & & high & 15.36 & 12.82 & 15.00 & 16.86 & 11.93 & 13.44 \\
\hline & & total & 13.80 & 13.28 & 12.43 & 15.14 & 13.80 & 16.94 \\
\hline & \multirow[t]{3}{*}{ no } & low & 14.20 & 10.49 & 13.73 & 9.46 & 15.53 & 13.31 \\
\hline & & high & 15.04 & 11.55 & 12.12 & 10.81 & 13.32 & 11.84 \\
\hline & & total & 14.73 & 11.03 & 12.73 & 10.23 & 14.15 & 12.29 \\
\hline & \multirow[t]{3}{*}{ total } & low & 13.29 & 12.22 & 11.90 & 11.73 & 15.48 & 16.70 \\
\hline & & high & 15.15 & 11.85 & 13.15 & 13.15 & 12.82 & 12.28 \\
\hline & & total & 14.33 & 11.97 & 12.60 & 12.47 & 14.00 & 14.36 \\
\hline \multirow{9}{*}{$\begin{array}{l}\text { Experimental } \\
(\mathrm{N}=76)\end{array}$} & \multirow[t]{3}{*}{ yes } & low & 14.80 & 13.16 & 11.93 & 11.77 & 10.80 & 10.39 \\
\hline & & high & 10.58 & 7.23 & 8.42 & 7.03 & 7.17 & 7.42 \\
\hline & & total & 12.93 & 10.95 & 10.37 & 9.93 & 9.19 & 9.21 \\
\hline & \multirow[t]{3}{*}{ no } & low & 12.60 & 11.00 & 10.84 & 11.89 & 8.16 & 9.16 \\
\hline & & high & 20.46 & 7.82 & 14.92 & 7.61 & 12.21 & 7.87 \\
\hline & & total & 16.45 & 10.27 & 12.84 & 10.13 & 10.14 & 8.71 \\
\hline & \multirow[t]{3}{*}{ total } & low & 13.43 & 11.74 & 11.25 & 11.71 & 9.15 & 9.59 \\
\hline & & high & 17.17 & 8.88 & 12.75 & 7.95 & 10.53 & 7.99 \\
\hline & & total & 15.20 & 10.58 & 11.96 & 10.07 & 9.80 & 8.84 \\
\hline \multirow{9}{*}{$\begin{array}{l}\text { Total } \\
(\mathrm{N}=146)\end{array}$} & \multirow[t]{3}{*}{ yes } & low & 13.58 & 13.40 & 11.03 & 12.58 & 13.19 & 15.88 \\
\hline & & high & 13.15 & 10.69 & 11.96 & 13.44 & 9.73 & 11.14 \\
\hline & & total & 13.39 & 12.13 & 11.46 & 12.87 & 11.61 & 13.91 \\
\hline & \multirow[t]{3}{*}{ no } & low & 13.20 & 10.70 & 11.93 & 11.01 & 10.93 & 11.33 \\
\hline & & high & 17.69 & 10.17 & 13.49 & 9.39 & 12.78 & 10.00 \\
\hline & & total & 15.67 & 10.59 & 12.79 & 10.12 & 11.94 & 10.60 \\
\hline & \multirow[t]{3}{*}{ total } & low & 13.37 & 11.86 & 11.54 & 11.64 & 11.92 & 13.45 \\
\hline & & high & 16.12 & 10.51 & 12.96 & 10.90 & 11.72 & 10.44 \\
\hline & & total & 14.78 & 11.24 & 12.27 & 11.25 & 11.82 & 11.95 \\
\hline
\end{tabular}

Note: $\mathrm{RR}=$ romantic relationship. $\mathrm{RE}=$ Time 1 Restrictive Emotionality.

There was a significant main effect for time, $F(2,137)=10.15, p<.001$. Posthoc within-subjects analyses revealed that the change in BSI-18 scores from Time 1 to Time 
2 was significant, $F(1,145)=20.42 ; p<.001$, as was the change from Time 1 to Time 3 , $F(1,145)=12.12, p=.001$. Overall, participants' self-reported psychological distress declined from Time 1 to Time 2 and from Time 1 to Time 3.

An examination of interaction effects revealed a significant time $\mathrm{x}$ condition interaction, $F(2,137)=4.18, p=.017$, and non-significant time $\mathrm{x}$ restrictive emotionality, time $\mathrm{x}$ relationship status, time $\mathrm{x}$ relationship status $\mathrm{x}$ condition, time $\mathrm{x}$ condition $\mathrm{x}$ restrictive emotionality, and time $\mathrm{x}$ condition $\mathrm{x}$ restrictive emotionality $\mathrm{x}$ relationship status interactions $(p s \geq .2)$.

Figure 1. Change in BSI-18 Scores (Psychological Distress) Across Time for Experimental and Control Participants.

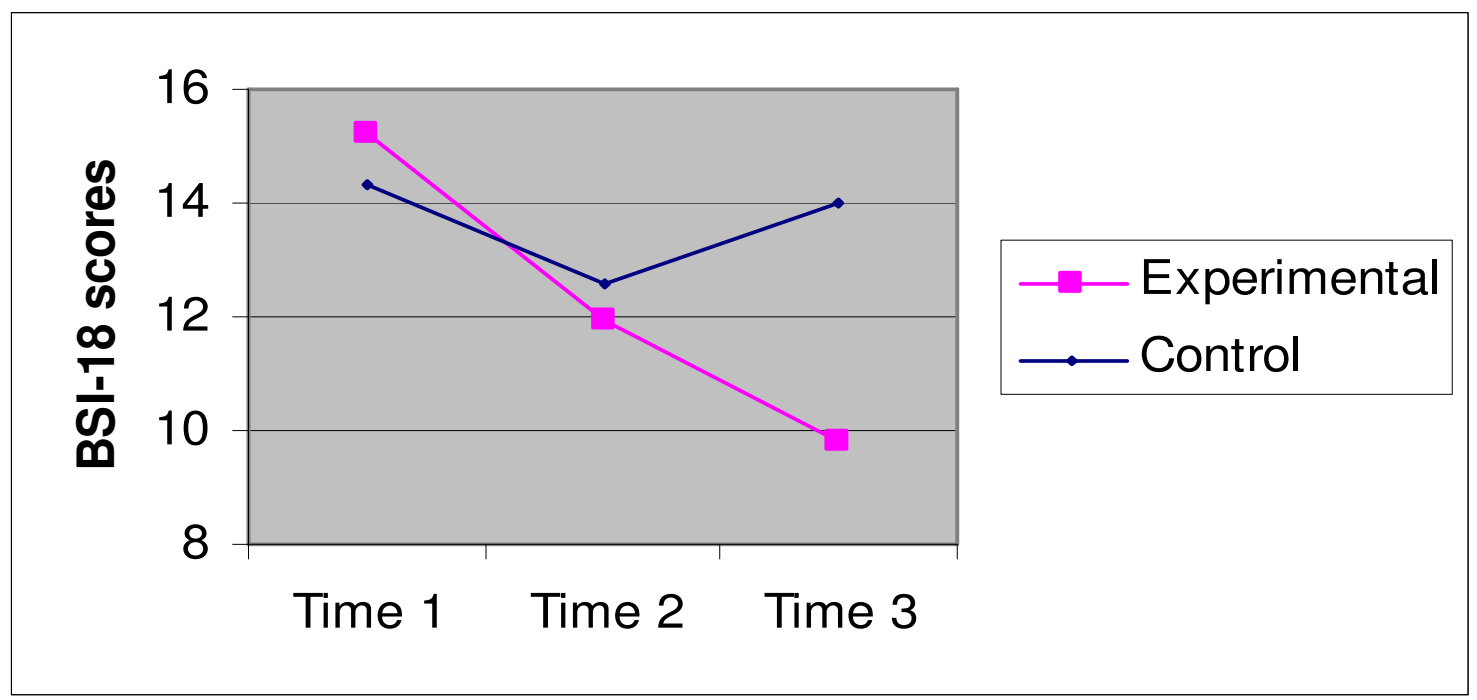

To decompose the condition $\mathrm{x}$ time interaction, two posthoc repeated measures ANOVAs were conducted with condition as the between-subject factor and time (Time 1 to Time 2 BSI-18 and Time 1 to Time 3 BSI-18) as the within-subject factor. Experimental and control participants did not differ significantly in their change in BSI18 scores from Time 1 to Time $2, p=.176$. However, experimental participants reported 
a significantly greater decrease in BSI-18 scores than did control participants between Time 1 and Time $3, F(1,142)=9.33, p=.003$.

To summarize, experimental participants reported a greater reduction in psychological distress than did control participants four weeks after the writing intervention (see Figure 1). None of the other hypothesized interactions were statistically significant.

\section{$4^{\text {th }}$ Set of Hypotheses: Personal Growth}

It was hypothesized that experimental participants would report a greater increase in personal growth than control participants after the writing intervention. In addition, it was predicted that there would be restrictive emotionality $\mathrm{x}$ condition $\mathrm{x}$ time and relationship status $\mathrm{x}$ condition $\mathrm{x}$ time interactions.

A repeated measures ANOVA was used to examine changes in PGS scores across time as well as interaction effects. The between-subject factors were condition, relationship status, and restrictive emotionality (high versus low levels based on a median split) and the within-subject factor was time (Times 1,2, and 3). The means and standard deviations of PGS scores by time, relationship status, and restrictive emotionality are reported in Table 6.

There was a significant main effect for time; $F(2,138)=9.38, p<.001$. Posthoc within-subjects analyses revealed a marginally significant decline in PGS scores from Time 1 to Time $2 ; F(1,146)=3.43 ; p=.066$, and a significant decline in PGS scores from Time 1 to Time $3, F(1,146)=18.38, p<.001$. In general, the self-reported personal growth of participants declined slightly from Time 1 to Time 2 and from Time 1 to Time 3. There were no significant time $\mathrm{x}$ restrictive emotionality, time $\mathrm{x}$ relationship status, 
time $\mathrm{x}$ relationship status $\mathrm{x}$ condition, time $\mathrm{x}$ condition $\mathrm{x}$ restrictive emotionality, and time $\mathrm{x}$ condition $\mathrm{x}$ restrictive emotionality $\mathrm{x}$ relationship status interactions (all $p \mathrm{~s} \geq .4$ ).

To summarize, participants in the control and experimental groups demonstrated approximately equivalent changes in personal growth across time. In addition, none of the other hypothesized interactions were significant.

Table 6

Means and Standard Deviations for PGS Scores (Personal Growth) by Time, Condition, Romantic Relationship Status, and Restrictive Emotionality.

\begin{tabular}{|c|c|c|c|c|c|c|c|c|}
\hline \multirow[b]{2}{*}{ Condition } & \multirow[b]{2}{*}{$\mathrm{RR}$} & \multirow[b]{2}{*}{$\mathrm{RE}$} & \multicolumn{2}{|c|}{ Time 1} & \multicolumn{2}{|c|}{ Time 2} & \multicolumn{2}{|c|}{ Time 3} \\
\hline & & & M & SD & M & SD & M & SD \\
\hline \multirow{9}{*}{$\begin{array}{l}\text { Control } \\
(\mathrm{N}=71)\end{array}$} & \multirow[t]{3}{*}{ yes } & low & 66.41 & 8.83 & 66.18 & 8.21 & 65.29 & 7.70 \\
\hline & & high & 69.21 & 9.17 & 65.29 & 13.69 & 65.86 & 13.99 \\
\hline & & total & 67.68 & 8.95 & 65.77 & 10.83 & 65.55 & 10.80 \\
\hline & \multirow[t]{3}{*}{ no } & low & 70.40 & 7.62 & 68.20 & 9.08 & 63.33 & 13.32 \\
\hline & & high & 66.56 & 9.35 & 66.20 & 10.56 & 65.36 & 10.82 \\
\hline & & total & 68.00 & 8.85 & 66.95 & 9.96 & 64.60 & 11.69 \\
\hline & \multirow[t]{3}{*}{ total } & low & 68.28 & 8.40 & 67.13 & 8.55 & 64.38 & 10.57 \\
\hline & & high & 67.51 & 9.26 & 65.87 & 11.61 & 65.54 & 11.87 \\
\hline & & total & 67.86 & 8.83 & 66.44 & 10.29 & 65.01 & 11.24 \\
\hline \multirow{9}{*}{$\begin{array}{l}\text { Experimental } \\
(\mathrm{N}=76)\end{array}$} & \multirow[t]{3}{*}{ yes } & low & 69.20 & 9.37 & 68.27 & 10.68 & 64.73 & 12.77 \\
\hline & & high & 66.50 & 7.89 & 64.00 & 9.54 & 61.75 & 11.76 \\
\hline & & total & 68.00 & 8.69 & 66.37 & 10.23 & 63.41 & 12.19 \\
\hline & \multirow[t]{3}{*}{ no } & low & 71.56 & 7.85 & 71.96 & 7.46 & 68.12 & 11.00 \\
\hline & & high & 68.63 & 8.65 & 68.04 & 11.66 & 64.17 & 11.73 \\
\hline & & total & 70.12 & 8.30 & 70.04 & 9.84 & 66.18 & 11.42 \\
\hline & \multirow[t]{3}{*}{ total } & low & 70.68 & 8.41 & 70.58 & 8.86 & 66.85 & 11.65 \\
\hline & & high & 67.92 & 8.35 & 66.69 & 11.03 & 63.36 & 11.63 \\
\hline & & total & 69.37 & 8.44 & 68.74 & 10.07 & 65.20 & 11.70 \\
\hline \multirow{9}{*}{$\begin{array}{l}\text { Total } \\
(\mathrm{N}=147)\end{array}$} & \multirow[t]{3}{*}{ yes } & low & 67.72 & 9.05 & 67.16 & 9.35 & 65.03 & 10.22 \\
\hline & & high & 67.96 & 8.54 & 64.69 & 11.74 & 63.96 & 12.92 \\
\hline & & total & 67.83 & 8.75 & 66.05 & 10.47 & 64.55 & 11.41 \\
\hline & \multirow[t]{3}{*}{ no } & low & 71.13 & 7.69 & 70.55 & 8.20 & 66.33 & 11.99 \\
\hline & & high & 67.57 & 8.98 & 67.10 & 11.03 & 64.78 & 11.17 \\
\hline & & total & 69.17 & 8.57 & 68.65 & 9.96 & 65.47 & 11.50 \\
\hline & \multirow[t]{3}{*}{ total } & low & 69.61 & 8.43 & 69.04 & 8.83 & 65.75 & 11.18 \\
\hline & & high & 67.71 & 8.78 & 66.27 & 11.27 & 64.49 & 11.73 \\
\hline & & total & 68.64 & 8.63 & 67.63 & 10.21 & 65.11 & 11.44 \\
\hline
\end{tabular}

Note $: \mathrm{RR}=$ romantic relationship. $\mathrm{RE}=$ Time 1 Restrictive Emotionality. 


\section{$5^{\text {th }}$ Set of Hypotheses: Positive Relations With Others}

It was hypothesized that experimental participants would report a greater increase in positive relations with others than control participants after the writing intervention. Further, it was predicted that there would be restrictive emotionality $\mathrm{x}$ condition $\mathrm{x}$ time and relationship status $\mathrm{x}$ condition $\mathrm{x}$ time interactions.

A repeated measures ANOVA was used to examine changes in PRWOS scores across time as well as interaction effects. The between-subject factors were condition, relationship status, and restrictive emotionality (high versus low levels based on a median split) and the within-subject factor was time (Times 1, 2, and 3). The means and standard deviations of PRWOS scores by time, relationship status, and restrictive emotionality are reported in Table 7.

There was a significant main effect for time; $F(2,136)=5.38, p=.006$. Posthoc within-subjects analyses revealed that the decline of PRWOS scores from Time 1 to Time 2 was significant, $\mathrm{F}(1,144)=4.00, p=.047$, as was the decline from Time 1 to Time 3 , $F(1,147)=12.37, p=.001$. Overall, participants' self-reported positive relations with others decreased slightly across time, regardless of their writing condition.

There was a significant restrictive emotionality $\mathrm{x}$ time interaction, $F(2,136)=$ 3.83, $p=.024$. Posthoc repeated measures ANOVAs indicated that high and low restrictive emotionality participants reported approximately similar changes in PRWOS scores between Time 1 and Time 2, $p=.396$. However, there was a significant time $\mathrm{x}$ restrictive emotionality interaction for change in PRWOS scores between Time 1 and Time 3, $F(2,143)=6.50, p=.012$. As illustrated in Figure 2, low restrictive emotionality participants reported a decline in positive relations with others between 
Time 1 and Time 3. In contrast, high restrictive emotionality participants reported approximately equivalent levels of positive relations with others at Time 1 and Time 3 .

Table 7

Means and Standard Deviations for PRWOS Scores (Positive Relations With Others) by Time, Condition, Romantic Relationship Status, and Restrictive Emotionality.

\begin{tabular}{|c|c|c|c|c|c|c|c|c|}
\hline \multirow[b]{2}{*}{ Condition } & \multirow[b]{2}{*}{ RR } & \multirow[b]{2}{*}{ RE } & \multicolumn{2}{|c|}{ Time 1} & \multicolumn{2}{|c|}{ Time 2} & \multicolumn{2}{|c|}{ Time 3} \\
\hline & & & $\mathrm{M}$ & SD & $\mathrm{M}$ & SD & $\mathrm{M}$ & $\mathrm{SD}$ \\
\hline \multirow{9}{*}{$\begin{array}{l}\text { Control } \\
(\mathrm{N}=70)\end{array}$} & yes & low & 67.69 & 7.97 & 65.44 & 8.13 & 64.25 & 9.16 \\
\hline & & high & 62.64 & 8.63 & 60.29 & 11.56 & 61.14 & 10.75 \\
\hline & & total & 65.33 & 8.53 & 63.03 & 10.05 & 62.80 & 9.88 \\
\hline & no & low & 65.80 & 8.87 & 64.33 & 9.49 & 60.00 & 9.29 \\
\hline & & high & 57.84 & 10.41 & 57.96 & 11.30 & 57.36 & 10.67 \\
\hline & & total & 60.83 & 10.50 & 60.35 & 10.99 & 58.35 & 10.14 \\
\hline & total & low & 66.77 & 8.33 & 64.90 & 8.68 & 62.19 & 9.32 \\
\hline & & high & 59.56 & 9.97 & 58.79 & 11.30 & 58.72 & 10.72 \\
\hline & & total & 62.76 & 9.89 & 61.50 & 10.60 & 60.26 & 10.20 \\
\hline \multirow{9}{*}{$\begin{array}{l}\text { Experimental } \\
(\mathrm{N}=75)\end{array}$} & yes & low & 68.33 & 11.17 & 67.13 & 13.02 & 65.53 & 12.12 \\
\hline & & high & 58.25 & 9.23 & 60.58 & 7.82 & 61.00 & 10.08 \\
\hline & & total & 63.85 & 11.37 & 64.22 & 11.32 & 63.52 & 11.28 \\
\hline & no & low & 68.56 & 8.40 & 67.44 & 7.77 & 65.00 & 10.09 \\
\hline & & high & 58.43 & 10.50 & 56.61 & 8.20 & 56.26 & 8.41 \\
\hline & & total & 63.71 & 10.67 & 62.25 & 9.60 & 60.81 & 10.22 \\
\hline & total & low & 68.48 & 9.39 & 67.33 & 9.90 & 65.20 & 10.74 \\
\hline & & high & 58.37 & 9.95 & 57.97 & 8.18 & 57.89 & 9.15 \\
\hline & & total & 63.76 & 10.85 & 62.96 & 10.22 & 61.79 & 10.62 \\
\hline \multirow{9}{*}{$\begin{array}{l}\text { Total } \\
(\mathrm{N}=145)\end{array}$} & yes & low & 68.00 & 9.49 & 66.26 & 10.63 & 64.87 & 10.53 \\
\hline & & high & 60.62 & 9.01 & 60.42 & 9.82 & 61.08 & 10.24 \\
\hline & & total & 64.63 & 9.91 & 63.60 & 10.59 & 63.14 & 10.48 \\
\hline & no & low & 67.53 & 8.57 & 66.28 & 8.47 & 63.13 & 9.98 \\
\hline & & high & 58.13 & 10.35 & 57.31 & 9.86 & 56.83 & 9.57 \\
\hline & & total & 62.40 & 10.63 & 61.39 & 10.24 & 59.69 & 10.20 \\
\hline & total & low & 67.73 & 8.92 & 66.27 & 9.40 & 63.89 & 10.19 \\
\hline & & high & 59.00 & 9.91 & 58.41 & 9.89 & 58.32 & 9.95 \\
\hline & & total & 63.28 & 10.37 & 62.26 & 10.40 & 61.05 & 10.41 \\
\hline
\end{tabular}

Note $: \mathrm{RR}=$ romantic relationship. $\mathrm{RE}=$ Time 1 Restrictive Emotionality. 
Figure 2. Change in PRWOS Scores (Positive Relations With Others) Across Time for High versus Low Restrictive Emotionality Participants.

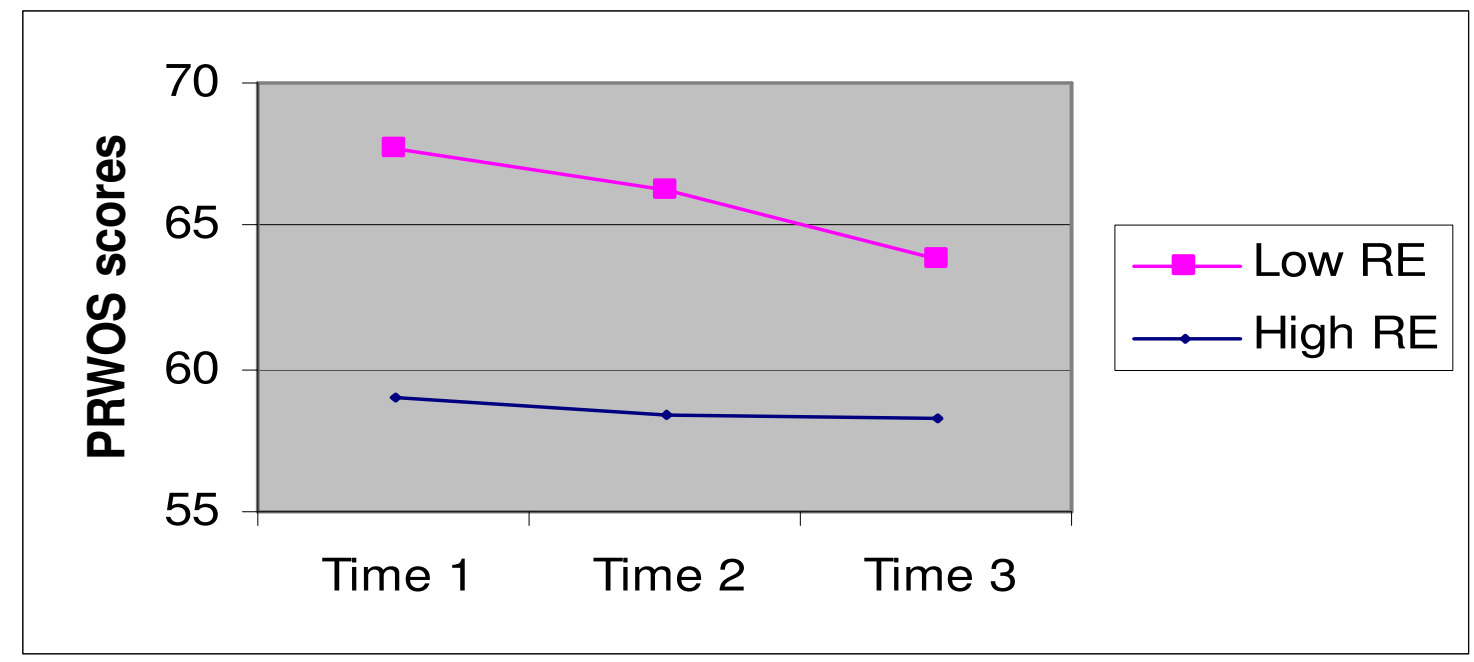

Note: Low RE = participants with lower levels of restrictive emotionality. High RE = participants with higher levels of restrictive emotionality.

There were no time $\mathrm{x}$ restrictive emotionality, time $\mathrm{x}$ relationship status, time $\mathrm{x}$ relationship status $\mathrm{x}$ condition, time $\mathrm{x}$ condition $\mathrm{x}$ restrictive emotionality, and time $\mathrm{x}$ condition $\mathrm{x}$ restrictive emotionality $\mathrm{x}$ relationship status interactions $(p s \geq .2)$.

In summary, participants in the control and experimental groups demonstrated approximately equivalent changes in positive relations with others across time. None of the hypothesized interactions were significant. However, high restrictive emotionality participants reported approximately equal levels of positive relations with others across time whereas low restrictive emotionality participants reported significantly less positive relations with others across time. 


\section{$6^{\text {th }}$ Set of Hypotheses: Expression of Emotional Intimacy}

The QEEICR (participation's version) and the QEEICR (others' version) were created for the purpose of examining the effect of the writing intervention on participants' expression of emotional intimacy in close relationships.

Preliminary Analyses

Profiles of participants whose romantic partners/significant others responded to the QEEICR. Because only 35 participants responded to the QEEICR (others' version), it is possible that these participants differed systematically from participants whose romantic partners/significant others did not complete the QEEICR (others' version). To examine this possibility, a MANOVA was conducted to examine potential differences between participants whose romantic partners/significant others responded to the QEEICR and those whose romantic partners/significant others did not. The independent variable was whether participants' romantic partners/significant others responded to the QEEICR (response versus no response) and the dependent variables were Time 3 RES, BSI-18, PGS, PRWOS, and QEEICR (participants' version). The analysis yielded a nonsignificant main effect, Hotelling's Trace $=.05, F(5,147)=1.41, p=.22$. Further, there were no significant effects at the univariate level (all $p \geq .2$ ). Hence, an examination of

Time 3 variables revealed no evidence that participants whose romantic partners/significant others responded to the QEEICR differed systematically from those whose romantic partners/significant others did not.

Factor analyses. An exploratory principal axis factor analysis was used to examine the factor structure of the QEEICR (participants' version). To determine the number of factors to retain, the following criteria were used: (a) eigenvalues greater than 
1.0 , and (b) factor interpretability (using factor loadings $\geq$ I.40l). An oblique rotation (i.e., direct oblimin) was used to allow the factors to be correlated. The initial extraction resulted in two factors that had eigenvalues exceeding 1.0. The first and second factors accounted for $61.38 \%$ and $7.59 \%$ of the total variance respectively. The factor loadings from the pattern matrix are shown in Table 8. Fourteen items loaded on factor 1, three items loaded on factor 2, and a one item loaded on both factors. An examination of the items that loaded on factor 2 (items 1,2,13, and 14) revealed that they tended to describe more practical and less emotionally-laden aspects of a relationship (e.g., accompanying a person to an event in item 2 and providing practical help in item 14). Since QEEICR was designed specifically as a measure of expression of emotional intimacy, the items that loaded on factor 2 were deleted from the scale.

A second principal axis factor analysis was conducted without the items that loaded on factor 2 (items 1,2,13, and 14). This analysis of the remaining 14 items yielded one factor that had an eigenvalue exceeding 1.0 and accounted for $66.28 \%$ of the total variance. Because of the small sample of romantic partners/significant others $(\mathrm{N}=$ 35) who completed the QEEICR, a factor analysis was not performed on items in the QEEICR (others' version). Hence, the revised 14-item measure was used in subsequent analyses for both versions of the QEEICR.

Construct validity of the QEEICR. Because the QEEICR was designed to assess individuals' expression of emotional intimacy in specific close relationships, it was hypothesized that both versions of the QEEICR would be related to other measures of interpersonal functioning (e.g., the PRWOS) and emotionality (e.g., the RES), but would be unrelated to measures that did not directly assess interpersonal functioning or 
emotionality (e.g., the BSI-18 and PGS). In addition, it was anticipated that participants' responses to the QEEICR would be related to their romantic partners/significant others' responses to the QEEICR.

Table 8 Pattern Factor Matrix of the QEEICR (participants' version)

\begin{tabular}{|c|c|c|c|}
\hline No. & Item & Factor 1 & Factor 2 \\
\hline 1. & Initiate an outing/date with you. & .078 & .729 \\
\hline 2. & $\begin{array}{l}\text { Accompany him/her to some kind of event (e.g., party or music } \\
\text { venue) or location (e.g., clothes store) that you wouldn't have } \\
\text { gone to on your own. }\end{array}$ & .053 & .767 \\
\hline 3. & Express concern for his/her needs. & .781 & .028 \\
\hline 4. & Confide personal information about your life to him/ her. & .728 & .088 \\
\hline 5. & Thank him/her for something he/she did. & 743 & 189 \\
\hline 6. & Express empathy for him/her. & .804 & 148 \\
\hline 7. & Tell him/her about what made you happy. & 738 & .123 \\
\hline 8. & Ask him/her about how his/her day went. & .956 & -.241 \\
\hline 9. & Tell him/her about your fears. & .503 & .358 \\
\hline 10. & Do something to encourage him/her. & .747 & 168 \\
\hline 11. & Tell him/her that you loved him/her. & .818 & -.156 \\
\hline 12. & Ask him/her for his/her opinion. & .793 & .059 \\
\hline 13. & Buy him/her a gift. & 091 & .620 \\
\hline 14. & Provide him/her with practical help. & .523 & .404 \\
\hline 15. & $\begin{array}{l}\text { Express physical affection to him/her in a nonsexual way (e.g., } \\
\text { gave him/her a hug). }\end{array}$ & .641 & 182 \\
\hline 16. & Tell him/her what you admired about him/her. & 657 & .255 \\
\hline 17. & Listen to him/her without interrupting. & .804 & -.111 \\
\hline 18. & Admit your faults to him/her. & .579 & .265 \\
\hline
\end{tabular}

Note: Factor loadings $\geq \mathrm{I} .40 \mathrm{I}$ are italicized.

To examine the construct validity of the QEEICR, a Pearson correlation was conducted to examine the intercorrelations among both versions of the QEEICR (participants' and significant others' versions) and other Time 3 variables. Time 3 variables were selected because participants responded to the QEEICR only at Time 3 . The results of the intercorrelations of all measures are presented in Table 9. As hypothesized, the QEEICR (participants' version) was negatively related to RES, 
positively related to PRWOS, and not significantly related to PGS and BSI-18. The QEEICR (others' version) was strongly and positively related to the QEEICR (participants' version), but not significantly related to the other Time 3 measures.

In addition, previous research suggests that emotional intensity and dependency are defining features of romantic relationships (Fisher, Aron, Mashek, Li, \& Brown, 2002; Hendrick \& Hendrick, 1986). Because of the emotionally-laden content of the QEEICR (e.g., saying, "I love you"), it was reasonable to expect that participants in romantic relationships would have higher scores on both versions of the QEEICR than participants who were not in romantic relationship. Two independent samples t-test confirmed this prediction. In general, participants in romantic relationships at Time 3 reported significantly higher QEEICR (participants' version) scores than did participants who were not in romantic relationships, $t(29.65)=4.48, p<.001$. Similarly, participants' romantic partners reported higher QEEICR (others' version) scores than did participants' significant others, $t(33)=4.41, p<.001$.

Table 9.

Intercorrelations among QEEICR and Time 3 Measures

\begin{tabular}{lcccccc}
\hline & QEEICR-P & QEEICR-O & RES & BSI-18 & PRWOS & PGS \\
\hline QEEICR-P & - & $.54 * *$ & $-.32^{* *}$ & .07 & $.18^{*}$ & -.05 \\
QEEICR-O & & - & -.19 & -.01 & .11 & -.11 \\
RES & & & - & .12 & $-.49 * *$ & $-.21^{* *}$ \\
BSI-18 & & & & - & $-.31^{* *}$ & $-.21^{* *}$ \\
PRWOS & & & & & - & $.57 * *$ \\
PGS & & & & & & - \\
\hline
\end{tabular}

Note: QEEICR-P = Questionnaire on the Expression of Emotional Intimacy in Close relationships (Participants' Version); QEEICR-O = Questionnaire on the Expression of Emotional Intimacy in Close relationships (Others' Version); RES = Restrictive Emotionality Scale; BSI-18 = Brief Symptoms Inventory-18; PRWOS = Personal Relations With Others Scale; PGS = Personal Growth Scale.

$* p<.05 . * * p<.01$ 
The above analyses provided some preliminary evidence for the construct validity of the QEEICR (participants' version) in this particular sample of college male students. Unfortunately, the small sample size of romantic partners/significant others who responded to the QEEICR (others' version) might have hampered the detection of significant relationships with some of the Time 3 measures.

Demographic profile of relationships. Each participant who responded to the QEEICR reported the level of his expression of emotional intimacy to either his romantic partner, if he was in a romantic relationship, or a significant other of his choice (e.g., a close friend or family member), if he was not in a romantic relationship. At Time 3, $39.2 \%$ of participants reported that they were in romantic relationships while $60.8 \%$ of participants were not in romantic relationships. Among participants who were not in romantic relationships, the vast majority of them rated their expression of emotional intimacy to their friends $(72.1 \%)$. The remaining participants rated their expression of emotional intimacy to their brothers $(9.7 \%)$, mothers $(7.5 \%)$, sisters $(4.3 \%)$, fathers (4.3\%), and others (e.g., ex-romantic partners; $2.2 \%)$.

Because participants and their romantic partners/significant others' responses to the QEEICR might be influenced by where their romantic partner/significant others lived (e.g., being in a long distance relationship might inhibit opportunities to express emotional intimacy), participants were asked whether their romantic partners or significant others lived in the Austin metropolitan area. Slightly more than two-thirds (67.3\%) of participants' romantic partners or significant others lived in the Austin metropolitan area. Participants whose romantic partners or significant others lived in the Austin metropolitan reported significantly higher QEEICR (participants' version) scores 
than did participants whose romantic partners or significant others lived outside the Austin metropolitan area, $t(151)=2.96, p=.004$. However, romantic partners $/$ significant others who lived in the Austin metropolitan area did not differ significantly from those who lived outside the Austin metropolitan area in their responses to the QEEICR (others' version), $p=.187$.

Expression of Emotional Intimacy (Participants' Perspective)

It was hypothesized that experimental participants would express more emotional intimacy in their close relationships than control participants. Further, it was predicted that there would be a relationship status $\mathrm{x}$ condition interaction and a restrictive emotionality $\mathrm{x}$ condition interaction. With regard to the restrictive emotionality $\mathrm{x}$ condition interaction, high restrictive emotionality experimental participants were expected to express more emotional intimacy than high restrictive emotionality control participants. However, among low restrictive emotionality participants, the experimental and control groups were not expected to differ in their expression of emotional intimacy.

Table 10.

Adjusted Means and Standard Deviations for QEEICR scores (Expression of Emotional Intimacy: participants'version) by Condition, Romantic Relationship Status, and Restrictive Emotionality.

\begin{tabular}{llllllll}
\hline & & \multicolumn{2}{c}{ Control } & \multicolumn{2}{c}{ Experimental } & \multicolumn{2}{c}{ Total } \\
\multicolumn{2}{c}{$\mathrm{R}=71)$} & \multicolumn{2}{c}{$(\mathrm{N}=76)$} & \multicolumn{2}{c}{$(\mathrm{N}=147)$} \\
\hline yes & RE & $\mathrm{M}$ & $\mathrm{SD}$ & $\mathrm{M}$ & $\mathrm{SD}$ & $\mathrm{M}$ & $\mathrm{SD}$ \\
& low & 4.85 & .38 & 4.35 & .40 & 4.60 & .28 \\
& high & 3.59 & .42 & 3.79 & .45 & 3.69 & .31 \\
& total & 4.22 & .28 & 4.07 & .30 & 4.14 & .21 \\
& low & 3.25 & .40 & 2.10 & .31 & 2.67 & .25 \\
& high & 1.87 & .31 & 1.91 & .32 & 1.89 & .22 \\
& total & 2.56 & .25 & 2.01 & .22 & 2.28 & .17 \\
total & low & 4.05 & .28 & 3.22 & .25 & 3.64 & .19 \\
& high & 2.73 & .26 & 2.85 & .28 & 2.79 & .19 \\
& total & 3.39 & .19 & 3.04 & .19 & 3.21 & .13 \\
\hline
\end{tabular}

Note $. \mathrm{RR}=$ romantic relationship; $\mathrm{RE}=$ Time 1 Restrictive Emotionality. 
To address these hypotheses, a three-way ANCOVA was conducted to analyze main and interaction effects. The dependent variable was QEEICR (participants' version) and the independent variables were condition, romantic relationship status, and restrictive emotionality (high versus low based on the median split). The covariate was romantic partners/significant others' place of residence (the Austin metropolitan area versus outside the Austin metropolitan area).

Figure 3. QEEICR (participants'version) scores for high versus low restrictive emotionality participants in the experimental and control groups.

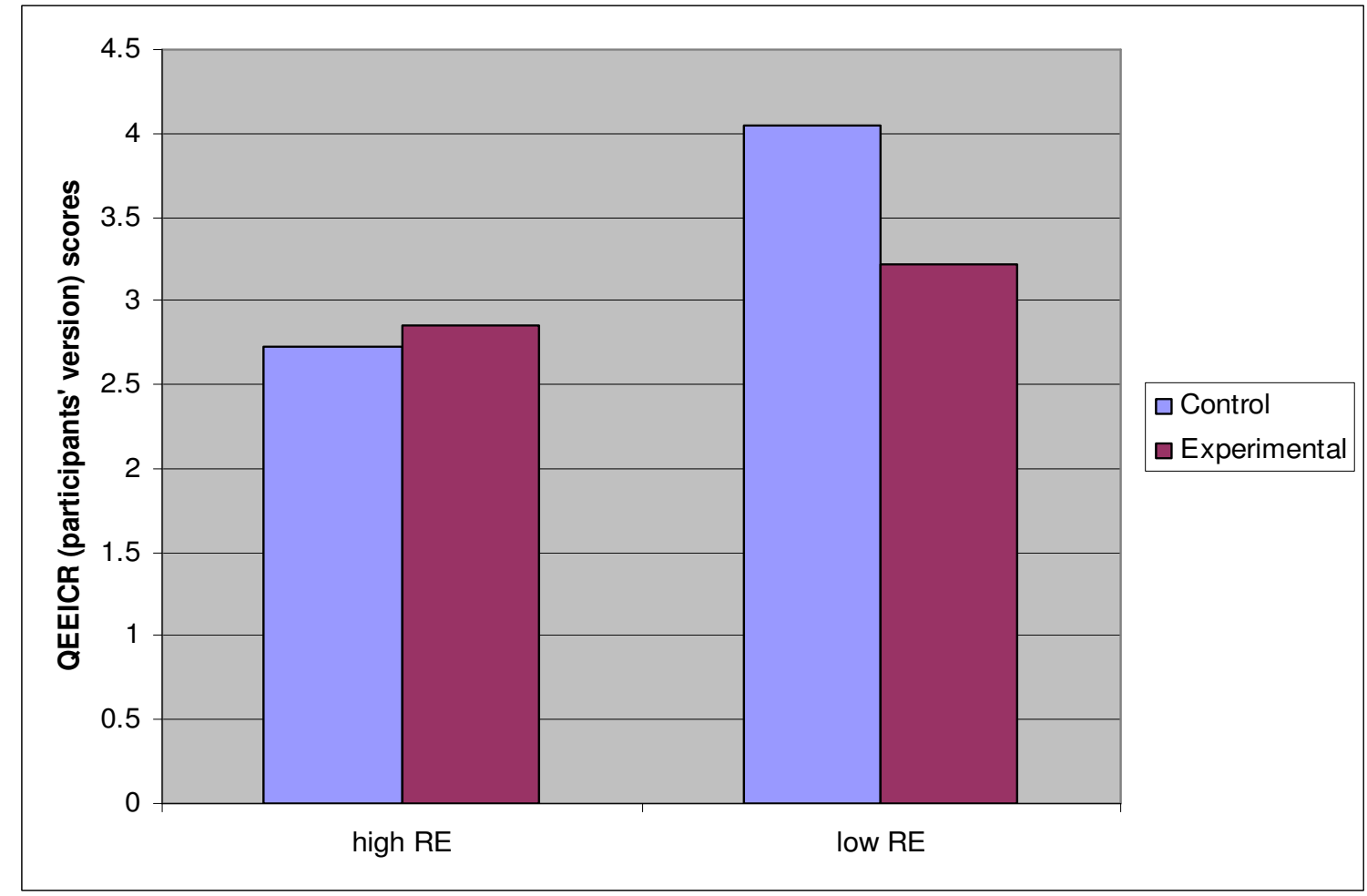

The means and standard deviations of QEESIR (participants' version) scores by condition, romantic relationship status, and restrictive emotionality are presented in Table 10. There was no significant main effect for condition $(p=.187)$. With regard to interaction effects, there were no significant condition $\mathrm{x}$ relationship status, condition $\mathrm{x}$ 
relationship status $\mathrm{x}$ restrictive emotionality, and relationship status $\mathrm{x}$ restrictive emotionality interactions, (all $p \mathrm{~s}>$.4). However, there was a marginally significant condition $\mathrm{x}$ restrictive emotionality interaction, $F(1,138)=3.05, p=.083$. As illustrated in Figure 3, among low restrictive emotionality participants, the control group expressed more emotional intimacy than did the experimental group. However, among high restrictive emotionality participants, the control and experimental groups expressed roughly equivalent levels of emotional intimacy to their romantic partners/significant others.

\section{Expression of Emotional Intimacy (Others' Perspective)}

It was hypothesized that experimental participants' romantic partners/significant others would report that participants demonstrated more emotional intimacy to them than control participants. Further, it was predicted that there would be a restrictive emotionality x condition interaction and a relationship status $\mathrm{x}$ condition interaction. However, because the small sample of romantic partners/significant others $(\mathrm{N}=35)$ who responded to the BEICIR (others' version) resulted in a lack of statistical power to detect interaction effects, the analysis was confined to an examination of group differences between the experimental and control conditions.

An independent samples t-test was used to examine group differences between experimental and control participants on the QEEICR (others' version). No significant differences were found, $p=.901$, control group: $M=3.14, \mathrm{SD}=1.77$, experimental group: $M=3.27, \mathrm{SD}=2.12$.

\section{Self-Regulation as Potential Mediator}

A posthoc analysis was conducted to uncover clues about how and why the expressive writing intervention in this study might be beneficial. The theoretical 
foundation of this writing study lay in the prediction that writing about one's ideal possible self would enhance one's self-regulation, which would, in turn, generate positive outcomes. Applying the self-regulation model to the present study, it would seem reasonable to expect that self-regulation would mediate the relationship between the writing condition and participants' psychosocial functioning. The outcome variable examined was participants' psychological distress because that was the only variable in which experimental and control participants differed significantly.

The proposed mediation model is outlined in Figure 4. To investigate the mediation model, the three conditions proposed by Baron and Kenny (1986) were used. They specified that support for a mediation model exists if (a) the predictor variable predicts the criterion variable; (b) the predictor variable predicts the proposed mediator variable; and (c) controlling for the predictor variable, the proposed mediator predicts the criterion variable.

Fig. 4. Hypothesized Model in which Self-Regulation (QSR scores) Mediates the Association between Condition and Time 3 Psychological Distress (BSI-18 scores), after Controlling for Time 1 Psychological Distress.

Mediator:

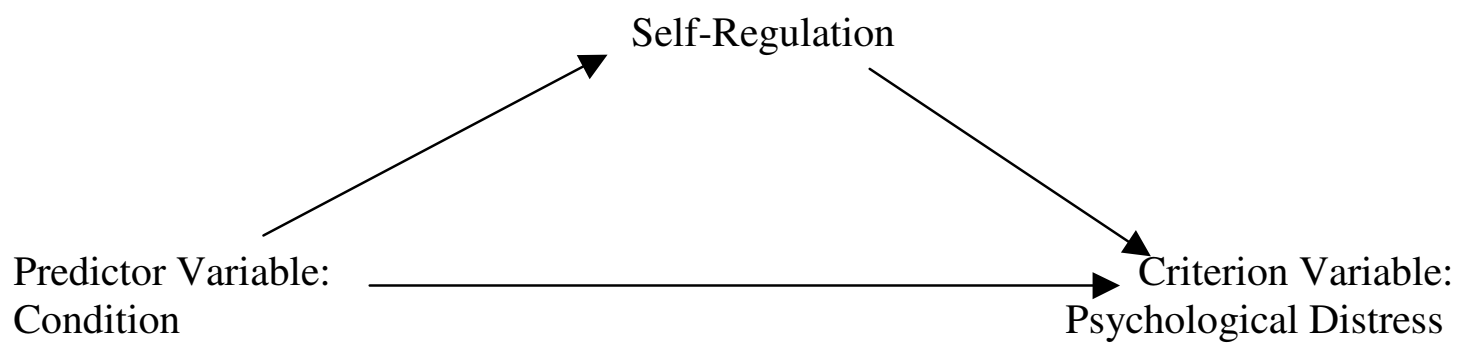

Controlling for Time 1 BSI-18 scores, condition (the predictor variable) was a significant predictor of Time 3 BSI-18 scores (criterion variable), $\beta=-.20, t=-3.15, p=$ .002 , thus satisfying the first condition. Satisfying the second condition, condition was a 
significant predictor of QSR scores (the proposed mediator), $\beta=.27, t=3.53, p=.001$, after controlling for Time 1 BSI-18 scores. Controlling for Time 1 BSI-18 scores and condition, QSR scores were not a significant predictor of Time 3 BSI-18 scores, $\beta=-.12$, $t=-.18, p=.071$, indicating that the third condition proposed by Baron and Kenny (1986) was not satisfied. Hence, there was insufficient support for the proposed mediation model. 


\section{Chapter IV: Discussion}

\section{Review of Findings}

The present study had two main objectives. First, it examined the relationship between male college students' restrictive emotionality and several other psychosocial variables. Second, this study assessed the potential benefits of writing about one's best possible emotional connectedness with a romantic partner for male college students with varying degrees of restrictive emotionality. A review of the main findings is provided below, with an emphasis on clarifying the significance of these results in light of previous research.

\section{Relationship Between Men's Restrictive Emotionality and Other Variables}

The prediction that participants' Time 1 restrictive emotionality would be significantly related to their use of affect words or at least some of the sub-categories of emotion words (e.g., negative emotion words) in their essays was not supported. One possible explanation for this unanticipated result is that restrictive emotionality may be a construct that reflects men's difficulty verbally expressing emotions within interpersonal contexts rather than their difficulty expressing feelings in non-verbal contexts. Such an explanation dovetails with the suggestions of Wong and Rochlen (2005). These authors proposed that men vary in their levels of emotional expressiveness depending on the mode of expression available to them. Hence, men who report high levels of restrictive emotionality might have difficulty communicating emotions verbally but may not necessarily have problems expressing feelings through writing.

In contrast to the non-significant finding on restrictive emotionality and the use of affect words, the hypotheses regarding the association between Time 1 restrictive 
emotionality and other Time 1 variables were confirmed. Men who reported higher levels of restrictive emotionality also reported significantly more psychological distress, less personal growth, and less positive relations with others, and were less likely to be in romantic relationships. However, when Time 1 restrictive emotionality was regressed on the other Time 1 variables, positive relations with others and romantic relationship status were the only variables that remained significantly associated with restrictive emotionality. High restrictive emotionality men reported less positive relations with others and were less likely to be in romantic relationships. These findings attest to the challenges emotionally restricted men face in interpersonal relationships (Bruch, 2002; Wong et al., 2006). Expressing emotions (especially vulnerable feelings) might engender intimacy in a relationship by eliciting compassion and communicating the expresser's trust in the relationship (Kennedy-Moore \& Watson, 2001). Hence, men who have difficulty expressing their emotions might be missing out on important opportunities to build more satisfying or intimate interpersonal relationships.

\section{Differences Between Experimental and Control Groups}

It was hypothesized that compared to control participants, experimental participants would report a greater decrease in restrictive emotionality and psychological distress, a greater increase in personal growth and positive relations with others, and more expression of emotional intimacy in their close relationships. There were no significant differences between experimental and control participants' with regard to restrictive emotionality, personal growth, positive relations with others, and expression of emotional intimacy (as reported by participants as well as by their romantic partners/significant others). The only finding that yielded a significant difference between 
both groups was change in psychological distress. As predicted, experimental participants reported a greater decrease in psychological distress four weeks after the writing intervention than did control participants.

The following are three quotations from the essays of experimental participants whose self-reported psychological distress decreased from Time 1 through Time 3. Although they vary in content, all three quotations appear to reflect a greater awareness or understanding of participants' relational life. One participant wrote about being more appreciative of his current romantic relationship:

"[Day 3] I have learned that I am very blessed with what God has given me. The last few years have been unbelievable and I pray that this is only the beginning. I have learned that our relationship is stronger than what I had thought. Rewriting all of the good things about what we have is just a reassurance of how blessed we are. I have never been so happy with a person in my entire life and I am still in awe that I have what I have... She has changed me for the better and has made me a better person. She has encouraged me to be a nicer person and be more outgoing, and that is one thing that I am very happy about."

Another participant wrote about realizing how much he missed being in a romantic relationship:

"[Day 2] This new me would be the same person I was when I was dating my last girlfriend. I would be able to communicate every thought I had verbally and nonverbally. I miss having such a relationship because it relives me when I can express my inner emotions to someone other than friends or family...[Day 3] Moral of the story, I being single, but I want a girlfriend. They make life easier 
and more fulfilling. Thanks... this survey has helped [sic] realize what I was hiding behind 'I like being single'... being single isn't really that cool."

A third participant discovered through his writing that he was capable of being "emotionally romantic" with his partner:

"[Day 1] Having great emotional connectedness not only involves making the other person happy but also letting them know when they have made you sad or upset. In this case I would not hesitate to tell my partner that what she did might have been wrong or inappropriate. The manner in which I would approach the situation would be the most important thing. The point is to let my partner know that she has upset me not to scold her and scream at her for her actions...[Day 3] I found out that I could be really emotionally romantic with my partner. I did not know that I was up for the romantic stuff. If anything I thought that I was more of a physical type of person."

It is noteworthy that among the main outcome variables in this study, the only benefit that experimental participants derived from the writing intervention was a greater decrease in psychological distress compared to control participants. This finding is interesting because compared to the other main outcome variables (restrictive emotionality, positive relations with others, personal growth, and expression of emotional intimacy), psychological distress seems to have the least direct relevance to the experimental writing topic of one's ideal emotional connectedness with a romantic partner.

Several tentative explanations might account for why a reduction in psychological distress was the only significant finding with regard to group differences. One possibility 
lies in the inherent limitations of self-report measures. Pennebaker (2004) has cautioned that self-reports might merely reflect participants' self-theories but not their actual behaviors outside laboratory settings. Consequently, expressive writing studies have tended to be more successful in producing positive results using behavioral measures such as job acquisition and visits to the doctor compared to self-report measures (Pennebaker, 2004). Although this study relied mainly on self-report measures, it might be that compared to the other measures, the BSI- 18 was a more objective measure that was less susceptible to participants' self-theories than the other measures. The BSI-18 focuses on a list of very specific experiences (e.g., pains in the heart or chest and feeling lonely) over the past seven days instead of more global characteristics used in some of the other outcome measures (e.g., "I enjoy personal and mutual conversations with family members or friends" in item 4, PRWOS).

Although the above explanation on the nature of the BSI-18 is plausible, it does not account for why the experimental and control groups did not differ significantly on the QEEICR, a measure that was similar to the BSI-18 in its focus on concrete experiences (specifically, behaviors that reflect expressions of emotional intimacy in close relationships). Another possible explanation for the lack of significant group differences lies in a possible distinction between psychological distress and all the other outcome variables. Among all the outcome variables, psychological distress was the only variable that relates to psychopathology. In contrast, positive relations with others, expression of emotional intimacy, and, arguably, restrictive emotionality tapped into participants' social functioning while personal growth was theorized to be a component of participants' psychological well-being (Ryff, 1989). Hence, in the short term (i.e., four 
weeks after the experiment), writing about one's best possible emotional connectedness with a romantic partner might have been most effective in reducing psychopathology, but was less useful in promoting psychological well-being or interpersonal effectiveness. Perhaps the writing intervention might have given experimental participants new perspectives on their relational lives that resulted in the alleviation of psychological distress four weeks after the writing. However, more time might be required for the insights gained from expressive writing to bear fruit in participants' interpersonal functioning and relationships.

Interaction Effects Relating to Restrictive Emotionality and Romantic Relationship Status

It was hypothesized that restrictive emotionality and romantic relationship status would moderate the relationship between condition and the outcome variables. Among high restrictive emotionality participants, the experimental group was expected to benefit more from the writing intervention than the control group, although among low restrictive emotionality participants, both conditions were expected to produce equivalent results. With regard to relationship status, two sets of alternative hypotheses were presented: (1) the experimental condition would produce greater benefits than the control condition for men in romantic relationships, but for men not in romantic relationships, both conditions would produce equivalent results; or (2) the experimental condition would produce greater benefits than the control condition for men not in romantic relationships, but for men in romantic relationships, both conditions would produce equivalent results.

None of the hypothesized interactions were confirmed, although two significant results merit comment. First, the analysis of change in participants' self-reported positive 
relations with others indicated a significant time by restrictive emotionality interaction. Specifically, men with low levels of restrictive emotionality reported a significant decline in positive relations with others from Time 1 to Time 3 . In contrast, men with high levels of restrictive emotionality reported roughly equivalent levels of positive relations with others from Time 1 to Time 3. It is possible that both experimental and control writing interventions might have prevented the quality of these men's interpersonal relationships from declining. In other words, writing about human relationships, regardless of whether the topic was impersonal (for control participants) or personal (for experimental participants), could have been beneficial to emotionally restricted men's interpersonal relationships. Nevertheless, in the absence of a non-writing control group, the above suggestion remains speculative and subject to further empirical verification.

Second, there was a marginally significant condition by restrictive emotionality interaction for participants' reported expression of emotional intimacy in close relationships. Unexpectedly, the nature of the interaction differed from the hypothesis for participants' expression of emotional intimacy. Among less emotionally restricted men, the control group reported more expression of emotional intimacy to their romantic partners/significant others than did the experimental group. However, among more emotionally restricted men, the control and experimental groups did not differ in their expression of emotional intimacy. This surprising result suggested that among less emotionally restricted men, the control condition had a more positive effect on their close relationships than the experimental condition. Because low restrictive emotionality participants might have less difficulty with emotional expression, the experimental writing topic of emotional connectedness could have been less beneficial than the 
intellectually engaging and socially-oriented control writing topics (e.g., how technology has influenced the way humans relate to one another). However, because participants' baseline expression of emotional intimacy was not assessed, these findings should be interpreted with caution and subject to further empirical validation in future studies.

To summarize, the expressive writing intervention produced approximately equal results for men who were in romantic relationships and men who were not in romantic relationships. With the exception of expression of emotional intimacy, the expressive writing intervention also produced roughly equivalent results for high versus low restrictive emotionality men. These results stand in contrast to previous expressive writing studies (e.g., Paez et al., 1999; Solano et al., 2003) indicating that individuals who have difficulty being emotionally open benefit more from expressive writing. The reliance on self-report measures might have hampered the detection of interaction effects.

\section{Additional Analyses}

Participants' subjective experience. Four weeks after the writing intervention, experimental participants completed a questionnaire on their subjective experience of the writing experiment. Experimental participants reported that they thought more about their writing experience and that the writing intervention had more positive long-lasting effects than did control participants. However, there were no significant differences between both groups' report of how much they had talked about their writing experience, the extent to which participants experienced negative long-lasting effects of writing, how happy and sad they felt since the writing exercise, how personally valuable the study was, and how likely they were to participate in the study again. 
Self-regulation as a potential mediator. The theoretical foundation of the writing intervention in this study was predicated on the idea that writing about one's ideal possible self would enhance one's self-regulatory capacities, which would, in turn, generate positive outcomes (Greenberg et al., 1996; King, 2002; King \& Burton, 2004). Consistent with these notions, experimental participants reported greater self-regulation as a result of the writing intervention than did control participants, and enhanced selfregulation was associated with a greater decrease in psychological distress. However, the hypothesis that self-regulation would mediate the relations between writing condition and psychological distress was not supported.

\section{Strengths of the Study}

In light of recent calls for appropriate interventions to address the psychological needs of men who restrict their emotions (Good et al., 2005), this study is significant in being the first known empirical assessment of an intervention to improve the mental health and interpersonal functioning of men with varying degrees of restrictive emotionality. Although the hypothesis that emotionally restricted men would benefit more from expressive writing than less emotionally restricted men was not confirmed, there were several interesting findings related to restrictive emotionality that warrant further investigation. Specifically, the time by restrictive emotionality interaction for men's positive relations with others and the condition by restrictive emotionality interaction for the expression of emotional intimacy provide some preliminary evidence that writing interventions might benefit some men more than others depending on their levels of restrictive emotionality. 
Second, a key benefit of the expressive writing intervention in this study is that it provided a relatively safe, anonymous, and potentially masculine-congruent forum for men to explore their deepest feelings about relationship issues (Wong \& Rochlen, 2005). For male college students who would have been uncomfortable seeking traditional faceto-face psychotherapy, the expressive writing intervention might have provided them with the freedom to explore their feelings without fears about their interpersonal functioning. Consequently, this study contributes to a growing body of research examining alternative clinical approaches to traditional face-to-face psychotherapy for men (e.g., Robertson \& Fitzgerald, 1992; Rochlen et al., 2004).

A third strength of this study is that it departs from previous expressive writing studies in the use of non-trivial writing instructions for the control group. Unlike trivial topics used in previous expressive writing studies (e.g., a detailed description of participants' surroundings in Greenberg et al., 1996), control participants in the present study wrote about intellectually engaging topics related to human relationships, e.g., how technology has influenced the way humans relate to one another. The analyses of participants' essays using LIWC indicated that (1) participants in both conditions used roughly equal proportions of social words, (2) control participants used a significantly greater percentage of causal words than did experimental participants, and (3) experimental participants wrote longer essays and used a greater proportion of insight words, affect words, and first person singular words than did control participants. Collectively, the above analyses suggested that compared to experimental participants' essays, control participants' essays were cognitively engaging, had an equal focus on human relationships, but were less personal, emotionally-laden, and insightful than the 
experimental group's essays. Hence, experimental participants' greater decrease in psychological distress after the writing intervention cannot be attributed solely to the importance of writing about something cognitively engaging or socially-oriented.

Fourth, this study adds to an emerging body of research (e.g., Austenfeld et al., 2006; King, 2001; Burton \& King, 2004) suggesting that it is possible for individuals to benefit from expressive writing without having to focus on upsetting or negative experiences in their writings. Two previous writing studies that utilized the ideal possible selves paradigm focused on generic best possible selves, i.e., writing about one's life in the future based on the assumption that everything has gone as well as it possibly could (Austenfeld et al., 2006; King, 2001). However, the current study demonstrated that focusing on a specific domain of one's ideal self (i.e., one's best possible emotional connectedness with a romantic partner) can also be potentially beneficial, at least in alleviating male college students' psychological distress.

Finally, anecdotal evidence from participants' responses to an open-ended question about the long-term consequences of the writing experiment at Time 3 suggested that a number of experimental participants experienced meaningful changes due to the writing intervention. The following are five quotations from the feedback of experimental participants:

"I feel that the experiment got me to realize what I was truly looking for in a close relationship. By putting it into words, I could in turn read back over the things I wrote and understand a bit more of the feelings that I feel."

"I think this experiment helped me think about my relationship with romantic partner again. I have gone out with her for long period, so I was kind of being 
selfish toward her, but with this experiment I could think about her that she is very special person for me [sic]."

"Well the experiment has made me realize what I really want out of a relationship and how I view myself in romantic relationships. It provided certain insight to who I am and gave me thoughts on how to improve on the skills and qualities that I desire but currently lacking [sic].”

"This has made me think of some of my weaknesses and allowed me to realize what needs to be changed in my life. This will always be helpful to me in the future as it has slightly changed my way of thinking."

"It made me look back on my life and evaluate how my values have evolved over time. The positive effects are: learn more about myself and how I view life."

As reflected in last two quotations, it appears that for some experimental participants, the perceived benefits of the writing intervention extended beyond the issue of romantic relationships to broader issues such as insights into their values.

\section{Limitations of the Study}

There were several limitations in this study. First, the generalizability of this study's findings is limited by its mainly heterosexual, White-majority, non-clinical, male college student sample. Although previous expressive writing studies have utilized samples with diverse educational levels, employment statuses, and nationalities (for a review, see Pennebaker, 1997), it is unclear whether the present results from a writing intervention based on one's best possible emotional connectedness with a romantic partner would extend to other populations. 
Second, the study relied mainly on self-report measures. The use of self-report measures instead of behavioral measures might have hampered the detection of significant effects (cf., Pennebaker, 2004, and the above discussion on the lack of significant differences between the experimental and control groups).

Third, unlike many other previous expressive writing studies (e.g., Gortner, Rude, \& Pennebaker, 2006, Pennebaker \& Beall, 1986), this study focused only on participants' psychological and social functioning, and not their physical health. A recent metaanalysis of nine writing studies using clinical populations found that the salutary effects of expressive writing was stronger for physical outcomes than for psychological outcomes (Frisina, Borod, \& Lepore, 2004). Hence, an examination of physiological variables would have allowed for a comparison of the effects of writing about one's ideal emotional connectedness with a romantic partner on participants' psychosocial functioning and physical health.

A fourth limitation of this study is that participants' baseline expression of emotional intimacy in close relationships was not assessed. Hence, the marginally significant condition by restrictive emotionality interaction for this outcome variable has to be interpreted with caution because it is unclear whether and to what extent experimental and control participants differed in their pretest expression of emotional intimacy.

Fifth, the small sample size of respondents $(\mathrm{N}=35)$ who completed the QEEICR (others' version) resulted in possible selection bias. Among the 158 participants in the study, only 79 participants provided consent for the researchers to contact their romantic partners/significant others, while only 35 romantic partners/significant others completed 
the QEEICR (others' version). An examination of Time 3 variables revealed no evidence that participants whose romantic partners/significant others responded to the QEEICR differed systematically from those whose romantic partners/significant others did not. Nonetheless, it is possible that those two groups differed in other unknown ways not reflected by the Time 3 variables. In addition, the small sample size resulted in a lack of statistical power which hampered the detection of significant main and interaction effects.

Finally, unlike several previous expressive writing studies (e.g., Gortner et al., 2006, King, 2001), this study only assessed outcome measures immediately after and four weeks after the writing intervention. Hence, the medium and long-term effects of the writing intervention (e.g., six months later) were not examined. Sloan and Marx (2004) have recommended that it would be useful for expressive writing studies to include multiple follow-up periods because it is possible that the beneficial effects obtained through expressive writing might dissipate after several weeks. It is also possible that some benefits of writing about one's best possible emotional connectedness with a romantic partner would have emerge only after several months.

\section{Recommendations for Future Research}

The findings and limitations of the present study present several implications for future masculinity and expressive writing research. First, the lack of a significant relationship between men's restrictive emotionality and their use of affect words in their writing deserves further research attention. Future studies should compare the association between self-reported restrictive emotionality and the use of affect words in men's spoken conversations versus written texts. If men's self-reported restrictive emotionality is negatively associated with the use of affect words in spoken conversations but not in 
their written language, this might imply that the Restrictive Emotionality Scale is a measure of men's difficulty expressing emotions in verbal interpersonal contexts rather than a generic measure of restrictive emotionality.

Second, masculinity researchers should continue to empirically assess clinical interventions that address the psychosocial needs of men who adhere strongly to traditional masculine norms, including emotionally restricted men (Addis \& Cohane, 2005). In this regard, researchers need to move beyond the use of vignette studies (e.g., Hurst, 1997; Wisch et al., 1995; Rochlen et al., 2004) to examining men's actual participation in a variety of clinical interventions. In addition to expressive writing studies, the benefits of specific types of psychotherapies should be examined. For example, based on the above mentioned vignette studies, it is hypothesized that cognition-centered, solution-focused, and online counseling would be particularly beneficial to men who adhere strongly to masculine norms.

Relatedly, another important area for future research involves comparing the benefits of expressive writing and short term psychotherapy for men with varying levels of restrictive emotionality. Based on previous research indicating that emotionally restricted men prefer online counseling to face-to-face counseling (Rochlen et al., 2004), and that men may be more emotionally expressive in expressive writing than in face-toface psychotherapy (Donnelly \& Murray, 1991), it is surmised that emotionally restricted men would benefit more from expressive writing than from short-term psychotherapy.

Fourth, future studies should examine the efficacy of writing about one's best possible emotional connectedness with a romantic partner using more diverse samples. The writing topic in this study might be especially relevant to individuals with romantic 
relationship stressors. The use of expressive writing as a therapeutic intervention in couples therapy is a relatively unexplored area worthy of future research attention (Snyder et al., 2004). Future studies could explore the potential benefits of writing about one's ideal relationship or marriage for individuals in couples therapy. Such an intervention might help couples clarify their relationship goals and priorities, thus equipping them to better resolve current relationship stressors.

Fifth, future expressive writing studies should examine the benefits of writing about one's ideal romantic relationship using diverse outcome variables (e.g., participants' physical health) and measures (e.g., behavioral measures). With regard to behavioral measures, a promising instrument that deserves greater research attention in expressive writing studies is the electronically activated recorder (EAR; Mehl, Pennebaker, Crow, Dabbs, \& Price, 2001). The EAR consists of a digital voice recorder attached to the participant's belt or around the participant's shoulder. The use of the EAR enables researchers to assess the effects of expressive writing on participants' naturalistic conversations instead of merely relying on the self reports of their social functioning (e.g., Kim, 2004). Future research might address whether writing about one's best possible romantic relationship would result in changes in the content and manner of participants' conversations and interactions with others.

A sixth area of future research involves further variations of the possible selves paradigm in expressive writing. Two studies have utilized generic best possible selves writing topics (Austenfeld et al., 2006; King, 2001) while this study focused specifically on participants' ideal possible selves in the arena of romantic relationships. Future 
expressive writing studies could examine the use of other dimensions of ideal possible selves such as one's ideal career or best possible spiritual life.

Finally, future expressive writing studies should continue to investigate moderators and mediators that help explain why expressive writing is beneficial, as well as how the benefits of expressive writing might vary depending on the types of writing topics, individuals, and outcome measures used (Sloan \& Marx, 2004). In the present study, romantic relationship status and restrictive emotionality did not conclusively explain why some participants benefited from writing about their best possible emotional connectedness with a romantic partner while others did not. It should be noted that restrictive emotionality refers to men's difficulty expressing emotions rather than men's unawareness of their feelings (cf., O’Neil et al., 1995; Wong et al., 2006). Perhaps future expressive writing studies should consider as potential moderators emotion-related constructs that tap into individuals' difficulty identifying their emotions (e.g., Solano et al., 2003). Other potential moderators to examine include conformity to male norms (Mahalik, Locke, et al., 2003) and cultural variables for individuals from diverse racial/ethnic groups (e.g., Kim, Li, \& Ng, 2005).

With regard to mediators, the LIWC (Pennebaker et al., 2001) is a promising tool that provides clues as to why expressive writing works. Past expressive writing studies (e.g., Pennebaker et al., 1997) have shown that changes in the use of causal and insight words, the use of positive emotion words, and the moderate use of negative emotion words predicted improved health outcomes. Future studies should examine whether different linguistic patterns might account for the benefits of expressive writing when 
diverse writing topics are employed (e.g., writing about one's stressful experiences versus writing about one's best possible self).

\section{Clinical Implications and Concluding Comments}

Not surprisingly, the success of the expressive writing research paradigm over the past two decades has generated considerable interest in its clinical applications (e.g., Esterling et al., 1999; Smyth \& Catley, 2002). A key benefit of expressive writing is that it provides a safe and cost-effective forum for individuals to disclose and sort out intensely personal and/or emotional topics.

Some scholars have proposed that expressive writing can be applied as an adjunct to traditional face-to-face psychotherapy, e.g., the use of writing as an assignment in psychotherapy (Graf, 2004). In addition, several structured writing interventions have been proposed for use as clinical interventions. These include interapy, a model for therapeutic writing through the internet (Lange, Schoutrop, Schrieken, \& Van De Ven, 2002) and distance writing, a therapeutic approach involving the use of workbooks containing a series of written homework assignments (L'Abate \& Kern, 2002).

Relatedly, the advent of the internet has facilitated the growing popularity of online counseling through asynchronous email and synchronous chats (Mallen, Vogel, Rochlen, \& Day, 2005; Rochlen, Zack, \& Speyer, 2004). Arguably, online counseling (especially in the form of asynchronous emails between the therapist and client) can be viewed as a clinical intervention that integrates elements of expressive writing with traditional psychotherapy. In light of the growing presence of managed care and strict cost controls in the health care professions, expressive writing might become an increasingly useful 
low-cost clinical treatment favored by clinicians, consumers, and insurance companies (Lepore \& Smyth, 2002).

Importantly, the growing interest in expressive writing as a clinical intervention dovetails with calls by scholars (Heesacker \& Prichard, 1992; Wester et al., 2002) to identify alternative approaches to addressing men's mental health and emotional needs, instead of simply relying on traditional face-to-face psychotherapy. For example, expressive writing might be a useful clinical intervention for men who struggle with being emotionally open in a face-to-face, verbal context (Wong \& Rochlen, 2005).

Unlike most other expressive writing studies, the expressive writing topic in this study encouraged a focus on some aspects of participants' ideal romantic relationship rather than on distressing experiences. It is noteworthy that the interest in positive expressive writing topics (e.g., Austenfeld et al., 2006; Burton \& King, 2004, King, 2001) has grown in tandem with recent interest in psychotherapeutic approaches that focus on clients' positive qualities and strengths (e.g., Gelso \& Woodhouse, 2003; Joseph \& Linley, 2004; Lopez, Flyod, Ulven, \& Snyder, 2000; Seligman, 2002; Wong, 2006a; 2006b). Interestingly, the ideal possible selves writing topics bear some resemblance to the miracle question technique used in solution-focused therapy (Hurn, 2003). Instead of analyzing and dwelling on the nature and causes of clients' problems, solution-focused therapy encourages a focus on existing positive aspects of clients' lives as well as how their lives can be better (Berg \& Dolan, 2001; de Shazer \& Berg, 1992; De Jong \& Berg, 1998). In this vein, the miracle question is used by the therapist to help the client reflect in detail on how her life would be different if her problems were to disappear as a result of a miracle. 
The preliminary findings from this study as well as other best possible selves writing studies (e.g., Austenfeld et al., 2006; King, 2001) suggest that solution-focused therapists and other strengths-based therapists could experiment with using expressive writing to help their clients envision how their lives can be better. For instance, clients might be instructed to write in their journals about how their lives would be different if they have better marriages, relationships, or mental health. Such best possible selves writing interventions also converge with Kelly and Hall's (1992) positive, developmental model for understanding masculinity and counseling men; consequently, they might be useful clinical interventions for therapists interested in strengths-based approaches to counseling men.

To conclude, this is the first known expressive writing study to examine the potential benefits of writing about one's best possible emotional connectedness with a romantic partner for male college students. Perhaps the most important finding from this study was that men in the expressive writing group reported a greater decrease in psychological distress four weeks after the writing intervention compared to men in the control group. Expressive writing appears to be a promising area that deserves more attention by researchers and clinicians interested in men's mental, physical, and social health. 
Appendix A

\section{Informed Consent to Participate in Research}

Title: Writing Plus

IRB PROTOCOL \# 2005-09-0015

Conducted By: Y. Joel Wong, M.A. and Aaron B. Rochlen, Ph.D.

Of University of Texas at Austin:

Educational Psychology/SZB 262

Tel: 512.469.0548

You are being asked to participate in a research study. This form provides you with information about the study. The person in charge of this research will also describe this study to you and answer all of your questions. Please read the information below and ask any questions you might have before deciding whether or not to take part. Your participation is entirely voluntary. You can refuse to participate without penalty or loss of benefits to which you are otherwise entitled. You can stop your participation at any time. To do so simply tell the researcher you wish to stop participation.

The purpose of this study is to examine the nature of writing and its relationships with certain aspects of your life. There are 188 participants in this study.

If you agree to be in this study, we will ask you to do the following things:

- Write continuously on certain topics for 20 minutes each day for 3 consecutive days. You will complete this portion of the study using a computer in a computer lab.

- Fill out several online questionnaires on the first and third days of the study in the computer lab.

- Fill out several online questionnaires about 4 weeks after the above writing sessions. This portion of the study can be completed from a computer of your choice with an internet connection.

Total estimated participation time in this study is 3 hours.

Risks and Benefits of being in the study

- It is possible that you may find focusing on yourself when responding to the questionnaires and the process of writing slightly unpleasant. There may be additional risks that are unknown at this time. If you wish to discuss the information above or any other risks you may experience, you may ask questions now or call the principal investigator listed on this form.

- There is no anticipated physical risk as a direct result of participation in this study.

- It is possible that you may benefit from the writing portion of this study, which in the past has helped people gain greater insight into their lives and has aided participants in achieving better mental and physical health. In addition, information gained from this study may contribute to research on an important understudied area of psychology and on improving some forms of psychological treatment. 
Compensation:

- You will receive subject pool course credit for your participation in this study. If you do not wish to participate in this study, please contact Bradley Gerber, coordinator of the undergraduate subject pool in the Department of Educational Psychology, at blgerber@mail.utexas.edu to discuss alternative assignments.

- Psychological services will not be provided for your participation in this study. However, we will provide you information about free mental health services at the University of Texas at Austin at the conclusion of this study.

Confidentiality and Privacy Protections:

- Your research data will be transmitted to the researcher using a secured computer server. Your research data will be kept confidential and will not be released to anyone without your written consent unless required by law or a court order. If any of your responses indicate that there is a clear, serious, and direct harm to yourself or others, or that a child or elderly person has been abused, we may be required by law to break confidentiality and report this information to the police or the Child Protection Services.

- The researchers in this project will analyze your responses to the questionnaires and open-ended questions in a manner that does not identify you personally.

- The data resulting from your participation may be made available to other researchers in the future for research purposes not detailed within this consent form. In these cases, the data will contain no identifying information that could associate you with it, or with your participation in any study.

The records of this study will be stored securely and kept confidential. Authorized persons from The University of Texas at Austin and members of the Institutional Review Board have the legal right to review your research records and will protect the confidentiality of those records to the extent permitted by law. All publications will exclude any information that will make it possible to identify you as a subject. Throughout the study, the researchers will notify you of new information that may become available and that might affect your decision to remain in the study.

Contacts and Questions:

If you have any questions about the study please ask now. If you have questions later or want additional information, call the researchers conducting the study. Their names, phone numbers, and e-mail addresses are at the top of this page. If you have questions about your rights as a research participant, complaints, concerns, or questions about the research please contact Lisa Leiden, Ph.D., Chair of The University of Texas at Austin Institutional Review Board for the Protection of Human Subjects, (512) 471-8871 or email: orsc@uts.cc.utexas.edu.

Please print a copy of this information to keep for your records.

I have read the above information and have sufficient information to make a decision about participating in this study.

$\square$ I consent to participate in the study.

$\square$ I am not willing to participate in this study. 
Appendix B

\section{Demographic Information}

Participant Identification Code:

Age:

Year: Freshman

Sophomore

Junior

Senior

Other

Race : __ African American/Black

Asian

Caucasian/White

Latino

Other: please specify:

\section{Sexual Orientation:}

_ Bisexual

_ Gay

_ Heterosexual

_ Other: please specify

Are you currently in a romantic relationships?

- Yes

_ No

_ Other (please specify): 
Appendix C

\section{Restrictive Emotionality Scale}

Choose the number that most closely represents the degree that you agree or disagree with the statement. There is no right or wrong answer to each statement; your own reaction is what is asked for.

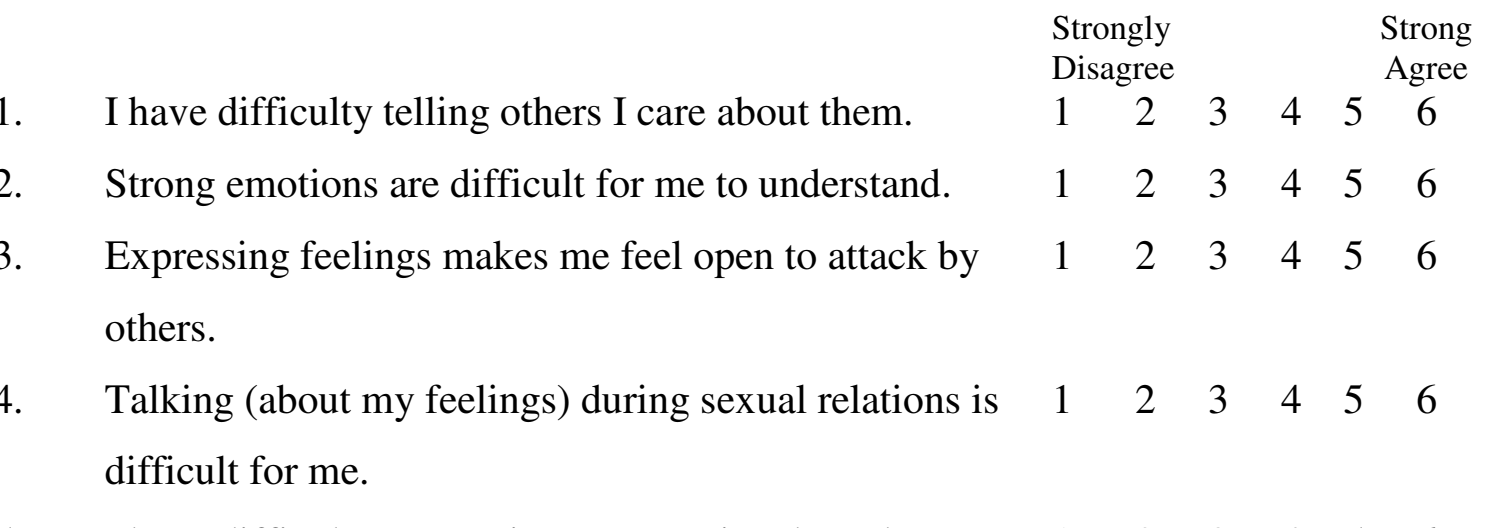

5. I have difficulty expressing my emotional needs to my $1 \begin{array}{llllll}1 & 2 & 3 & 4 & 5 & 6\end{array}$ partner.

6. I have difficulty expressing my tender feelings. $\quad \begin{array}{lllllll}1 & 2 & 3 & 4 & 5 & 6\end{array}$

7. Telling others of my strong feelings is not part of my $\begin{array}{lllllll}1 & 2 & 3 & 4 & 5 & 6\end{array}$ sexual behavior.

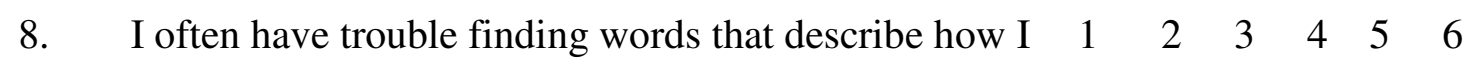
am feeling.

9. $\quad$ I do not like to show my emotions to other people $\quad \begin{array}{llllllll}1 & 2 & 3 & 4 & 5 & 6\end{array}$

10. Telling my partner my feelings about him/her during $\quad \begin{array}{lllllll}1 & 2 & 3 & 4 & 5 & 6\end{array}$ sex is difficult for me. 


\section{Brief Symptom Inventory-18}

Below is a list of problems people sometimes have. Read each one carefully and indicate the number that best describes how much that problem has distressed or bothered you during the past 7 days including today.

\section{Not At all \\ 0 \\ A Little Bit Moderately \\ 2

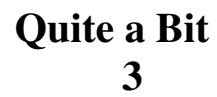 \\ Extremely \\ 4}

How much were you distressed by:

(rate 0 to 4$)$

1. Faintness or dizziness

2. Feeling no interest in things

3. Nervousness or shakiness inside

4. Pains in heart or chest

5. Feeling lonely

6. Feeling tense or keyed up

7. Nausea or upset stomach

8. Feeling blue

9. Suddenly scared for no reason

10. Trouble getting your breath

11. Feelings of worthlessness

12. Spells of terror or panic

13. Numbness or tingling in parts of your body

14. Feeling hopeless about the future

15. Feeling so restless you couldn't sit still

16. Feeling weak in parts of your body

17. Thoughts of ending your life

18. Feeling fearful 
Appendix E

\section{Positive Relations With Others Scale}

Choose the number that most closely represents the degree that you agree or disagree with the statement.

\begin{tabular}{|c|c|c|c|c|c|}
\hline $\begin{array}{c}\text { Strongly } \\
\text { disagree }\end{array}$ & $\begin{array}{c}\text { Moderately } \\
\text { disagree }\end{array}$ & $\begin{array}{c}\text { Slightly } \\
\text { disagree }\end{array}$ & $\begin{array}{c}\text { Slightly } \\
\text { agree }\end{array}$ & $\begin{array}{c}\text { Moderately } \\
\text { agree }\end{array}$ & $\begin{array}{c}\text { Strongly } \\
\text { agree }\end{array}$ \\
\hline 1 & 2 & 3 & 4 & 5 & 6 \\
\hline
\end{tabular}

1. Most people see me as loving and affectionate.

2. Maintaining close relationships has been difficult and frustrating for me

3. I often feel lonely because I have few close friends with whom to share my concerns.

4. I enjoy personal and mutual conversations with family members or friends.

5. It is important to me to be a good listener when close friends talk to me about their problems.

6. I don't have many people who want to listen when I need to talk.

7. I feel like I get a lot out of my friendships.

8. It seems to me that most other people have more friends than I do.

9. People would describe me as a giving person, willing to share my time with others.

10. I have not experienced many warm and trusting relationships with others.

11. I often feel like I'm on the outside looking in when it comes to friendships.

12. I know that I can trust my friends, and they know they can trust me.

13. I find it difficult to really open up when I talk with others.

14. My friends and I sympathize with each other's problems.

Note: Items in italics are reversed-scored. 


\section{Personal Growth Scale}

Choose the number that most closely represents the degree that you agree or disagree with the statement.

\begin{tabular}{|c|c|c|c|c|c|}
\hline $\begin{array}{c}\text { Strongly } \\
\text { disagree }\end{array}$ & $\begin{array}{c}\text { Moderately } \\
\text { disagree }\end{array}$ & $\begin{array}{c}\text { Slightly } \\
\text { disagree }\end{array}$ & $\begin{array}{c}\text { Slightly } \\
\text { agree }\end{array}$ & $\begin{array}{c}\text { Moderately } \\
\text { agree }\end{array}$ & $\begin{array}{c}\text { Strongly } \\
\text { agree }\end{array}$ \\
\hline 1 & 2 & 3 & 4 & 5 & 6 \\
\hline
\end{tabular}

1. I am not interested in activities that will expand my horizons.

2. In general, I feel that I continue to learn more about myself as time goes by.

3. I am the kind of person who likes to give new things a try.

4. I don't want to try new ways of doing things--my life is fine the way it is.

5. I think it is important to have new experiences that challenge how you think about yourself and the world.

6. When I think about it, I haven't really improved much as a person over the years.

7. In my view, people of every age are able to continue growing and developing.

8. With time, I have gained a lot of insight about life that has made me a stronger, more capable person.

9. I have the sense that I have developed a lot as a person over time.

10. I do not enjoy being in new situations that require me to change my old familiar ways of doing things.

11. For me, life has been a continuous process of learning, changing, and growth.

12. I enjoy seeing how my views have changed and matured over the years.

13. I gave up trying to make big improvements or changes in my life a long time ago.

14. There is truth to the saying you can't teach an old dog new tricks.

Note: Items in italics are reversed-scored. 


\section{Writing Instructions}

Appendix G

\section{Generic instructions given to control and experimental groups}

This section is an extremely important project looking at writing. Over the next three days, you will be asked to write about one of several topics for 20 minutes each day. We ask that you write continuously for the entire time. If you run out of things to say, just repeat what you have already written. Keep writing until the researcher tells you to stop. In your writing, don't worry about grammar, spelling, or sentence structure. Just write. Different people will be asked to write about different topics. Because of this, I ask that you not talk with other participants in this study about the experiment. Also, do remember that your writing is anonymous and confidential. Please do not write your name in your essay.

(The above instructions were provided in verbal and written forms and were repeated on all 3 days of writing).

\section{Control group instructions}

Day 1

Many scholars have observed that humans have an intrinsic need to connect with one another. Over the next 3 days, we would like you to write about important topics related to human connections.

Please write about how technology has influenced the way humans relate to one another. In your essay, you should try to be as objective as possible. Do not discuss your personal feelings and do not refer to any examples from your personal life or the lives of your friends and family members. Remember to keep writing until you're told to stop.

Day 2

Please write about the changes in the way humans relate to one another over the past 100 years. In your essay, you should try to be as objective as possible. Do not discuss your personal feelings and do not refer to any examples from your personal life or the lives of your friends and family members. Remember to keep writing until you're told to stop.

Day 3

Please write about why a country might have a close relationship with one country but an unfriendly relationship with another country. In your essay, you should try to be as objective as possible. Do not discuss your personal feelings and do not refer to any examples from your personal life or the lives of your friends and family members. Remember to keep writing until you're told to stop. 


\section{Experimental group instructions}

\section{Day 1}

Many scholars have observed that humans have an intrinsic need to connect with one another. Over the next 3 days, we would like you to write about an important topic related to human connections: how your life would be different if you have the best possible emotional connectedness with a romantic partner.

Imagine yourself as someone with the best possible emotional connectedness with a romantic partner. (You can focus on your current romantic partner or an imaginary/future romantic partner.) You are comfortable revealing your emotions (e.g., sadness, gratitude, fear, and empathy) to your partner, and you also try to understand how your partner feels. How would your life be different? Try to mentally visualize how you would be communicating with your romantic partner. Reflect on what you would be specifically doing, thinking, saying, and feeling. Now write in as much detail as possible about what you imagined. We really want you to let go and fully immerse yourself in the "new you." Remember to keep writing until you're told to stop.

Day 2

Today, please continue writing about how your life would be different if you are someone with the best possible emotional connectedness with a romantic partner. You can explore other aspects of the "new you." If you run out of things to write, simply repeat what you wrote on Day 1.

For your convenience, the instructions from Day 1 are reproduced below:

Imagine yourself as someone with the best possible emotional connectedness with a romantic partner. (You can focus on your current romantic partner or an imaginary/future romantic partner.) You are comfortable revealing your emotions (e.g., sadness, gratitude, fear, and empathy) to your partner, and you also try to understand how your partner feels. How would your life be different? Try to mentally visualize how you would be communicating with your romantic partner. Reflect on what you would be specifically doing, thinking, saying, and feeling. Now write in as much detail as possible about what you imagined. We really want you to let go and fully immerse yourself in the "new you." Remember to keep writing until you're told to stop.

Day 3

Since this is the last day of the writing exercise, we would like you to reflect on what you've written over the past few sessions concerning your best possible emotional connectedness with a romantic partner. How has what you've written shaped your understanding of your current life and your future? What have you learned about your relationships, goals, values, and priorities? Are there aspects of your life that you want to change as a result of what you've written? Remember to keep writing until you're told to stop. 
Over the past 3 days of the study, I wrote about my relationship with:

- My current romantic partner.

_ An imaginary romantic partner.

_ An actual person whom I wish is my romantic partner.

_Other (specify): 


\section{Questionnaire on Self-Regulation}

In answering the following questions, consider all 3 days of writing:

\begin{tabular}{|c|c|c|c|c|c|}
\hline $\begin{array}{c}\text { Strongly } \\
\text { disagree }\end{array}$ & $\begin{array}{c}\text { Moderately } \\
\text { disagree }\end{array}$ & $\begin{array}{c}\text { Slightly } \\
\text { disagree }\end{array}$ & $\begin{array}{c}\text { Slightly } \\
\text { agree }\end{array}$ & $\begin{array}{c}\text { Moderately } \\
\text { agree }\end{array}$ & $\begin{array}{c}\text { Strongly } \\
\text { agree }\end{array}$ \\
\hline 1 & 2 & 3 & 4 & 5 & 6 \\
\hline
\end{tabular}

As a result of the writing experiment:

1. I am more aware of my values in life.

$\begin{array}{llllll}1 & 2 & 3 & 4 & 5 & 6\end{array}$

2. I have gained insight into my priorities.

$\begin{array}{llllll}1 & 2 & 3 & 4 & 5 & 6\end{array}$

3. I have a better idea of how to achieve my goals.

$\begin{array}{llllll}1 & 2 & 3 & 4 & 5 & 6\end{array}$

4. I have a better sense of what's truly important in life.

$\begin{array}{llllll}1 & 2 & 3 & 4 & 5 & 6\end{array}$

5. I have a clearer understanding of what makes my life more fulfilling.

$\begin{array}{llllll}1 & 2 & 3 & 4 & 5 & 6\end{array}$

6. I know what aspects of my life to change to meet my needs.
$\begin{array}{llllll}1 & 2 & 3 & 4 & 5 & 6\end{array}$

7. I am better able to devise strategies to achieve my goals.
1
23
45
6

8. I am more equipped to cope with life's challenges.
12
23
4
5
6 


\section{Demographic Questions on Participants' Romantic Partners or Significant Others}

Are you currently in a dating relationship?

- Yes

- No

\section{For participants in romantic relationships only}

1. I have been in a relationship with my romantic partner for:

a. less than 1 month

b. $1-6$ months

c. 6 months -12 months

d. more than 12 months

2. My romantic partner lives in the Austin metropolitan area.

- Yes

- No

\section{For participants who are not in romantic relationships only}

We would like you to answer some questions about your relationship with any one person you are close to, e.g., a family member or a close friend. Please focus on just one specific person. The person should satisfy the following criteria:

- Be at least 18 years old;

- Have an email address and is familiar with the use of the internet;

- Have regular contact with you (i.e., you talk with this person at least once a week); and

- Reads and writes English fluently.

1. The person I have selected is my
a. Father
b. Mother
c. Brother
d. Sister
e. Other family member
f. Friend
g. Other: please specify:

2. This person is:
a. Male
b. Female

3. This person lives in the Austin metropolitan area.

- Yes

- No 
Appendix $\mathbf{J}$

\section{Questionnaire on the Expression of Emotional Intimacy in Close relationships ${ }^{1}$}

\section{Participants' Version}

You've just responded to some items about a specific person you're close to (e.g., your partner/family member/friend). Please answer the following questions with regard to your relationship/friendship with this person.

Within the last $\underline{7 \text { (SEVEN) }}$ days, including today, how many days did you:

1. Initiate an outing/date with him/her.

0 days 1 day 2 days 3 days 4 days 5 days 6 days 7 days

2. Accompany him/her to some kind of event (e.g., party or music venue) or location (e.g., clothes store) that you wouldn't have gone to on your own.

0 days 1 day 2 days 3 days 4 days 5 days 6 days 7 days

3. Express concern for his/her needs.

0 days 1 day 2 days 3 days 4 days 5 days 6 days 7 days

4. Confide personal information about your life to him/her.

0 days 1 day 2 days 3 days 4 days 5 days 6 days 7 days

5. Thank him/her for something he/she did.

0 days 1 day 2 days 3 days 4 days 5 days 6 days 7 days

6. Express empathy for him/her.

0 days 1 day 2 days 3 days 4 days 5 days 6 days 7 days

7. Tell him/her about what made you happy.

0 days 1 day 2 days 3 days 4 days 5 days 6 days 7 days

8. Ask him/her about how his/her day went.

0 days 1 day 2 days 3 days 4 days 5 days 6 days 7 days

9. Tell him/her about your fears.

0 days 1 day 2 days 3 days 4 days 5 days 6 days 7 days

10. Do something to encourage him/her.

0 days 1 day 2 days 3 days 4 days 5 days 6 days 7 days

12. Tell him/her that you loved him/her.

\footnotetext{
${ }^{1}$ Pursuant to a factor analysis on the 18 items, items $1,2,13$, and 14 were deleted from the participants and others' versions of this questionnaire.
} 
0 days 1 day 2 days 3 days 4 days 5 days 6 days 7 days

12. Ask him/her for his/her opinion.

0 days 1 day 2 days 3 days 4 days 5 days 6 days 7 days

13. Buy him/her a gift.

0 days 1 day 2 days 3 days 4 days 5 days 6 days 7 days

14. Provide him/her with practical help.

0 days 1 day 2 days 3 days 4 days 5 days 6 days 7 days

15. Express physical affection to him/her in a nonsexual way (e.g., gave him/her a hug).

0 days 1 day 2 days 3 days 4 days 5 days 6 days 7 days

16. Tell him/her what you admired about him/her.

0 days 1 day 2 days 3 days 4 days 5 days 6 days 7 days

17. Listen to him/her without interrupting.

0 days 1 day 2 days 3 days 4 days 5 days 6 days 7 days

18. Admit your faults to him/her.

0 days 1 day 2 days 3 days 4 days 5 days 6 days 7 days

If there's any additional information about your relationship with your romantic partner that is important for us to know, please describe in the space below.

\section{Others' (Partner/Significant Others) Version}

Please answer the following questions with regard to your relationship/friendship with the specific person indicated in the email we sent you.

Within the last $\underline{7 \text { (SEVEN) }}$ days, including today, how many days did he:

1. Initiate an outing/date with you.

0 days 1 day 2 days 3 days 4 days 5 days 6 days 7 days

2. Accompany you to some kind of event or location that he wouldn't have gone to on his own.

0 days 1 day 2 days 3 days 4 days 5 days 6 days 7 days

3. Express concern for your needs.

0 days 1 day 2 days 3 days 4 days 5 days 6 days 7 days 
4. Confide personal information about his life to you.

0 days 1 day 2 days 3 days 4 days 5 days 6 days 7 days

5. Thank you for something you did.

0 days 1 day 2 days 3 days 4 days 5 days 6 days 7 days

6. Express empathy for you.

0 days 1 day 2 days 3 days 4 days 5 days 6 days 7 days

7. Tell you about what made him happy.

0 days 1 day 2 days 3 days 4 days 5 days 6 days 7 days

8. Ask you about how your day went.

0 days 1 day 2 days 3 days 4 days 5 days 6 days 7 days

9. Tell you about his fears.

0 days 1 day 2 days 3 days 4 days 5 days 6 days 7 days

10. Do something to encourage you.

0 days 1 day 2 days 3 days 4 days 5 days 6 days 7 days

11. Tell you that he loved you.

0 days 1 day 2 days 3 days 4 days 5 days 6 days 7 days

12. Ask you for your opinion.

0 days 1 day 2 days 3 days 4 days 5 days 6 days 7 days

13. Buy you a gift.

0 days 1 day 2 days 3 days 4 days 5 days 6 days 7 days

14. Provide you with practical help.

0 days 1 day 2 days 3 days 4 days 5 days 6 days 7 days

15. Express physical affection to you in a nonsexual way (e.g., gave you a hug).

0 days 1 day 2 days 3 days 4 days 5 days 6 days 7 days

16. Tell you what he admired about you.

0 days 1 day 2 days 3 days 4 days 5 days 6 days 7 days

17. Listen to you without interrupting.

0 days 1 day 2 days 3 days 4 days 5 days 6 days 7 days

18. Admit his faults to you.

0 days 1 day 2 days 3 days 4 days 5 days 6 days 7 days 
If there's any additional information about your relationship with your romantic partner that is important for us to know, please describe in the space below. 


\section{Recruitment of romantic partner/significant other}

Appendix K

\section{Recruitment of romantic partner}

You have just completed a questionnaire about your relationship with your romantic partner. With your consent, we would like to invite your romantic partner to participate in this research project by filling out an online questionnaire about his/her relationship with you. We will contact your partner by email only.

We will NOT divulge any of your responses or written essays to your partner. Only your email address will be disclosed to this person. The completion of this questionnaire is expected to take less than $\mathbf{5}$ minutes and your partner will be compensated by being given the opportunity to participate in a lottery draw for a gift of $\mathbf{\$ 5 0}$.

Participation in this online survey is completely voluntary and your partner may end his/her participation at any time.

If you are agreeable to our contacting your partner to participate in this research project, please provide his/her email address below. Remember that we are referring to the specific partner whose relationship you have just described in the above questionnaire.

My romantic partner's email address:

\section{Recruitment of significant other}

You have just completed a questionnaire about your relationship/friendship with a person you are close to. With your consent, we would like to invite this person to participate in this research project by filling out an online questionnaire about his/her relationship/friendship with you. We will contact him/her by email only.

We will NOT divulge any of your responses or written essays to this person. Only your name will be disclosed to this person. The completion of this questionnaire is expected to take less than 5 minutes and this person will be compensated by being given the opportunity to participate in a lottery draw for a gift of $\mathbf{\$ 5 0}$.

Participation in this online survey is completely voluntary and he/she may end his/her participation at any time.

If you are agreeable to our contacting this person to participate in this research project, please provide his/her email address below. Remember that we are referring to the specific person whose relationship/friendship you have just described in the above questionnaire.

This person's email address: 


\section{Appendix L}

\section{Questionnaire on Participants' Subjective Experiences of the Study}

Now, please think back about this experiment.

1. Since your participating in the writing experiment, how much have you thought about what you wrote?

$\begin{array}{ccccccl}1 & 2 & 3 & 4 & 5 & 6 & 7 \\ \text { not at all } & & & & & & \text { a great deal }\end{array}$

2. Since the writing experiment, how much have you talked to other people about what you wrote?

$\begin{array}{ccccccl}1 & 2 & 3 & 4 & 5 & 6 & 7 \\ \text { not at all } & & & & & & \text { a great deal }\end{array}$

3. Looking back on the experiment, to what degree do you feel that the experiment had a positive long-lasting effect on you?

$\begin{array}{ccccccl}1 & 2 & 3 & 4 & 5 & 6 & 7 \\ \text { not at all } & & & & & & \text { a great deal }\end{array}$

4. Looking back on the experiment, to what degree do you feel that the experiment had a negative long-lasting effect on you?

$\begin{array}{ccccccl}1 & 2 & 3 & 4 & 5 & 6 & 7 \\ \text { not at all } & & & & & & \text { a great deal }\end{array}$

5. Since the experiment, how happy have you felt?

$\begin{array}{ccccccc}1 & 2 & 3 & 4 & 5 & 6 & 7 \\ \text { not at all } & & & & & & \text { a great deal }\end{array}$

6. Since the experiment, how sad or depressed have you felt?

$\begin{array}{ccccccc}1 & 2 & 3 & 4 & 5 & 6 & 7 \\ \text { not at all } & & & & & & \text { a great deal }\end{array}$

7. Looking back on the experiment, to what degree has this experiment been valuable or meaningful for you (not counting the class credit and money you will receive)?

$\begin{array}{ccccccc}1 & 2 & 3 & 4 & 5 & 6 & 7 \\ \text { not at all } & & & & & & \text { a great deal }\end{array}$

8. If you had the chance to do it over again, would you participate in this study: 
definitely yes

probably yes

don't know

probably no

definitely

no

9. Now that the experiment is completed, could you tell us how it may have influenced you in the long run? What have been the positive effects as well as the negative effects?

10. Any other comments you have about the experiment would be greatly appreciated. 
Appendix M

\section{Description of Purpose of the Study and Information About Counseling Services}

In this project, you were either assigned to write about your relationship with a romantic partner or about other topics related to human connections. We hope to understand whether writing about one's best possible emotional connectedness with a romantic partner improves men's psychological and social functioning. Results from this project could provide useful information on how to address men's psychological and social needs. Hence, we appreciate your involvement and honest responses.

We also want to take this opportunity to inform you of the free counseling resources that are available to all students on campus. We particularly want to encourage you to seek out these services if participating in this study was at all upsetting, if you feel you may currently be experiencing symptoms of depression, or for any other mental health concern. For personal counseling, you can contact the Counseling \& Mental Health Center at 471-3515 or at their website, http://www.utexas.edu/student/cmhc/. The Counseling Center, located on the 5th floor of the Student Services Building, is open Monday through Friday, 8:00 AM - 5:00 PM, and provides individual and group counseling free of charge.

Again, thank you for your involvement in this study. If you have additional questions, please email me at joelwong@mail.utexas.edu.

Sincerely,

Joel Wong

Principal Investigator 
Email Recruitment of Participants' Partners/Significant Others

Appendix N

You are receiving this email because your partner/family member/friend [male

participant's name] is participating in a research project on the nature of writing and its relationship and various aspects of individuals' lives at the University of Texas at Austin. We have asked and obtained his consent to invite you to participate in this research project.

Participation in this research project involves filling out an online questionnaire about your friendship/relationship with the above person. For most participants, completing this questionnaire will take less than 5 minutes. To compensate you for your involvement, you will be given the opportunity to participate in a lottery draw for a gift of $\underline{\mathbf{\$ 5 0}}$.

There are no known risks to participation in this study. Your participation will contribute to our understanding of individuals' relational lives. You might also gain some insight into your relationship with others.

Participation is completely voluntary and you may end your participation at any time. Your responses will be kept strictly confidential, and will not be disclosed to your partner/family member/friend. We will also not divulge your email address or contact particulars to anyone else.

To protect your identity, you will be asked in the survey to enter a participation number instead of your name. Please enter this participation number: $[\mathbf{x x}]$. To complete the questionnaire, click on:

[survey weblink]

Please note that individuals who agree to participate understand that no compensation is available from The University of Texas at Austin and its employees for any injury resulting from your participation in this research. Participation in this study also certifies that they are 18 years of age or older.

This study has been approved by the Institutional Review Board for the Protection of Human Subjects. If you have questions about this study, please feel free to contact the lead researcher at joelwong@mail.utexas.edu. If you have any questions regarding your rights as a research participant, please contact Lisa Leiden, Ph.D., Chair of The University of Texas at Austin Institutional Review Board for the Protection of Human Subjects, (512) 471-8871 or email: orsc@uts.cc.utexas.edu.

Thank you for your help.

Y. Joel Wong, M. A.

Aaron B. Rochlen, Ph. D. 


\section{References}

Addis, M. E., \& Cohane, G. E. (2005). Social scientific paradigms of masculinity and their implications for research and practice in men's mental health. Journal of Clinical Psychology, 61, 633-647.

Addis, M. E., \& Mahalik, J. R. (2003). Men, masculinity, and the contexts of help seeking. American Psychologist, 58, 5-14.

Arnett J. J. (2000). Emerging Adulthood: A theory of development from late teens through the twenties. American Psychologist, 55, 469-480.

Arnett J. J. (2004). Emerging adulthood: The winding road from late teens through the 20s. New York: Oxford University Press.

Austenfeld, J. L., Paolo, A. M., \& Stanton, A. L. (2006). Effects of writing about emotions versus goals on psychological and physical health among third-year medical students. Journal of Personality, 74, 267-286.

Bagby, R. M., Parker, J. D. A., \& Taylor, G. J. (1994). The Twenty-Item Toronto Alexithymia Scale-I. Item selection and cross-validation of the factor structure. Journal of Psychosomatic Research, 38, 23-32.

Balswick, J. (1988). The inexpressive male. Massachusetts: Lexington Books.

Baron, R. M., \& Kenny, D. A. (1986). The moderator-mediator variable distinction in social psychological research: Conceptual, strategic, and statistical considerations. Journal of Personality \& Social Psychology, 51, 1173-1182.

Berg, I. K., \& Dolan, Y. (2001). Tales of solutions: A collection of hope-inspiring stories. New York: Norton \& Co.

Berscheid, E. (2003). Relationships with others: The human's greatest strength. In L. G. 
Aspinwall \& U. M. Staudinger (Eds.), A psychology of human strengths:

Perspectives on an emerging field (pp. 37-48). Washington, DC: American Psychological Association.

Betz, N. E., \& Fitzgerald, L. F. (1993). Individuality and diversity: theory and research in counseling psychology. Annual Review of Psychology, 44, 343-382.

Blazina, C., \& Watkins Jr., C. E. (1996). Masculine gender role conflict: Effects on college men's psychological well-being, chemical substance usage and attitudes toward help-seeking, Journal of Counseling Psychology, 43, 461-465.

Booth, R. J., Petrie, K. J., \& Pennebaker, J. W. (1997). Changes in circulating lymphocyte numbers following emotional disclosure: Evidence of buffering? Stress Medicine, 13, 23-29.

Brooks, G. R. (1998). A new psychotherapy for traditional men. San Francisco: JosseyBass.

Brooks, G. R., \& Good, G. E. (2001). The new handbook of psychotherapy and counseling with men. San Francisco: Jossey-Bass.

Brooks-Harris, J. E., Heesacker, M., Mejia-Millan, C. (1996). Changing men's male gender-role attitudes by applying the elaboration likelihood model of attitude change. Sex Roles, 35, 563-580.

Bruch, M. A. (2002). Shyness and toughness: unique and moderated relations with men's emotional inexpression. Journal of Counseling Psychology, 49, 28-34.

Buirs, R. S., \& Martin, J. (1997). The therapeutic construction of possible selves: Imagination and its constraints. Journal of Constructivist Psychology, 10, 153166. 
Burton, C. M., \& King, L. A. (2004). The health benefits of writing about intensely positive experiences. Journal of Research in Personality, 38, 150-163.

Campbell, J. L., \& Snow, B. M. (1992). Gender role conflict and family environment as predictors of men's marital satisfaction. Journal of Family Psychology, 6, 84-87.

Clark, L. F. (1993). Stress and the cognitive-conversational benefits of social interaction. Journal of Social and Clinical Psychology, 12, 25-55.

Cournoyer, R. J. (1994). A developmental study of gender role conflict in men and its changing relationship to psychological well-being. (Doctoral dissertation, Boston College). Dissertation Abstracts International, 54/12, 6476.

Deci, E. L., \& Ryan, R. M. (1991). A motivational approach to self: Integration in personality. In R. Dienstbier (Ed.), Nebraska symposium on motivation: Vol. 38. Perspectives on motivation (pp. 237-288). Lincoln, NE: University of Nebraska Press.

De Jong, P., \& Berg, I. K. (1998). Interviewing for solutions. Belmont, CA: Brooks/Cole Publishing Co.

De Shazer, S., \& Berg, I. K. (1992). Doing therapy: A post-structural re-vision. Journal of Marital and Family Therapy, 18, 71-81.

Derogatis, L. R. (2000). BSI-18: Brief Symptom Inventory-18: Administration, scoring, and procedures manual. Minneapolis, MN: Pearson Assessments.

Derogatis, L. R., \& Melisaratos, N. (1983). The brief symptom inventory: an introductory report. Psychological Medicine, 13, 595-605. 
Donnelly, D. A., \& Murray, E. J. (1991). Cognitive and emotional changes in written essay and therapy interviews. Journal of Social and Clinical Psychology, 10, 334350.

Esterling, B. A., L'Abate, L., Murray, E. J., \& Pennebaker, J. W. (1999). Empirical foundations for writing in prevention and psychotherapy: Mental and physical health outcomes. Clinical Psychology Review, 19, 1, 79-96.

Fischer, A. R., \& Good, G. E. (1997). Men and psychotherapy: an investigation of alexithymia, intimacy, and masculine gender roles. Psychotherapy, 34, 160-170.

Fisher, H. E., Aron, A., Mashek, D., Li, H., \& Brown, L. L. (2002). Defining the brain systems of lust, romantic attraction, and attachment. Archives of Sexual Behavior, 31, 413-419.

Foa, E. B., \& Kozak, M.J. (1986). Emotional processing of fear: Exposure to corrective information. Psychological Bulletin, 99, 20-35.

Frazier, P. A., Tix, A. P., \& Barron, K. E. (2004). Testing moderator and mediator effects in counseling psychology research. Journal of Counseling Psychology, 51, 115134.

Frisina, P. G., Borod, J. C., \& Lepore, S. J. (2004). A meta-analysis of the effects of written emotional disclosure on the health outcomes of clinical populations The Journal of Nervous and Mental Disease, 192, 629-634.

Gelso, C. J., \& Woodhouse, S. (2003). Toward a positive psychotherapy: Focus on human strength. In W. B. Walsh (Ed.), Counseling psychology and human strengths (pp. 344-369). NY: Erlbaum.

Gertner, D. M. (1994). Learning men: Effects of a semester academic course in men's 
studies on gender role conflict and gender role journey of male participants (Doctoral dissertation, University of Northern Colorado). Dissertation Abstracts International, 55/01, 0046.

Good, G. E. \& Mintz, L. B. (1990). Depression and the male gender role: Evidence for compounded risk. Journal of Counseling and Development, 69, 17-21.

Good, G. E., Robertson, J. M., Fitzgerald, L. F., Stevens, M.A., \& Bartels, K. M. (1996). The relation between masculine role conflict and psychological distress in male university counseling center clients. Journal of Counseling and Development, 75, 44-49.

Good, G.E., Robertson, J. M., O'Neil, J. M., Fitzgerald, L. F., Stevens, M., DeBord, K., et al. (1995). Male gender role conflict: Psychometric issues and relations to psychological distress. Journal of Counseling Psychology, 42, 3-10.

Good, G. E., Thomson, D. A., \& Brathwaite, A. D. (2005). Men and therapy: Critical concepts, theoretical frameworks, and research recommendations. Journal of Clinical Psychology, 61, 699-711.

Gortner, E. M., Rude, S. S., \& Pennebaker, J. W. (2006). Benefits of expressive writing in lowering rumination and depressive symptoms. Behavior Therapy, 37, 292303.

Gosling, S. D., Vazire, S., Srivastava, S., \& John, O. P. (2004). Should we trust Webbased studies? A comparative analysis of six preconceptions about Internet questionnaires. American Psychologist, 59, 93-104.

Graf, M.C. (2004). Written emotional disclosure: What are the benefits of expressive 
writing in psychotherapy? (Doctoral dissertation, Drexel University). Dissertation Abstracts International, 65/02, 1028.

Greenberg, M. A., \& Stone, A. A. (1992). Emotional disclosure about traumas and its relation to health: Effects of previous disclosure and trauma severity. Journal of Personality and Social Psychology, 63, 75-84.

Greenberg, M. A., Wortman, c. B., \& Stone, A. A. (1996). Emotional expression and physical health: Revising traumatic memories or fostering self-regulation? Journal of Personality and Social Psychology, 71, 588-602.

Hendrick, S. S., \& Hendrick, C. (1986). A theory and method of love. Journal of Personality and Social Psychology, 50, 392-402.

Heesacker, M., \& Pritchard, S. (1992). In a different voice, revisited: Men, women, and emotion. Journal of Mental Health Counseling, 14, 274-290.

Hoskins, M., \& Lesho, J. (1996). Changing metaphors of the self: Implications for counseling. Journal of Counseling \& Development, 74, 243-252.

Hook, M. K., Gerstein, L. H., Detterich, L., \& Gridley, B. (2003). Measuring intimacy and examining gender differences. Journal of Counseling \& Development, 81, $462-472$.

Hooker, K., \& Kaus, C. R. (1994). Health-related possible selves in young and middle adulthood. Psychology and Aging, 9, 126-133.

Hurst, M. A. (1997). The best fit in counseling men: Are there solutions to treating men as the problem? Unpublished doctoral dissertation, Ball State University, Muncie, IN.

Hurn, R. (2003). Butterflies in possibility land: An example of the miracle question when 
counseling briefly. Counselling Psychology Review, 18, 17-27.

Joseph, S., \& Linley, P. A. (2004). Positive therapy: A positive psychological theory of therapeutic practice. In P. A. Linley \& S. Joseph (Eds.), Positive psychology in practice (pp. 354-368). Hoboken, NJ: John Wiley \& Sons.

Kato, K., \& Markus, H. R. (1993). The role of possible selves in memory. Psychologia: An International Journal of Psychology in the Orient, 36, 73-83.

Kelly, K. R., \& Hall, A. S. (1992). Toward a developmental model for counseling men. Journal of Mental Health Counseling, 14, 257-273.

Kennedy-Moore, E., \& Watson, J. C. (2001). How and when does emotional expression help? Review of General Psychology, 5, 187-212.

Keyes, C. L. M. (2003). Complete Mental Health: An agenda for the $21^{\text {st }}$ Century. In C. L. M. Keyes \& J. Haidt. (Eds.), Flourishing: Positive psychology and the life well-lived (pp. 293-312). Washington, DC: American Psychological Association.

Keyes, C. L. M., Shmotkin, D., \& Ryff, C. D. (2002). Optimizing well-being: The empirical encounter of two traditions. Journal of Personality and Social Psychology, 82, 1007-1022.

Kim, B. S. K., Li, L. C., \& Ng, G. F. (2005). Asian American Values Scale Multidimensional: Development, reliability, and validity. Cultural Diversity and Ethnic Minority Psychology, 11, 187-201.

Kim, Y. (2004). Effects of expressive writing among Mexican and Korean bilinguals on social, physical, and mental well-being. Unpublished doctoral dissertation, The University of Texas at Austin. 
King, L. A. (2001). The health benefits of writing about life goals. Personality and Social Psychology Bulletin, 27, 798-807.

King, L. A. (2002). Gain without pain? Expressive writing and self-regulation. In. S. J. Lepore \& J. M. Smyth. (Eds.), The writing cure: How expressive writing promotes health and emotional well-being (pp. 119-134). Washington DC: American Psychological Association.

King, L. A., \& Miner, K. N. (2000). Writing about the perceived benefits of traumatic events: Implications for physical health. Personality and Social Psychology Bulletin. 26, 220-230.

King, L. A., \& Smith, N. G. (2004). Gay and straight possible selves: Goals, identity, subjective well-being, and personality development. Journal of Personality, 72, 967-994.

Kirk, S. B. (1998). Written disclosure of stressful experiences: Differential effects of emotional expression and cognitive processing on psychological and physical health. (Doctoral dissertation, University of Kansas). 60/02, 833.

Klein, K., \& Boals, A. (2001). Expressive writing can increase working memory capacity. Journal of Experimental Psychology: General, 130, 520-533.

Knobloch, L. K., \& Solomon, D. H. (2004). Interference and facilitation from partners in the development of interdependence within romantic relationships. Personal Relationships, 11, 115-130.

Korobov, N., \& Thorne, A. (2006). Intimacy and distancing: Young men's conversations about romantic relationships. Journal of Adolescent Research, 21, 27-55. 
L'Abate, L., \& Kern, R. (2002). Workbooks: Tools for the expressive writing paradigm. In S. J. Lepore \& J. M. Smyth. (Eds.), The writing cure: How expressive writing promotes health and emotional well-being (pp. 239-256). Washington DC: American Psychological Association.

Lange, A. Schoutrop, M., Schrieken, B., \& Van De Ven, J. (2002). Interapy: A model for therapeutic writing through the internet. In S. J. Lepore \& J. M. Smyth. (Eds.), The writing cure: How expressive writing promotes health and emotional wellbeing (pp. 215-238). Washington DC: American Psychological Association.

Langens, T. A., \& Schuler, J. (2005). Written emotional expression and emotional wellbeing: The moderating role of fear of rejection. Personality and Social Psychology Bulletin, 31, 818-830.

Lepore, S. J. (1997). Expressive writing moderates the relation between intrusive thoughts and depressive symptoms. Journal of Personality and Social Psychology, 73, 1030-1037.

Lepore S. J., \& Greenberg M. A. (2002). Mending broken hearts: Effects of expressive writing on mood, cognitive processing, social adjustment, and health following a relationship breakup. Psychology and Health, 17, 547-560.

Lepore, S. J., \& Smyth, J. M. (2002). The writing cure: An overview. In. S. J. Lepore \& J. M. Smyth. (Eds.), The writing cure: How expressive writing promotes health and emotional well-being (pp. 3-14). Washington DC: American Psychological Association.

Levant, R. F. (2001). Desperately seeking language: Understanding, assessing, and 
treating normative male alexithymia. In G.R. Brooks and G. Good (Eds.), The new handbook of counseling and psychotherapy for men. Vol. 1 (pp. 355-368). CA: Jossey-Bass.

Liu, W., Rochlen, A. B., \& Mohr, J. J. (2005). Real and ideal gender role conflict: Exploring psychological distress among men. Psychology of Men \& Masculinity, $6,137-148$.

Lopez, S. J., Floyd, R. K., Ulven, J. C., \& Snyder, C. R. (2000). Hope therapy: Helping clients build a house of hope. In C. R. Snyder (Ed.), Handbook of hope: Theory, measures, and interventions (pp. 123-150). San Diego: Academic Press.

Maddux, J. E., Snyder, C. R., \& Lopez, S. J. (2004). Positive clinical psychology: Deconstructing the illness ideology and constructing an ideology of health and human potential. In P. A. Linley \& S. Joseph (Eds.), Positive psychology in practice (pp. 320-334). Hoboken, NJ: Wiley.

Mahalik, J. R. (2000). Gender role conflict in men as a predictor of self-ratings of behavior on the Interpersonal Circle. Journal of Social \& Clinical Psychology, 19, 276-292.

Mahalik, J. R., \& Cournoyer, R. J. (2000). Identifying gender role conflict messages that distinguish mildly depressed from nondepressed men. Psychology of Men \& Masculinity, 1, 109-115.

Mahalik, J. R., Cournoyer, R. J., DeFranc, W. Cherry, M., \& Napolitano, J. M. (1998). Men's gender role conflict and use of psychological defenses. Journal of Counseling Psychology, 45, 247-255. 
Mahalik, J. R., Good, G. E., \& Englar-Carlson, M. (2003). Masculinity scripts, presenting concerns and help-seeking: Implications for practice and training. Professional Psychology: Theory, Research and Practice, 34, 123-131.

Mahalik, J.R., Locke, B., Ludlow, L., Diemer, M., Scott, R. P. J., Gottfried, M., et al. (2003). Development of the conformity to masculine norms inventory. Psychology of Men and Masculinity, 4, 3-25.

Mallen, M. J., Vogel, D. L., Rochlen, A. B., Day, S. X. (2005). Online Counseling Research: Reviewing the literature from a counseling psychology framework. The Counseling Psychologist, 33(6), 819-871.

Markus, H., \& Nurius, P. (1986). Possible selves. American Psychologist, 41, 954-969.

Meara, N. M., Day, J. D., Chalk, L. M., \& Phelps, R. E. (1995). Possible selves: Applications for career counseling. Journal of Career Assessment, 3, 259-277.

Mehl, M. R., Pennebaker, J. W., Crow, M. D., Dabbs, J., \& Price, J. H. (2001). The Electronically Activated Recorder (EAR): A device for sampling naturalistic daily activities and conversations. Behavior Research Methods, Instruments, and Computers, 33, 517-523.

Montgomery, M. (2005). Psychosocial intimacy and identity: From early adolescence to emerging adulthood. Journal of Adolescent Research, 20, 346-374.

Moore, C. M. (1993). A study of male sex-role attitudes and self-concept differences between alcoholics and nonalcoholics and the effects of a psychoeducational group on these variables and subsequent relapse rates (Doctoral dissertation, University of Texas-Austin), Dissertation Abstracts International, 54/04, 2215. 
Monsour, M. (1992). Meaning of intimacy in cross- and same-sex friendships. Journal of Social and Personal Relationships, 9, 277-295.

Moradi, B., Tokar, D. M., Schaub, M. Jome, L. M. \& Serna, G. S. (2000). Revisiting the structural validity of the gender role conflict scale. Psychology of Men and Masculinity, 1, 62-69.

Nahon, D. (1992). The effectiveness of "masculinist" group psychotherapy in the treatment of recently separated men. Unpublished doctoral dissertation, University of Montreal, Quebec, Canada.

Niederhoffer, K. G., \& Pennebaker, J. W. (2002). Sharing one's story: On the benefits of writing or talking about emotional experiences. In C. R. Snyder \& S. J. Lopez (Eds.), Handbook of Positive Psychology (pp. 573-583). New York: Oxford University Press.

Nurius, P. S. (1989). The self-concept: A social-cognitive update. Social Casework: The Journal of Contemporary Social Work, 70, 285-294.

O'Neil, J. M. (1981a). Males sex-role conflict, sexism, and masculinity: Implications for men, women, and the counseling psychologist. The Counseling Psychologist, 9 , $61-80$.

O’Neil, J. M. (1981b). Patterns of gender role conflict and strain: Sexism and fear of femininity in men's lives. The Personnel and Guidance Journal, 60, 203-210.

O’Neil, J. M., Good, G. E., \& Holmes, S. (1995). Fifteen years of theory and research on men's gender role conflict: New paradigms for empirical research. In R. Levant \& W. Pollack (Eds.), The new psychology of men (pp. 164-206). New York: Basic Books. 
O’Neil, J. M., Helms, B. J., Gable, R. K., David, L., \& Wrightsman, L. S. (1986). Gender-role conflict scale: College men's fear of femininity. Sex Roles, 14, 335350.

Oyserman, D., Bybee, D., Terry, K., \& Hart-Johnson, T. (2004). Possible selves as roadmaps. Journal of Research in Personality, 38, 130-149.

Oyserman, D., \& Markus, H. R. (1990). Possible selves and delinquency. Journal of Personality and Social Psychology, 59, 112-125.

Paez, D., Velasco, C., \& Gonzales, J. L. (1999). Expressive writing and the role of alexithymia as a dispositional deficit in self-disclosure and psychological health. Journal of Personality and Social Psychology, 77, 630-641.

Parks, M. R. (1996). Meaning for closeness and intimacy in friendship. Journal of Social and Personal Relationships, 13, 85-107.

Pease, B., \& Pease, A. (2004). Why men don't have a clue and women always need more shoes: The ultimate guide to the opposite sex. New York: Broadway Books.

Pennebaker, J.W. (1989). Confession, inhibition, and disease. In L. Berkowitz (Ed.), Advances in experimental social psychology (Vol. 22, pp. 211-244). New York: Academic Press.

Pennebaker, J. W. (1997). Writing about emotional experiences as a therapeutic process. Psychological Science, 8, 162-166.

Pennebaker, J. W. (2004). Theories, therapies, and taxpayers: On the complexities of the expressive writing paradigm. Clinical Psychology: Science and Practice, 11, 138142.

Pennebaker, J. W., \& Beall, S. K. (1986). Confronting a traumatic event: Toward an 
understanding of inhibition and disease. Journal of Abnormal Psychology, 95, 274281.

Pennebaker, J. W., \& Chung, C. K. (2007). Expressive writing, emotional upheavals, and health. In H. Friedman and R. Silver (Eds.), Handbook of health psychology (pp. 263-284). New York: Oxford University Press.

Pennebaker, J. W., Colder, M., \& Sharp, L. K. (1990). Accelerating the coping process. Journal of Personality and Social Psychology, 58, 528-537.

Pennebaker, J. W., Francis, M. E. \& Booth, R. J. (2001). Linguistic Inquiry and Word Count (LIWC 2001): A computerized text analysis program. Mahwah, NJ: Erlbaum Publishers.

Pennebaker, J.W., Kiecolt-Glaser, J., \& Glaser, R. (1988). Disclosure of traumas and immune function: Health implications for psychotherapy. Journal of Consulting and Clinical Psychology, 56, 239-245.

Pennebaker, J. W., \& King, L. A. (1999). Linguistic Styles: Language use as an individual difference. Journal of Personality and Social Psychology, 77, 1296-1312.

Pennebaker, J. W., Mayne, T. J., \& Francis, M. E. (1997). Linguistic predictors of adaptive bereavement. Journal of Personality and Social Psychology, 72, 863-871.

Pennebaker, J. W., Mehl, M. R., \& Niederhoffer, K. G. (2003). Psychological aspects of natural language use: Our words, our selves. Annual Review of Psychology, 54, 547577.

Pennebaker, J. W., \& Seagal, J. (1999). Forming a story: The health benefits of narrative. Journal of Clinical Psychology, 55, 1243-1254.

Pleck, J. H. (1981). The myth of masculinity. Cambridge, MA: MIT Press. 
Pleck, J. H. (1995). The gender role strain paradigm. An update. In R. F. Levant \& W. S. Pollack (Eds.), The new psychology of men (pp. 11-32). New York: Basic Books.

Pollack, W. S., \& Levant, R. F. (Eds.), (1998). New psychotherapy for men. NY: John Wiley \& Sons.

Robertson, J. M. (2001). Counseling men in college settings. In G. R. Brooks \& G. E. Good. (Eds.), The new handbook of psychotherapy and counseling with men (pp. 146-169). San Francisco: Jossey-Bass.

Robertson, J. M., \& Fitzgerald, L. F. (1992). Overcoming the masculine mystique:

Preferences for alternative forms of assistance among men who avoid counseling. Journal of Counseling Psychology, 39, 240-246.

Rochlen, A. B., Land, L. N. \& Wong, Y. J. (2004). Male restrictive emotionality and evaluations of online versus face-to-face counseling. Psychology of Men \& Masculinity, 5, 190-200.

Rochlen, A. B., \& Mahalik, J. R. (2004). Women's perceptions of male partners' gender role conflict as predictors of psychological well-being and relationship satisfaction. Psychology of Men and Masculinity, 5, 147-157.

Rochlen, A. B., \& O’Brien, K. M. (2002). The relation of male gender role conflict and attitudes toward career counseling to interest in and preferences for different career counseling styles. Psychology of Men \& Masculinity, 3, 9-21.

Rochlen, A., Zack, J., \& Speyer, C. (2004). Online therapy: Review of relevant definitions, debates, and current empirical support. Journal of Clinical Psychology, 60, 269-283 
Ruvolo, A. P., \& Markus, H. R. (1992). Possible selves and performance: The power of self-relevant imagery. Social Cognition, 10, 95-124.

Ryff, C. D. (1989). Happiness is everything, or is it? Explorations of the meaning of psychological well-being. Journal of Personality and Social Psychology, 57(6), 1069-1081.

Ryff, C. D., \& Singer, B. (1998). The contours of positive human health. Psychological Inquiry, 9, 1-28.

Scher, M. (1981). Men in hiding: A challenge for the counselor. The Personnel and Guidance Journal, 199-202.

Schwartz, C. E., \& David, E. (2002). To everything there is a season: A written expression intervention for closure at the end of life. In S. J. Lepore \& J. M. Smyth (pp. 257-278). Washington, DC: American Psychological Association.

Seligman, M.E.P. (2002). Positive psychology, positive prevention, and positive therapy. In C. R. Snyder \& S. J. Lopez (Eds.) Handbook of Positive Psychology. (pp. 3-9). New York: Oxford University Press.

Sileo, F. J. (1996). Gender role conflict: Intimacy and closeness in male-male friendships. (Doctoral dissertation, Fordham University). Dissertation Abstracts International, $56 / 8-B, 4645$.

Slatcher, R. B., \& Pennebaker, J. W. (2006). How do I love thee? Let me count the words: The social effects of expressive writing. Psychological Science, 17, 660664. 
Sloan, D. M., \& Marx, B. P. (2004). Taking pen to hand: Evaluating theories underlying the written disclosure paradigm. Clinical Psychology: Science and Practice, 11, 124-136.

Sharpe, M. J. (1994). Gender role and psychological well-being in adult men. (Doctoral dissertation, University of Missouri-Columbia). Dissertation Abstracts International, 54/10, 5373.

Sharpe, M. J., \& Heppner, P. P. (1991). Gender role, gender role conflict, and psychological well-being in men. Journal of Counseling Psychology, 38, 323330.

Shepard, D. S. (2002). A negative state of mind: Patterns of depressive symptoms among men with high gender role conflict, Psychology of Men \& Masculinity, 3, 3-8.

Sher, K. J., Wood, P. K., \& Gotham, H. J. (1996). The course of psychological distress in college: a prospective high-risk study. Journal of College Student Development, $37,42-51$

Schoutrop, M. J. A., Lange, A., Hanewald, G., Davidovich, U., \& Salomon, H. (2002). Structured writing and processing major stressful events: A controlled trial. Psychotherapy and Psychosomatics, 71, 141-157.

Smiler, A. P. (2004). Thirty years after the discovery of gender: Psychological concepts and measures of masculinity. Sex Roles, 50, 15-26.

Smyth, J. M. (1998). Written emotional expression: Effects sizes, outcomes types, and moderating effects. Journal of Consulting and Clinical Psychology, 66, 174-184.

Smyth, J. M., \& Catley, D. (2002). Translating research into practice: Potential of 
expressive writing in the field. In S. J. Lepore \& J. M. Smyth (Eds.), The writing cure: How expressive writing promotes emotional health and well-being (pp. 199-214). Washington, DC: American Psychological Association.

Solano, L., Donati, V., Pecci, F., Persichetti, S., \& Colaci, A. (2003). Postoperative course after papilloma resection: Effects of written disclosure of the experience in subjects with different alexithymia levels. Psychosomatic Medicine, 65, 477-484.

Spera, S. P., Buhrfeind, E. D., Pennebaker, J. W. (1994). Expressive writing and coping with job loss. Academy of Management Journal, 37, 722-733.

Stein, R. I. (2000). Development and validation of a scale of emotional intimacy. Dissertation Abstracts International, 61, 1097.

Strauss, R., \& Goldberg, W. A. (1999). Self and possible selves during the transition to fatherhood. Journal of Family Psychology, 13, 244-259.

Stroebe, M., Stroebe, W., Schut, H., Zech, E., \& van den Bout, J. (2002). Does disclosure of emotions facilitate recovery from bereavement? Evidence from two prospective studies. Journal of Consulting and Clinical Psychology, 70, 169-178.

Snyder, D. K., Gordon, K. C., \& Baucom, D. H. (2004). Treating affair couples: Extending the written disclosure paradigm to relationship trauma. Clinical Psychology: Science and Practice, 11, 155-159.

Tedeschi, R., \& Calhoun, L. (1996). Posttraumatic growth inventory: Measuring the positive legacy of trauma, Journal of Traumatic Stress, 9, 455-471.

Thomas, D. (2005). Masculine role conflict, shame-proneness and psychological adjustments: Testing a mediational model. (Doctoral dissertation, University of Missour-Columbia). Dissertation Abstracts International, 65/9-B, 4854. 
Tokar, D. M., Fischer, A. R., Schaub, M, \& Moradi, B. (2000). Masculine gender roles and counseling-related variables: Links with and mediation by personality. Journal of Counseling Psychology, 47, 380-393.

U. S. Department of Health and Human Services, National Center for Health Statistics. (1992, January 7). Monthly Vital Statistics Report, 40 (Suppl. 2).

Weis, A. C. (2004). Writing about the terrorist attacks of 9-11. A comparison of focused expression and positive reappraisal. (Doctoral dissertation, Ohio University). 64/12-B, 6345.

Wester, S.R., Vogel, D. L., \& Archer, J. (2004). Male restricted emotionality and counseling supervision. Journal of Counseling and Development, 82, 91-98.

Wester, S. R., Vogel, D. L., Pressly, P. K., \& Heesacker, M. (2002). Sex differences in emotion: A critical review of the literature and implications for counseling psychology. The Counseling Psychologist, 30, 630-652.

Whitty, M. (2002). Possible selves: An exploration of the utility of a narrative approach. Identity: An International Journal of Theory and Research, 2, 211-228.

Wilcox, D. W., \& Forrest, L. (1992). The problem of men and counseling: Gender bias or gender truth? Journal of Mental Health Counseling, 14, 291-304.

Wisch, A. F., Mahalik, J. R., Hayes, J. A., \& Nutt, E. A. (1995). The impact of gender role conflict and counseling technique on psychological help-seeking in men. Sex Roles, 33, 77-89. Wong, Y. J. (2006). The future of positive therapy. Psychotherapy, 43, 151-153.

Wong, Y. J. (2006a). Strength-centered therapy: A social constructionist, virtuesbased psychotherapy. Psychotherapy, 43, 133-146. 
Wong, Y. J. (2006b). The future of positive therapy. Psychotherapy, 43, 151-153.

Wong, Y. J., Pituch, K. A., Rochlen, A. B. (2006). Men's restrictive emotionality: An investigation of associations with other emotion-related constructs, anxiety, and underlying dimensions. Psychology of Men and Masculinity, 9, 113-126.

Wong, Y. J., \& Rochlen, A. B. (2005). Demystifying men's emotional behavior: New directions and implications for counseling. Psychology of Men \& Masculinity, 6, $62-72$.

Zamarripa, M. X., Wampold, B. E. \& Gregory, E. (2003). Male gender role conflict, depression, and anxiety: Clarification and generalizability to women. Journal of Counseling Psychology, 50, 333-338. 


\section{VITA}

Yang Joel Wong was born in Singapore on October 14, 1972, the son of Chiang Siang Wong and Lily Wong. He entered the National University of Singapore (NUS) in 1993 and graduated with a Bachelor of Laws (Honors) from NUS in May 1997. In August 2002, he was admitted into the doctoral program in Counseling Psychology at the University of Texas at Austin. He received the degree of Master of Arts from the University of Texas at Austin in May 2005.

Permanent Address: 1069 Colchester Court, Bloomington, Indiana 47401.

This dissertation was typed by the author. 